\title{
THESIS
}

\section{RESIDENCY OF RHENIUM AND OSMIUM IN A HEAVY CRUDE OIL}

\author{
Submitted by \\ Jenna DiMarzio \\ Department of Geosciences
}

\author{
In partial fulfillment of the requirements \\ For the Degree of Master of Science \\ Colorado State University \\ Fort Collins, Colorado
}

Spring 2017

Master's Committee:

Advisor: Holly Stein

Co-Advisor: Judith Hannah

Svetoslav Georgiev

Richard Finke 
Copyright by Jenna Marie DiMarzio 2017

All Rights Reserved 


\section{ABSTRACT \\ RESIDENCY OF RHENIUM AND OSMIUM IN A HEAVY CRUDE OIL}

The Re-Os geochronometer is an emerging tool for the study of oil formation and migration processes, and a new technology for petroleum exploration. Very little is known, however, about the residency of Re and Os within asphaltene and maltene sub-fractions of crude oil. This information is crucial for better understanding of petroleum systems in general, and especially for successful geochronology of key processes such as oil formation, migration, or biodegradation.

In this work, a heavy crude oil was separated into soluble (maltene) and insoluble (asphaltene) fractions using $n$-heptane as the asphaltene-precipitating agent. The asphaltenes were separated sequentially into sub-fractions using two different solvent pairs (heptane-DCM and acetone-toluene), and the bulk maltene was separated into saturate, aromatic, and resin (SAR) fractions using open column chromatography. Each asphaltene and maltene sub-fraction was analyzed for Re and Os. The asphaltene sub-fractions and bulk samples were analyzed for a suite of trace metals by ICP-MS.

Our results show that Re and Os concentrations co-vary between the asphaltene sub-fractions, and that both elements are found mostly in the highly polar, highly aromatic sub-fractions; significant Re and Os are also present in the aromatic and resin fractions of the maltenes. However, each asphaltene and maltene sub-fraction has a distinct isotopic composition, and these sub-fractions are not isochronous. This may suggest that asphaltene sub-fractionation separates Re-Os complexes to the point that the isotopic integrity of the 
geochronometer is undercut. The decoupling possibilities of radiogenically produced ${ }^{187} \mathrm{Os}$ from Re remain elusive, and more work is needed to determine the mobility of radiogenically produced ${ }^{187} \mathrm{Os}$. Re-Os and Ni-V budgets track each other, suggesting that some Re and Os may form metalloporphyrins. On the other hand, Re correlates strongly with Mo and $\mathrm{Cd}$ in the asphaltene sub-fractions; as Re and Os track each other, this suggests that Re-Os, Mo, and Cd occupy similar sites. Finally, we suggest that progressive asphaltene precipitation during migration and mixing of oils can change the resultant oil's isotopic ratios. This is key to interpretation of Re-Os data for tar mats and live oils, whether the data form an isochron or scatter. By combining data from source rocks, oils, and asphaltenes generated along the migration pathway, we are constructing temporal histories for whole petroleum systems. 


\section{ACKNOWLEDGEMENTS}

From the AIRIE Program, I'd like to thank my advisors Holly Stein and Judy Hannah for

their support, guidance, and encouragement; Svet Georgiev for his mentorship, unending aid, and patience; and Nicole Hurtig for long hours spent helping with ICP-MS work. Thanks also to Berit Løken Berg, University of Oslo, for help with SEM images, and Micaela Nali and Roberto Galimberti, Eni, Donato, Italy, for providing oil samples. The CHRONOS grant (HS-JH) through the Centre for Earth Evolution and Dynamics (CEED) at the University of Oslo funded my M.S. thesis work and my R.A. with the AIRIE Program. The CHRONOS project is funded by a consortium of Norwegian petroleum companies (Eni Norge, Lundin, Det Norske, now under Aker BP). Additional thanks to Richard Finke for being on my committee.

Finally, thanks to my parents, friends, and family for their support. 


\section{TABLE OF CONTENTS}

ACKTRACT




\section{LIST OF TABLES}

TABLE 1 - SUB-FRACTIONATION OF ASPH VIA HEPTANE-DCM (H-SERIES) AND TOLUENE-ACETONE (A-SERIES)

TABLE 2 - RESULTS OF CRUDE OIL FRACTIONATION, EXPRESSED AS WT.\% FROM THE ORIGINAL CRUDE OIL WEIGHT. PERCENTAGES OF Re AND Os STORED IN EACH FRACTION ARE BASED ON MASS-BALANCE CALCULATIONS.........17

TABLE 3 - RESULTS OF ASPH SUB-FRACTIONATIONS, EXPRESSED AS WT.\% FROM THE STARTING BULK ASPH WEIGHT. PERCENTAGES OF Re AND Os STORED IN EACH FRACTION ARE BASED ON MASS-BALANCE CALCULATIONS..........18

TABLE 4 - RESULTS OF MALT SUB-FRACTIONATIONS, EXPRESSED AS WT.\% FROM THE STARTING BULK MALT WEIGHT. PERCENTAGES OF Re AND Os STORED IN EACH FRACTION ARE BASED ON MASS-BALANCE CALCULATIONS..........19

TABLE 5 - Re-Os RESULTS .20

TABLE 6 - ICP-MS RESULTS (PPB) OF TRACE METALS THAT RETURNED



TABLE 7 - Re-Os CONCENTRATIONS OF SOLVENT BLANKS …..................................53

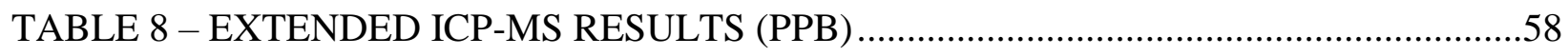

TABLE 9 - ICP-MS PROPAGATED UNCERTAINTIES (RSD\%).........................................59

TABLE 10 - ICP-MS INSTRUMENT AND MEASUREMENT PARAMETERS ……...............60

TABLE 11 - Re-Os ISOTOPE CONCENTRATIONS ..........................................................61 


\section{LIST OF FIGURES}

FIGURE 1 - CRUDE OIL, ASPH, AND MALT COMPONENTS …......................................2

FIGURE 2 - PROCEDURE USED FOR SEPARATION OF CRUDE OIL INTO SOLUBILITY

FRACTIONS AND SUB-FRACTIONS

FIGURE 3 - BACK SCATTERED ELECTRON (BSE) IMAGES OF (A) AN H-SERIES

SUB-FRACTION (H3), (B) AN A-SERIES SUB-FRACTION (A1), AND (C, D) THE

BULK ASPH

FIGURE 4 - Re AND Os CONCENTRATIONS (A, B) AND ISOTOPIC RATIOS (C, D) OF THE H-SERIES AND A-SERIES ASPH SUB-FRACTIONS ….................................21

FIGURE 5 - Re-Os CONCENTRATIONS (A, B) AND ISOTOPIC RATIOS (C, D) OF MALT SUB-FRACTIONS FOR TWO SEPARATE RUNS

FIGURE 6 - WEIGHT PERCENTAGES AND Re-Os BUDGETS OF ASPH SUB-

FRACTIONS FOR TWO SEPARATE FRACTIONATIONS, AND FOR THE BULK CRUDE OIL

FIGURE 7 - WEIGHT PERCENTAGES AND Re-Os BUDGETS OF MALT

SUB-FRACTIONS FOR TWO SEPARATE RUNS

FIGURE 8 - Ni, V, AND Re CONCENTRATIONS (A) AND BUDGETS (B) IN

H-SERIES ASPH SUB-FRACTIONS

FIGURE 9-ENRICHMENT/DEPLETION PLOTS OF TRACE METALS IN THE H-SERIES AND A-SERIES ASPH SUB-FRACTIONS

FIGURE 10 - Re-Os ISOCHRON PLOTS OF THE H-SERIES (A) AND A-SERIES (B) ASPH SUB-FRACTIONS

FIGURE 11 - CORRELATIONS BETWEEN Os ISOTOPES AND Re FOR ASPH SUBFRACTIONS

FIGURE 12 - Re-Os ISOTOPIC RATIOS OF SEPARATED MALT SUB-FRACTIONS PLOTTED IN ISOCHRON SPACE

FIGURE 13 - EFFECT OF THE PROGRESSIVE PRECIPITATION OF ASPH SUB-

FRACTIONS ON THE ISOTOPIC RATIOS OF THE REMAINING CRUDE OIL ......38

FIGURE 14 - PROCEDURE USED FOR CALCULATING ADJUSTED WEIGHT PERCENTAGES OF CRUDE OIL SOLUBILITY FRACTIONS

FIGURE 15 - PROCEDURE USED FOR CALCULATING THE ADJUSTED WEIGHT PERCENTAGES OF H-SERIES ASPH SUB-FRACTIONS

FIGURE 16 - EXPLANATION OF WEIGHT PERCENTAGE CALCULATIONS OF A-SERIES ASPH SUB-FRACTIONS

FIGURE 17 - PLOT OF ${ }^{187}$ Os $/{ }^{188}$ Os vs. ${ }^{187} \mathrm{Re} /{ }^{188}$ Os USING Re-CORRECTED ${ }^{187} \mathrm{Re} /{ }^{188} \mathrm{Os}$ RATIOS OF MALT SUB-FRACTIONS FROM SEPARATIONS I AND II 


\section{CHAPTER 1 - INTRODUCTION}

Accurate knowledge on the timing(s) of oil generation and migration provides critical information on the inner workings of petroleum systems. The affinity of Re and Os for certain organic compounds allows for application of the Re-Os geochronometer (based on the decay of

${ }^{187} \operatorname{Re}$ to ${ }^{187} \mathrm{Os} ; \lambda=1.666 \pm 0.017 \times 10^{-11} \mathrm{y}^{-1}$; Smoliar et al., 1996) to constrain the timing of bitumen and oil generation (Selby et al., 2005; Selby and Creaser, 2005; Selby et al., 2007; Georgiev et al., 2016). Correct interpretation of Re-Os isochrons requires understanding the residency of Re-Os and the processes that affect these elements in crude oil. In this contribution, we provide detailed information of Re-Os residency in a previously characterized oil sample from the Gela field in Sicily, Italy (Georgiev et al., 2016).

Crude oil can be separated into two solubility-defined fractions, namely the asphaltenes (ASPH, insoluble in $n$-alkane) and the maltenes (MALT, soluble in $n$-alkane). (Fig. 1). The ASPH are currently best described by the Yen-Mullins model, in which individual ASPH molecules combine to form nanoaggregates, which in turn form clusters (Fig. 1) (Mullins et al., 2012, 2013). The heptane-soluble remainder of the crude oil, the maltenes (MALT), can be divided by column chromatography into saturates, aromatics, and resins, or "SAR" fractions. The saturates contain saturated hydrocarbons (e.g., alkanes and cycloalkanes), while the aromatics contain compounds with conjugated rings or ring systems (e.g., benzene, naphthalene, and substituted aromatics) and the resins contain heteroatomic and aromatic polar compounds (e.g., furans, thiophenes, pyridines) (e.g., Andersen and Speight, 2001; Speight, 2006). Polarity increases from saturates to aromatics to resins, and the resins are separated from the ASPH essentially by molecular weight and solubility in the precipitating $n$-alkane (Fig. 1). 
Previous research has shown that Re and Os contents in crude oil vary between the ASPH and MALT fractions (e.g. Selby et al., 2007; Georgiev et al., 2016). As with most other trace metals (Manning and Gize, 1993), both Re and Os are preferentially concentrated in the ASPH fraction, with subordinate amounts present in the complementary MALT fraction. Recently, analyses of Re and Os concentrations in ASPH sub-fractions showed that the most polararomatic ASPH sub-fractions are also the most enriched in Re and Os, suggesting the complexes that house Re and Os are highly polar and/or aromatic (Mahdaoui et al., 2013).
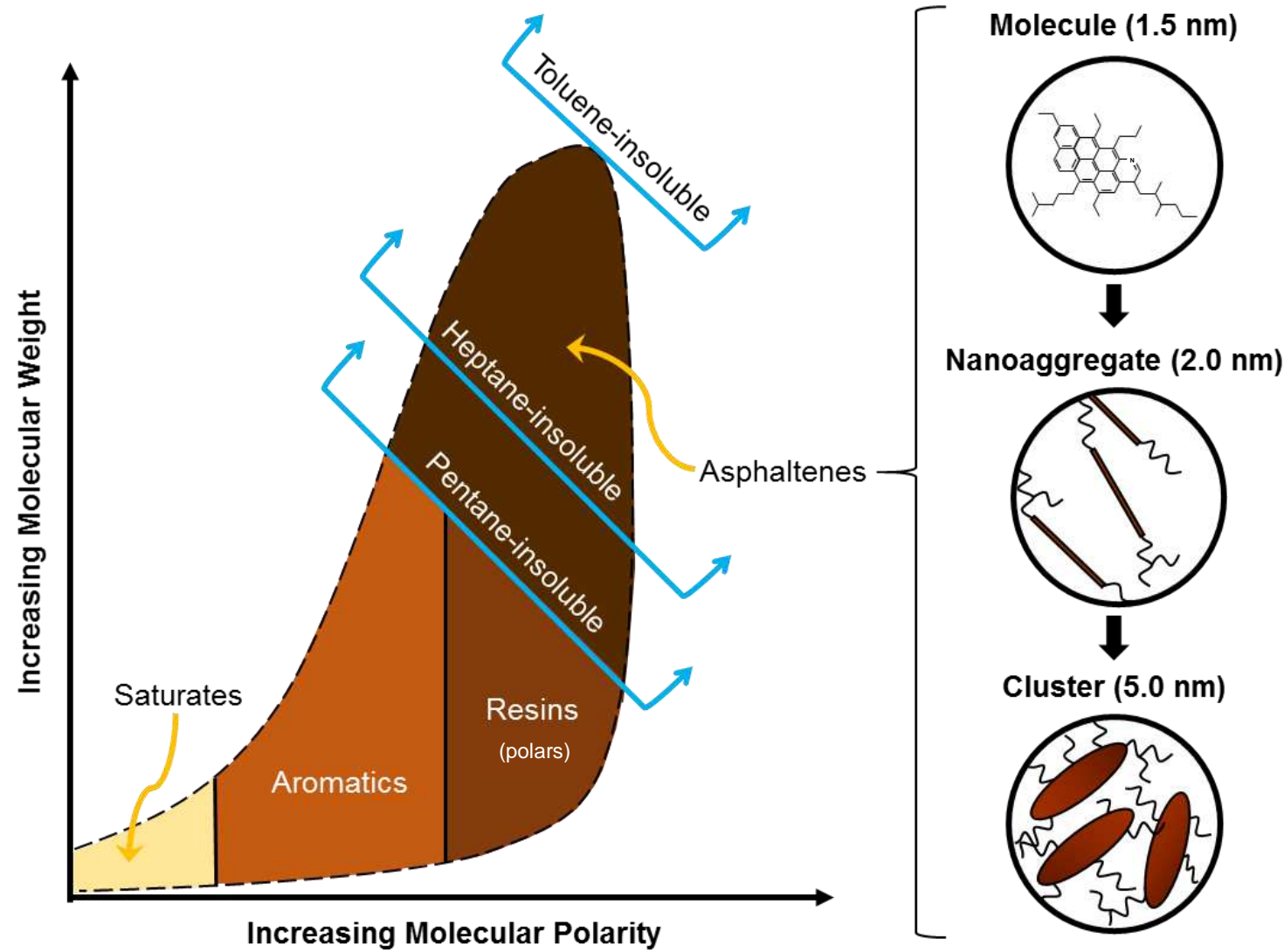

Figure 1: Crude oil, ASPH, and MALT components. Generally, molecular weight and molecular polarity increase from saturates, to aromatics, to resins, to asphaltenes. Asphaltenes are very similar to resins, and are separated from them mainly by molecular weight and solubility in the precipitating $n$-alkane. The Yen-Mullins model of asphaltenes is shown on the right (Mullins et al., 2012; 2013). A single (hypothetical) asphaltene molecule is on average about 1.5 $\mathrm{nm}$ in length, and contains about 7 aromatic rings (top). These molecules can stack and form $\sim 2 \mathrm{~nm}$ nanoaggregates of less than 10 molecules each (center), which are slightly porous and are capable of entrapping other molecules during ASPH precipitation (Acevedo et al., 2012; Derakhshesh et al., 2013). When highly concentrated in solution, nanoaggregates can form clusters of less than 10 units that are $\sim 5 \mathrm{~nm}$ in size (bottom). Left, modified from Andersen and Speight (2001). Right, modified from Mullins et al. (2012). 
Although MALT Re-Os concentrations are significantly lower compared to those of ASPH (Selby et al., 2007; Georgiev et al., 2016), no work has been done on determining Re-Os systematics and residency within the SAR sub-fractions. However, the general expectation based on decreasing Re-Os content with decreasing ASPH sub-fraction polarity (Mahdaoui et al., 2013) is that resins, which in terms of polarity are a transitional class between ASPH and the rest of the MALT, should carry the largest amount of Re and Os within the MALT sub-fractions. Selby et al. (2007) also suggest that Re and Os may be present in the aromatics.

Trace metal contents (e.g., Ni and V), and their ratios in crude oil can be used for source rock-oil and oil-oil correlations, and provide constraints for the type and depositional environment of source rocks (e.g., Lewan, 1984; Barwise, 1990). These applications are especially valuable in biodegraded oils that lack an abundance of biomarkers. In crude oil, trace metals can be housed in salts (Na, K, Mg, Ca, Mn) (e.g., Speight, 2006; Wu et al., 2014), oilsoluble compounds and organometallic complexes (e.g. V, Cu, Ni, Fe) (e.g., Speight, 2006; Wu et al., 2014), organometallic soaps ( $\mathrm{Zn}, \mathrm{Ti}, \mathrm{Ca}, \mathrm{Mg}$ ) (Speight, 2006), and maybe even as metal "grain" complexes (Pillay et al., 2011).

The most studied trace metals in crude oil, Ni and V, are known to form metalloporphyrins (Filby and Van Berkel, 1987; Filby, 1994), a class of cyclic molecules composed of a porphyrin (a cyclic tetrapyrrole with single carbon bridges between pyrrole units) and a central metal ion. In fact, a majority of metals are stable when chelated to the porphyrin ring (Buchler, 1975, 1978). For example, copper porphyrins were identified in deep-sea sediments (e.g. Palmer and Baker, 1978; Baker and Louda, 1986) and iron porphyrins have been identified in crude oil (e.g. Franceskin et al., 1986). However, several factors, such as availability of ions, the stability of the metal-nitrogen bonds, and the reducibility of metal oxides influence 
whether or not certain metalloporphyrins will be found in nature (Quirke, 1987; Furimsky, 2016).

Calculated stability indices show that Re and Os can form stable metalloporphyrins (Buchler, 1975, 1978), and recent research suggests that Re metalloporphyrins might be found in sedimentary environments (Miller, 2004). Like Re-Os, V, Ni, Fe, and $\mathrm{Cu}$ are most highly concentrated in the ASPH fraction (Dreyfus et al., 2005; Speight, 2006), which is also the largest sink for porphyrin rings (Speight, 2006). However, it has been suggested, based on Ni-V and Re-Os concentration profiles of ASPH sub-fractions, that Re and Os do not exist as metalloporphyrins within crude oil (Mahdaoui et al., 2013), but rather are bound to more polar compounds.

Initial reports on Re/Os isotopic systematics in crude oils and fractions show generally similar isotopic ratios between crude oils and respective ASPH and MALT fractions with few exceptions (Selby et al., 2007). Subsequent improvements in digestion protocols and analytical procedures revealed that the ${ }^{187} \mathrm{Re} /{ }^{188} \mathrm{Os}$ and ${ }^{187} \mathrm{Os} /{ }^{188} \mathrm{Os}$ ratios systematically decrease from ASPH to crude oil to MALT (Georgiev et al., 2016), suggesting there must be some process that fractionates Re from Os during or after oil generation. Selby et al. (2007) hypothesize that biodegradation could account for Re and Os isotopic partitioning between the ASPH and MALT, but the Noto oil studied by Georgiev et al. (2016) is not biodegraded and still shows the characteristic isotopic difference between crude oil and its fractions. Mahdaoui et al. (2013) argue that ${ }^{187} \mathrm{Os} /{ }^{188} \mathrm{Os}$ ratios of successively precipitated ASPH sub-fractions do not vary significantly, and have addressed and discounted the idea that ASPH precipitation could cause spread in isotopic ratios. However, their data do show differences in Re/Os and ${ }^{187} \mathrm{Os} /{ }^{188}$ Os ratios between precipitated ASPH sub-fractions. Later experiments define oil-water interaction as an 
additional process that can change or overprint the isotopic composition of oil (Mahdaoui et al., 2015; Hurtig et al., 2016); it could be that preferential uptake of Re and Os in the ASPH over the MALT during oil-water interactions causes the spread in Re/Os ratios between these fractions. Thus far, no work addresses changes in ${ }^{187} \mathrm{Re} /{ }^{188}$ Os between ASPH sub-fractions, and little is understood about the effects of ASPH precipitation on crude oil ratios. This is critical, as Re-Os geochronology relies on precise measurements of both ${ }^{187} \mathrm{Re} /{ }^{188} \mathrm{Os}$ and ${ }^{187} \mathrm{Os} /{ }^{188} \mathrm{Os}$ ratios. Re-Os systematics and residency within the SAR sub-fractions, notably the resins, also remain unknown. To address these unknowns, we assess the residency of Re-Os in sub-fractions of a well-characterized crude oil by splitting the oil into its main constituents (ASPH, MALT, adsorbed resins) and looking into several methods for ASPH sub-fraction precipitation. Further, we split the MALT into saturate, aromatic, and resin sub-fractions, and report the first Re-Os measurements on these MALT-sub-fractions, and the first set of ${ }^{187} \mathrm{Re} /{ }^{188} \mathrm{Os}$ and ${ }^{187} \mathrm{Os} /{ }^{188} \mathrm{Os}$ isotopic ratios for all ASPH and MALT sub-fractions. We also present trace metal data for ASPH sub-fractions and bulk samples to draw correlations between Re-Os behavior and that of other trace metals within the ASPH fraction. With this new information, we then discuss the implications for Re-Os geochronology. 


\section{CHAPTER 2 - SAMPLES AND METHODS}

\subsection{Samples}

We studied a heavy oil from the Gela field in Sicily, Italy. We used a separate split (a different bottle provided by Eni-Milano) from the Noto oil, previously studied by Georgiev et al. (2016). The oil was recovered from the Gela-1 well at 3243-3280 m core depths within the anoxic shales and shaly limestones of the Upper Triassic Noto Formation (see details in Georgiev et al., 2016). This Noto oil has high ASPH, sulfur, and trace metal contents, and organic biomarkers and an $n$-alkane distribution consistent with oil generation at peak maturation from a carbonate source rock with no subsequent biodegradation (Georgiev et al., 2016). ASPH, crude oils, and MALT from Noto oil yield a Re-Os isochron age of $42 \pm 12 \mathrm{Ma}$, whereas the ASPH-crudes only yield a $28.3 \pm 4.8 \mathrm{Ma}$ isochron, interpreted to represent Oligocene oil or bitumen generation events related to regional tectonic events (Georgiev et al., 2016). Importantly, high Re-Os content in this oil and its fractions make it a suitable target for Re-Os analyses of ASPH and MALT sub-fractions.

\subsection{Separation of Crude Oil into ASPH and MALT}

In this study, ASPH and MALT fractions are defined by their solubility in $n$-heptane (Fig. 2). At the start of the procedure, $\sim 25 \mathrm{~g}$ of crude oil was dissolved in a dichloromethane/methanol solution (DCMM; 93 vol.\% dichloromethane, 7 vol.\% methanol), diluted with 4L of $n$-heptane, and stirred with a magnetic stir bar overnight in the dark for at least 18 hours at $<25{ }^{\circ} \mathrm{C}$. After centrifuging the resulting mixture of precipitated solids and dissolved MALT, the two fractions were separated mechanically by decanting off the supernatant, containing the dissolved MALT. 


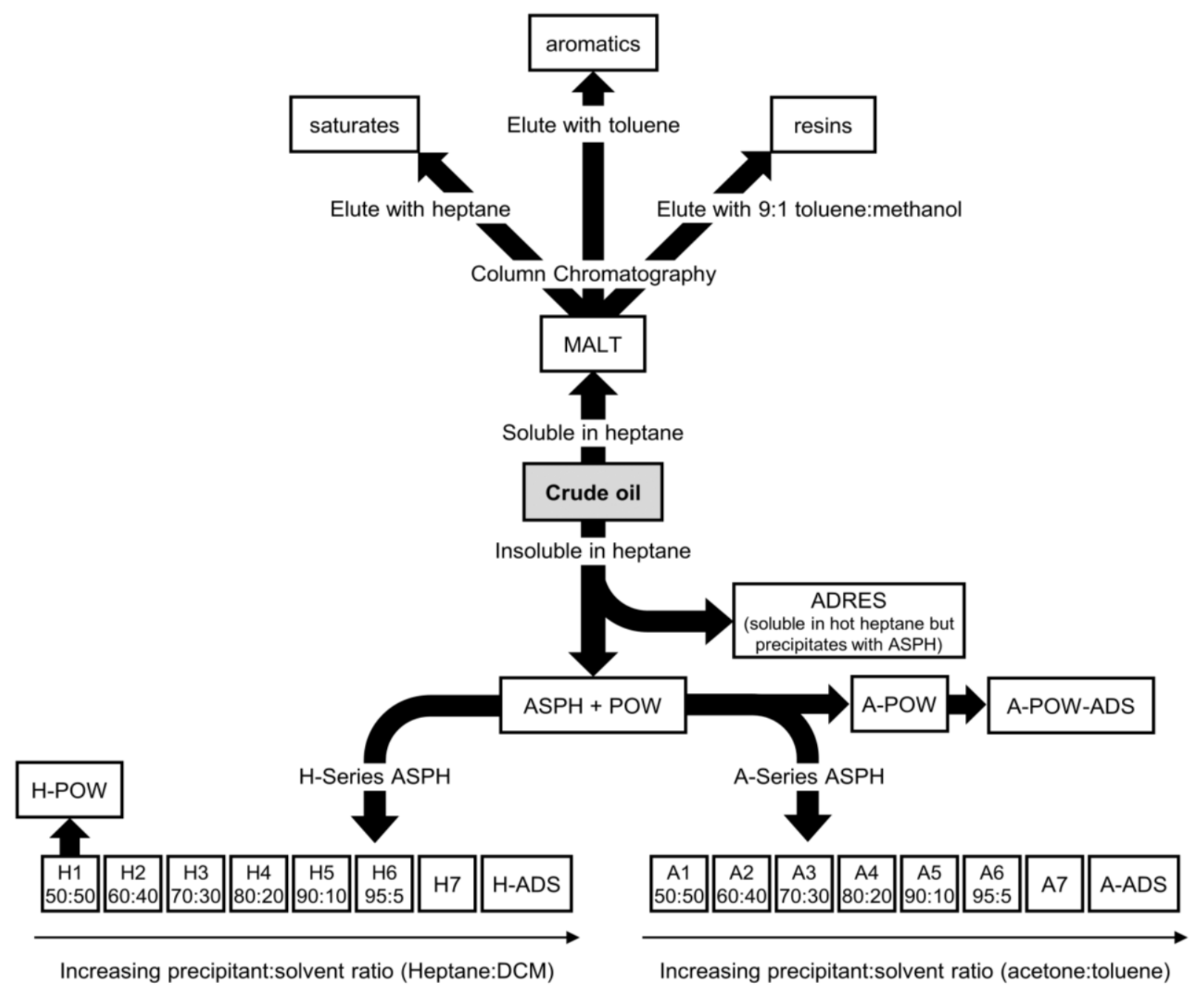

Figure 2: Procedure used for separation of crude oil into solubility fractions and sub-fractions. Abbreviations: MALT - maltenes; ADRES - resins adsorbed on the heptane-insoluble fraction; ASPH - asphaltenes;

POW - insoluble powder; H-series - asphaltene sub-fractions separated by heptane-dichloromethane; A-series asphaltene sub-fractions separated by acetone-toluene; H-POW - insoluble powder separated with the H-series subfractions; H1, H2, H3, .. - sub-fractions 1-7 of the H-series asphaltenes, separated with heptane-dichloromethane mixtures; H-ADS - asphaltenes adsorbed on beaker walls following H-series sub-fractionation; A-POW - insoluble powder removed from asphaltenes before separating the A-series sub-fractions; A-POW-ADS - Asphaltenes adsorbed onto the insoluble powder removed from the A-series bulk asphaltene sample; A1, A2, A3, . - - subfractions 1-7 of the A-series asphaltenes, separated with acetone-toluene mixtures; A-ADS - asphaltenes adsorbed on beaker walls following A-series fractionation. See text and the Appendix for additional details. 
A portion of the heptane-insoluble portion can be removed by washing the ASPH with hot heptane;

the resulting filtrate has been described as both adsorbed resins (Speight, 2004; de Souza et al., 2007) and as non-colloidal asphaltenes (Miller et al., 1998). In this work, we refer to them as adsorbed resins (ADRES). A mineral powder (POW) also precipitates with the ASPH and ADRES, and is insoluble in both polar and non-polar solvents. The precipitated solids (ASPH, ADRES, and POW) and dissolved MALT were dried in the fume hood at $<40{ }^{\circ} \mathrm{C}$ for up to a week until both fractions achieved stable masses.

\subsection{Separation of Asphaltene Sub-fractions}

After precipitation of the heptane-insoluble materials, the adsorbed resins (ADRES) were removed from these solids by washing with hot heptane $\left(\sim 43^{\circ} \mathrm{C}\right)$ in a Soxhlet extractor for three days. The ADRES, extracted into the heptane, were dried, and the remaining solid precipitate, including ASPH and insoluble powder (POW), was used for ASPH sub-fractionation. Two precipitant-solvent systems, heptane-DCM and acetone-toluene, were used to fractionate the ASPH (+POW) into solubility-based sub-fractions.

Fractionation by heptane-DCM (called the H-series) followed procedures similar to those of Mahdaoui et al. (2013) (Table 1, Fig. 2). About $1 \mathrm{~g}$ of Soxhlet-rinsed asphaltenes (including POW) was dissolved in $100 \mathrm{~mL}$ of DCM and diluted with $100 \mathrm{~mL}$ of heptane to produce a solution with a 50:50 precipitant (heptane) to solvent (DCM) ratio. This mixture was stirred for $30 \mathrm{~min}$ in a $2 \mathrm{~L}$ glass beaker, centrifuged for $10 \mathrm{~min}$ in $50 \mathrm{~mL}$ centrifuge tubes, and the supernatant was decanted back into the beaker. The precipitated solids in the centrifuge tube were re-dissolved in DCMM and centrifuged, leaving an insoluble mineral powder (H-POW) in the bottom of the tube and the first ASPH sub-fraction (H1) dissolved in the DCMM. The 
Table 1: Sub-fractionation of ASPH via heptane-DCM (H-series) and toluene-acetone (A-series)

\begin{tabular}{cccccccc}
\hline Sub-fraction & H1 & H2 & H3 & H4 & H5 & H6 & H7 $^{\text {a }}$ \\
& A1 & A2 & A3 & A4 & A5 & A6 & A7 $^{\text {a }}$ \\
& & & & & & & \\
$\begin{array}{c}100 \mathrm{~mL} \text { solvent (S, DCM or toluene) } \\
\text { were used to dissolve bulk ASPH }\end{array}$ & & & & & & & \\
$\begin{array}{c}\text { New volume of precipitant (P, } \\
\text { heptane or acetone) added to } \\
\text { dissolved ASPH }\end{array}$ & 100 & 50 & 83 & 167 & 500 & 1000 & 0 \\
$\quad \begin{array}{c}\text { Cumulative volume P } \\
\text { Cumulative volume P+S }\end{array}$ & 100 & 150 & 233 & 400 & 900 & 1900 & 1900 \\
P:S ratio of solution & 500 & 250 & 333 & 500 & 1000 & 2000 & 2000 \\
\hline
\end{tabular}

${ }^{a}$ The $7^{\text {th }}$ sub-fraction was obtained by evaporating the supernatant after the precipitation of the $6^{\text {th }}$ subfraction. See Section 2.3 for details, as this procedure differed slightly between the two separations.

DCMM-H1 solution was decanted, and H-POW was rinsed with DCMM to remove adsorbed asphaltenes. All DCMM solutions and washes were combined into H1, filtered through a 0.45 $\mu \mathrm{m}$ syringe filter, and dried to stable mass in air (typically $24-48 \mathrm{hr}$ ) under $40{ }^{\circ} \mathrm{C}$; $\mathrm{H}-\mathrm{POW}$ was dried separately. Fifty $\mathrm{mL}$ of fresh heptane were then added to the supernatant in the $2 \mathrm{~L}$ mixing beaker, stirred for 30 minutes, and the second sub-fraction was removed by centrifuging the mixture. This time, as no powder precipitated, the solids were directly re-dissolved in DCMM and filtered, producing ASPH sub-fraction $\mathrm{H} 2$. This process of adding heptane, mixing for 30 min, centrifuging, and filtering was repeated four more times, leading to six sub-fractions in total (H1 to H6) defined by their solubility in solutions with precipitant:solvent ratios according to Table 1. Sub-fraction H6 was left to stir in its heptane-DCM mixture overnight, and was centrifuged and collected the next day. The supernatant remaining after precipitation of H6 was transferred to a separate beaker and evaporated, producing the $7^{\text {th }}$ sub-fraction $(\mathrm{H} 7)$. Residual ASPH adsorbed on the walls of the mixing and pouring beakers were then dissolved in DCMM and collected (H-ADS). These H-ADS represent mixtures of variable but tiny amounts of all other ASPH sub-fractions. All separated sub-fractions except H-POW were filtered through 0.45 $\mu \mathrm{m}$ syringe filters. These sub-fractions are called the "H-series" throughout the rest of this paper. 
For the second precipitant-solvent system (called the A-series), acetone and toluene were used in a procedure similar to that of Buenrostro-Gonzalez et al. (2002) (Table 1, Fig. 2). Opposite to the $\mathrm{H}$-series, the precipitant is polar and the solvent is non-polar; this was done to test if the choice of precipitant and solvent would influence sub-fraction Re-Os concentrations and isotopic ratios. To circumvent removing the insoluble powder from the first precipitated ASPH sub-fraction, a sample of ASPH+POW was first dissolved in DCMM, centrifuged, and the precipitate (A-POW) was collected, weighed, and washed via Soxhlet extraction with DCMM. The small amount of ASPH that were released from the powder was also collected and analyzed (A-POW-ADS). The leftover pure ASPH, dissolved in DCMM, were filtered through a $0.45 \mu \mathrm{m}$ syringe filter. Once dry, $\sim 1 \mathrm{~g}$ of these ASPH were dissolved in toluene, and the process of sequential precipitation with increasing precipitant:solvent ratio was repeated according to Table 1 using acetone as the precipitant and toluene as the solvent. This time, sub-fraction A6 was stirred in solution for only 30 minutes; in addition, while the supernatant was drying after the precipitation of A7, some of the ASPH adsorbed to the sides of the beaker were re-dissolved and mixed with the supernatant; therefore, this sub-fraction (A7) is not directly compared with H7. Similar to the H-series, the leftover ASPH in the mixing and pouring beakers that were not re-dissolved were also collected and analyzed (A-ADS). All sub-fractions (excluding A-POW) were filtered through $0.45 \mu \mathrm{m}$ syringe filters, and are called the "A-series" throughout the rest of this paper.

\subsection{Separation of Maltene Sub-fractions}

The MALT were separated via open column chromatography into saturates, aromatics, and resins using high purity grade silica gel (silica gel 60, 70-230 mesh, Sigma Aldrich), which was heated at $160{ }^{\circ} \mathrm{C}$ for $48 \mathrm{~h}$ to drive off adsorbed water prior to use. For each run, the 
chromatography column was packed with silica gel and heptane, the MALT samples were dissolved in heptane and added to the column, and the saturates, aromatics, and resins were eluted with heptane, toluene, and 9:1 toluene:methanol washes, respectively (similar to Vazquez and Mansoori, 2000, and Gaspar et al., 2012) (Fig. 2).

Two MALT separations were performed with two different columns. Separation I, a test run, used a small $24 \mathrm{~cm} \times 1.3 \mathrm{~cm}$ O.D. column with a solvent reservoir. A mixture of saturates, aromatics, and resins was obtained from the heptane elution, and after the heptane ran clear, the remaining aromatics (“Aromatics Ia") and resins ("Resins Ia") were eluted with toluene and toluene:methanol, respectively. The heptane-eluted mixture was loaded onto a newly packed column, and from this separate saturate ("Saturates Ib"), aromatic ("Aromatics Ib") and resin ("Resins Ib") sub-fractions were eluted. The fractions were then evaporated, re-dissolved in DCMM, filtered through $0.45 \mu \mathrm{m}$ syringe filters, and dried to constant mass in air at $<40{ }^{\circ} \mathrm{C}$. The two aromatic and two resin eluates were combined to give single aromatic and resin fractions ("Aromatics Ia+Ib" and "Resins Ia+Ib"). Separation II used a larger column (70 cm x $2.4 \mathrm{~cm}$ I.D. x $2.8 \mathrm{~cm}$ O.D., Sigma Aldrich), and clean separations were achieved for all three sub-fractions, yielding "Saturates IIa", “Aromatics IIa", and "Resins IIa." These sub-fractions were dried, dissolved in DCMM, and filtered directly into separate quartz vessels for Re-Os analysis (see Section 2.5). About $300 \mathrm{~mL}$ and $900 \mathrm{~mL}$ of solvent were used for the elution of each sub-fraction from the smaller and larger column, respectively.

\subsection{Re-Os Analyses}

\subsubsection{Methodology}

Re and Os data were measured by isotope dilution coupled with negative thermal ionization mass spectrometry (ID-NTIMS) at the AIRIE Program, Colorado State University. 
Pre-weighed ASPH and MALT sub-fractions were added to clean $90 \mathrm{~mL}$ quartz digestion vessels together with a known amount of ${ }^{185} \mathrm{Re}$ and ${ }^{190} \mathrm{Os}$ spike and $7 \mathrm{~mL}$ of twice re-distilled concentrated nitric acid, which was previously pre-purified with hydrogen peroxide for at least 5 hours to reduce Os blanks (Yang et al., 2015). The vessels were then sealed with Teflon tape and quartz caps, and the samples digested overnight in an Anton Paar HPA-S high-pressure asher following the recommended procedure in Georgiev et al. (2016). Osmium was extracted from the digested sample solutions into chloroform, then into hydrobromic acid, and was twice distilled into $18 \mu \mathrm{L}$ of fresh hydrobromic acid using $35 \mu \mathrm{L}$ of a chromic-sulfuric acid mixture as an oxidizing agent (see Georgiev et al., 2016).

Rhenium was extracted using a 5M sodium hydroxide-acetone treatment similar to Du et al. (2004). The sodium hydroxide solution was pre-cleaned by mixing with equal volume of acetone, shaking the mixture vigorously for 5 minutes, centrifuging for 10 minutes, and discarding the acetone. This was repeated in total 3 times to scavenge Re from the sodium hydroxide, which can be a major contributor of Re to total analytical blanks. The remaining nitric acid solutions after chloroform extraction of Os were dried down in Teflon beakers and then re-dissolved in the pre-cleaned sodium hydroxide solution, heated at $60-80{ }^{\circ} \mathrm{C}$ for 30 minutes, and transferred to cleaned $15 \mathrm{~mL}$ centrifuge tubes. Next, $4.5 \mathrm{~mL}$ of acetone were added to each solution to bind Re, and the mixture was shaken for 5 minutes and centrifuged for 10 minutes. The acetone was transferred to tall $75-100 \mathrm{~mL}$ Teflon beakers and dried overnight at $<50{ }^{\circ} \mathrm{C}$, and the sodium hydroxide solutions were discarded. The dried acetone was re-dissolved in a few drops of concentrated nitric acid, dried down again, and re-dissolved in a few drops of a $30 \%$ hydrogen peroxide solution. This was dried, and the nitric acid step was repeated. Samples 
were then further purified using anion beads and nitric acid solutions of varying concentration (similar to Du et al., 2004, and Zimmerman et al., 2014).

Dried Re and Os samples were dissolved in $4 \mu \mathrm{L}$ of acid (hydrobromic acid for Os and nitric acid for $\mathrm{Re}$ ), transferred to outgassed platinum filaments, and $0.8 \mu \mathrm{L}$ of barium hydroxide and barium nitrate activators were loaded on top of Os and Re samples, respectively. The beads of acids with sample, and later the activators, were dried down on the filaments by running a current of $<0.75$ A through the wires; filaments were loaded in a Triton NTIMS. Re isotopic ratios were measured consecutively at $740{ }^{\circ} \mathrm{C}, 760{ }^{\circ} \mathrm{C}, 780{ }^{\circ} \mathrm{C}, 800{ }^{\circ} \mathrm{C}$, and $820^{\circ} \mathrm{C}$ in static mode, and Os isotopic ratios were measured by SEM in a peak-hopping mode. Propagated uncertainties include the uncertainties in spike weight and spike calibration, analytical uncertainties from isotopic ratio measurements, and uncertainties from the blank contribution.

Total analytical blanks, which were processed through Re-Os chemistry, were measured with each data set. Measured blanks contributed $2.3 \pm 0.8 \mathrm{pg}$ Re and $102 \pm 48 \mathrm{fg}$ Os with ${ }^{187} \mathrm{Os} /{ }^{188}$ Os ratios of $0.5 \pm 0.6(1 \mathrm{SD}, \mathrm{n}=5)$. Removal of one particular blank with a high ${ }^{187} \mathrm{Os} /{ }^{188} \mathrm{Os}$ results in a ${ }^{187} \mathrm{Os} /{ }^{188} \mathrm{Os}$ ratio of $0.24 \pm 0.02(1 \mathrm{SD}, \mathrm{n}=4)$ for the remaining blanks. Measured Re blanks contributed about $0.002 \%$ (crude oil), $0.0006 \%$ (ASPH), $0.04 \%$ (MALT), 0.03\% (ADRES), 0.0008-0.52\% (H-series asphaltenes, including H-POW), 0.003-1.4\% (A-series asphaltenes, including A-POW-ADS and A-POW), 15.5-38.1\% (saturates), 0.07-0.09\% (aromatics), and 0.04-0.2\% (resins) of the total measured Re. Measured Os blanks contributed about $0.06 \%$ (crude oil), $0.02 \%$ (ASPH), $0.9 \%$ (MALT), 0.8\% (ADRES), 0.02-5.0\% (H-series asphaltenes, including H-POW), 0.12-11.4\% (A-series asphaltenes, including A-POW-ADS and A-POW), $28.1-44.8 \%$ (saturates), 2.2-3.4\% (aromatics), and $0.9-3 \%$ (resins) of the total measured Os. 


\subsubsection{Standard measurements and reproducibility}

In-house standards (Re, 1407 molybdenite processed with acetone extraction; Os, N-4 standard solution from Markey et al., 2007) were measured with each data set. The ${ }^{185} \operatorname{Re} /{ }^{187} \operatorname{Re}$ of the 1407 Re standard averaged $0.59698 \pm 0.00021(1 \mathrm{SD}, \mathrm{n}=7)$, within the range of ${ }^{185} \mathrm{Re} /{ }^{187} \mathrm{Re}$ for natural rhenium $(0.59738 \pm 0.00039,95 \%$ confidence and including uncertainty in composition of separated isotopes and chemical analysis; Gramlich et al., 1973). The measured ${ }^{187} \mathrm{Os} /{ }^{188} \mathrm{Os}$ ratios for our N4 Os standard averaged $0.12360 \pm 0.00013(1 \mathrm{SD}, \mathrm{n}=7)$, within 2 standard deviations of the value originally obtained by Markey et al. (2007) (0.123373). Two splits of a Venezuelan oil (NIST 8505) were also measured for quality control. Re and Os contents $(2.566 \pm 0.134$ and $0.0327 \pm 0.0017 \mathrm{ppb}$, respectively; $1 \mathrm{SD}, \mathrm{n}=2)$ and ${ }^{187} \mathrm{Os} /{ }^{188} \mathrm{Os}$ and ${ }^{187} \mathrm{Re} /{ }^{188}$ Os ratios $(1.511 \pm 0.002$ and $448.4 \pm 47.1$, respectively; $1 \mathrm{SD}, \mathrm{n}=2)$ are in agreement with results for this oil reported previously by Sen and Peucker-Ehrenbrink (2014) (average

${ }^{187} \mathrm{Os} /{ }^{188} \mathrm{Os}$ of $\left.1.62 \pm 0.15, \mathrm{n}=7,1 \mathrm{SD}\right)$ and Georgiev et al. $(2016)\left({ }^{187} \mathrm{Re} /{ }^{188} \mathrm{Os}\right.$ of $419.0 \pm 6.9$ and $442.9 \pm 7.8,2 \sigma$ uncertainty).

Internal reproducibility (RSD\%) between duplicate Re analyses of ASPH sub-fractions is $<2 \%(\mathrm{H} 4, \mathrm{H}-\mathrm{ADS}, \mathrm{A} 7)$ and 44\% (A4). Internal reproducibility between duplicate Os analyses is $<1 \%(\mathrm{H} 4)$ and 6-7\% (H-ADS, A4, A7). For samples with better reproducibility (all but A4), we report Re-Os data as average values of the two replicate analyses. For sample A4, we report only one analysis (ORG-1831).

\subsection{ICP-MS Analyses}

\subsubsection{Methodology}

All samples, plus one analytical blank, were digested overnight in the HPA using redistilled nitric acid and the same digestion parameters as with Re-Os sample digestion. The 
resulting solutions were transferred to Savillex vials and dried; this drying step took several days, as many of the samples became gel-like and were difficult to evaporate. For ASPH sub-fraction H7, the spiked nitric acid solution remaining after Re-Os chemistry was used for ICP-MS analysis due to insufficient sample amount for a separate digestion. Once dry, the samples were diluted with $10 \mathrm{~mL}$ of a pre-made $1 \%$ nitric acid solution spiked with 5 ppb In, 20 ppb Sc, and 5 ppb Y, and the vials were closed and heated at $110{ }^{\circ} \mathrm{C}$ for 3 hours. The solutions were then cooled, and, if deemed necessary based on expected metal contents, extra dilutions were made with the In-Sc-Y-spiked nitric acid solution. Sample solutions, as well as pre-diluted standards, In-Sc-Y spike blanks, and a redistilled nitric acid total analytical blank, were then analyzed for V, Cr, Mn, Fe, Co, Ni, Cu, Zn, As, Sr, Zr, Mo, Ag, Cd, Sb, Ba, Re, Se, Pb, and U by ICP-MS with a Perkin Elmer DCRII using a Cetac ASX-520 auto-sampler at Colorado State University. Readings included three replicates of 50 sweeps each, and $\mathrm{Cr}, \mathrm{Mn}, \mathrm{Fe}, \mathrm{Se}$, and $\mathrm{Cu}$ were measured in a reaction cell. Data was reduced manually to account for drift and carry-over, and certain metals (Zn, Zr, U, Ag, Re, Cr, Fe, Cu, Mn) were corrected for high total analytical blank contributions. The Re concentration of sub-fraction $\mathrm{H} 7$ was calculated via isotope dilution. Propagated uncertainties (RSD\%) include the analytical uncertainty of ICP-MS measurements (RSD\% of three replicate measurements) and uncertainty in the chosen calibration line, as well as a small pipetting error for sub-fraction $\mathrm{H} 7$. These propagated uncertainties vary depending on sample amount and metal content and are generally $<5 \%(\mathrm{Ni}, \mathrm{Pb}, \mathrm{Cu}),<10 \%(\mathrm{Co}, \mathrm{Ba}, \mathrm{Sb}, \mathrm{Ag}$, $\mathrm{Cr}, \mathrm{Fe}),<20 \%$ (Mo, V, Zn, Sr, U, As, Re, Mn) and <30\% (Zr, Cd). Uncertainties for Se errors range from $9.1 \%-98.6 \%$, due to inconsistent and non-linear standard behavior. Due to these standard issues and problems with blank measurements, these Se data should be regarded with suspicion. 
For extended details about ICP-MS data acquisition, data reduction, error propagation, and instrument parameters, see the Appendix.

\subsubsection{Standard measurements and reproducibility}

Comparison of results for NIST SRM 1634c to certified and reference values (Schiller et al., 2014) give RSD\% of 9.4\% (V), $12.5 \%$ (Ni), and 66.9\% (Se). Comparison with published values in Ventura et al. (2015) give RSD\% of $14.8 \%(\mathrm{Mo}), 10.9 \%(\mathrm{~V}), 11.7 \%(\mathrm{Ni})$, and $140.2 \%$ $\mathrm{Cu}$. The relatively high deviations can partly reflect propagated uncertainties for each of these elements (especially for Se), but also indicate additional potential factors such as the length of time the oil was stirred before sampling, the length of time the solutions were dried while uncapped, the freshness of the prepared calibration standards, or the use of previously measured calibration standards for calculations. Regardless of these variations, in this paper we mainly consider the behavior of trace metals between sub-fractions, rather than their absolute concentrations.

Comparison of ICP-MS results to NTIMS results for ASPH sub-fractions and bulk samples give RSD\% of <1\% (H4, H6, H7, A4, A6), <6\% (H3, H5, A1, A3, A7, bulk MALT, ADRES, bulk ASPH), 11\% (A2), and 33\% (A5). 


\section{CHAPTER 3 - RESULTS}

\subsection{Weight Percentages of Sub-fractions}

The heptane-soluble (MALT) fraction accounts for $64.9 \%$ of the crude oil weight, whereas the heptane-insoluble (ASPH, ADRES, and POW) fraction accounts for $27.6 \%$ of the crude oil weight (Table 2). The missing portion of $~ 7.5 \mathrm{wt} . \%$ is made up of the ASPH/MALT mixture either left adsorbed onto the glass beaker walls or small spills while pouring the ASPH/MALT mixture into centrifuge tubes $(\sim 3.5 \%)$ plus the wt.\% of small MALT molecules that were lost by evaporation (missing MALT).

\begin{tabular}{|c|c|c|c|c|c|}
\hline \multirow{3}{*}{ Initial separation } & \multirow{3}{*}{$\begin{array}{c}\begin{array}{c}\text { heptane- } \\
\text { soluble } \\
\text { (MALT) }\end{array} \\
64.9\end{array}$} & \multicolumn{3}{|c|}{ heptane-insoluble } & \multirow{3}{*}{$\begin{array}{l}\text { Sum } \\
92.5\end{array}$} \\
\hline & & & 27.6 & & \\
\hline & & ADRES & POW & ASPH & \\
\hline $\begin{array}{c}\text { Insoluble } \\
\text { fraction broken } \\
\text { down }\end{array}$ & 64.9 & 1.4 & 0.9 & 24.3 & 91.4 \\
\hline Powder-free $^{\mathrm{a}}$ & 65.4 & 1.4 & & 24.5 & 91.4 \\
\hline$\% \operatorname{Re}$ & 3.5 & 0.2 & & 98.3 & 102.0 \\
\hline$\% \mathrm{Os}$ & 4.6 & 0.2 & & 98.2 & 102.9 \\
\hline
\end{tabular}

Breaking the heptane-insoluble precipitate down further translates to a crude oil that is 64.9 wt.\% MALT, 24.3 wt.\% ASPH, 1.4 wt.\% ADRES, and 0.9 wt.\% POW. However, because the crude oil and all solubility fraction samples were filtered before being analyzed for Re-Os, these weight percentages were adjusted to exclude the weight of POW, and the adjusted, final weight percentages are 65.4\% MALT, 1.4\% ADRES, and 24.5\% ASPH (Table 2) (See Appendix for detailed calculations). These values are similar to ASPH (27.7 wt.\%) and measured MALT (66.4 wt.\%) contents reported for the Noto oil by Georgiev et al. (2016), the small differences 
reflecting different ASPH precipitation procedures employed here (e.g., separation of ADRES).

A SEM image of the bulk ASPH is shown in Figure 3.

The weight percentages of sub-fractions in the H-series (Table 3) are highly variable. H1 and $\mathrm{H} 2$ together only constitute $\sim 2 \%$ of the ASPH weight, while $\mathrm{H} 4$ alone accounts for $34 \%$, and $\mathrm{H} 3, \mathrm{H} 4$, and $\mathrm{H} 5$ together account for about $65 \%$. In the A-series, the weight percentages are more evenly distributed among sub-fractions than in the H-series, with A1-A4 each having at least $10 \%$ of the total ASPH weight, and A5-A6 accounting for $10 \%$ together (Table 3). Select SEM images of H- and A-series ASPH sub-fractions are shown in Figure 3.

Table 3: Results of ASPH sub-fractionations, expressed as wt.\% from the starting bulk ASPH weight. Percentages of Re and Os stored in each fraction are based on mass-balance calculations.

\begin{tabular}{ccccccccccccc}
\hline & & POW & 1 & 2 & 3 & 4 & 5 & 6 & 7 & ADS & Total \\
\hline H-series & wt.\% & $3.3^{\mathrm{a}}$ & 1.0 & 0.6 & 11.5 & 32.9 & 18.5 & 7.0 & 10.6 & 11.3 & 96.6 \\
& $\begin{array}{c}\text { Powder- } \\
\text { free b }\end{array}$ & & 1.0 & 0.6 & 11.9 & 34.0 & 19.2 & 7.3 & 10.9 & 11.7 & 96.5 \\
& $\%$ Re & & 0.5 & 0.3 & 19.7 & 44.4 & 14.3 & 3.4 & 0.6 & 2.8 & 86.0 \\
& \%Os & & 0.6 & 0.3 & 21.7 & 44.8 & 12.5 & 2.8 & 0.6 & 2.5 & 85.6 \\
A-series & wt.\% & $3.4^{\mathrm{c}}$ & 13.8 & 18.1 & 19.3 & 13.8 & 8.0 & 1.9 & 27.2 & 1.7 & 103.9 \\
& \%Re & & 19.7 & 25.5 & 20.2 & 12.4 & 6.8 & 1.1 & 14.0 & 1.7 & 101.3 \\
& \%Os & & 19.7 & 22.1 & 20.3 & 14.2 & 6.6 & 1.1 & 12.2 & 1.8 & 98.1 \\
\hline
\end{tabular}

${ }^{\mathrm{a}}$ Collected with $\mathrm{H} 1$ and removed during sub-fractionation.

${ }^{\mathrm{b}}$ Adjusted weight percentages which exclude the weight percentage of H-POW, for ease of comparison with the A-series. See Appendix for details.

${ }^{c}$ Calculated weight percentage of A-POW based on the wt.\% of A-POW-ADS in the [A-POW + A-POW-ADS] total. A sample of de-powdered asphaltene was used for this separation after the removal of A-POW, thus weight percentages are based off a pure ASPH weight and need not be adjusted as with the H-series. The wt.\% of A-POW (3.4\%) represents the contribution of A-POW to the ASPH+POW+A-POW-ADS mixture, and is not included in the A-series wt.\% total (103.9\%). Both powders (A-POW and H-POW) and A-POW-ADS are not included in Re-Os budget calculations. See Appendix and Section 2.3 for details.

For the MALT, Separation I, which initially resulted in a mixture of products, and Separation II, which was a better, more complete separation, show similar proportions of saturates, aromatics, and resins (Table 4). On average, the saturates are 14.9\%, aromatics are $52.9 \%$, and resins are $32.9 \%$ of the MALT weight. 


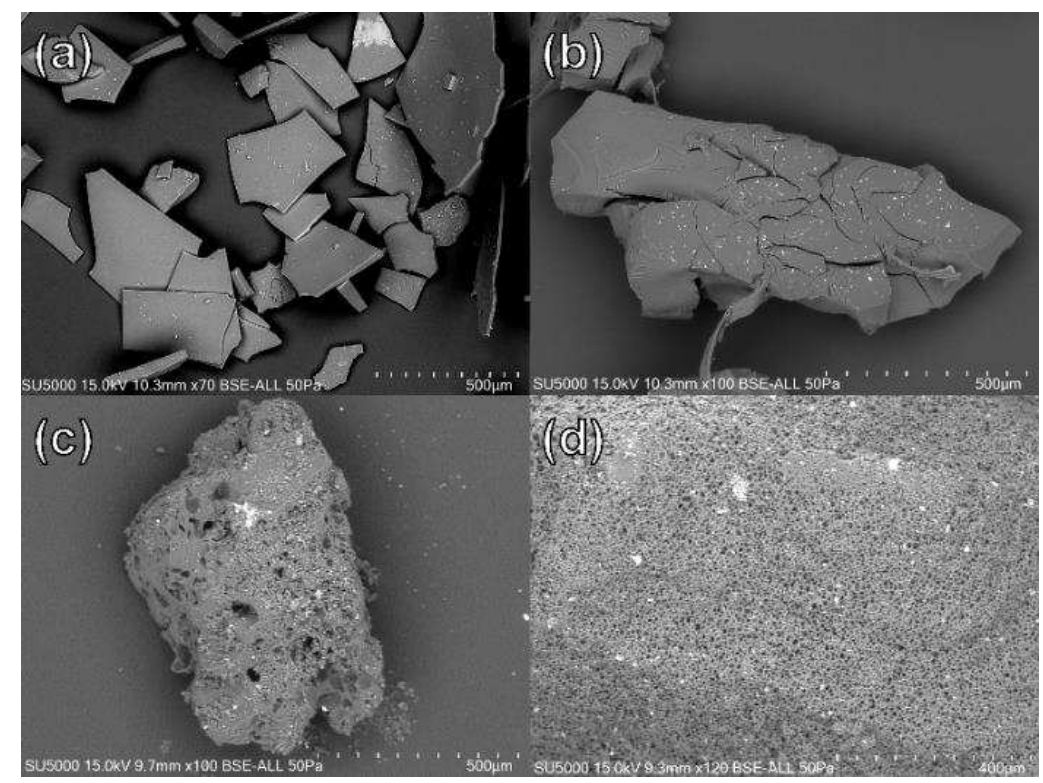

Figure 3: Back scattered electron (BSE) images of (a) an H-series sub-fraction (H3), (b) an A-series sub-fraction (A1), and (c, d) the bulk ASPH. SEM work carried out at University of Oslo, Norway, on a Hitachi SU5000 FE microscope. Applied voltage was $15.0 \mathrm{kV}$, pressure was $50 \mathrm{~Pa}$, and working distance was 9.3-10.3 mm.

Table 4: Results of MALT sub-fractionations, expressed as wt.\% from the
starting bulk MALT weight. Percentages of Re and Os stored in each
fraction are based on mass-balance calculations.
\begin{tabular}{lccccc} 
Sub-fraction & & Saturates & Aromatics & Resins & Total \\
\hline Separation I & wt.\% & 15.5 & 56.7 & 31.1 & 103.3 \\
& $\%$ Re & 0.3 & 61.0 & 31.5 & 92.8 \\
& $\% O s$ & 5.1 & 55.4 & 62.1 & $122.6^{\mathrm{a}}$ \\
Separation II & wt.\% & 14.2 & 49.2 & 34.8 & 98.2 \\
& $\%$ Re & $<0.1$ & 34.8 & 62.9 & 97.8 \\
& $\% O \mathrm{Os}$ & 1.1 & 38.4 & 91.0 & $130.5^{\mathrm{a}}$ \\
\hline
\end{tabular}

${ }^{a}$ See discussion for comments on excess Os.

\subsection{Re-Os Results}

All Re-Os results are shown in Table 5. Bulk crude oil concentrations (225.9 ppb Re and 0.3395 ppb Os) are similar to those obtained by Georgiev et al. (2016) for the Noto oil (216.9230.6 ppb Re and 0.3408-0.3618 ppb Os). Heptane-precipitated ASPH and MALT Re-Os concentrations from this study show reproducibility (RSD\%) of $\sim 7-8 \%$ (ASPH) and $\sim 16-27 \%$ (MALT) compared to Re- Os values reported in Georgiev et al. (2016). These differences likely reflect the different ASPH precipitation procedures employed here (see above), and perhaps minor sample heterogeneity (a different bottle of Noto oil was used in this study). 
Table 5: Re-Os Results

\begin{tabular}{|c|c|c|c|c|c|c|c|c|c|c|}
\hline $\begin{array}{l}\text { AIRIE } \\
\text { Run \# }\end{array}$ & Sample & $\begin{array}{c}\mathrm{Re} \\
(\mathrm{ng} / \mathrm{g})\end{array}$ & $2 \sigma$ & $\begin{array}{c}\text { Os } \\
(\mathrm{ng} / \mathrm{g})\end{array}$ & $2 \sigma$ & ${ }^{187} \mathrm{Re} /{ }^{188} \mathrm{Os}$ & $2 \sigma$ & ${ }^{187} \mathrm{Os} /{ }^{188} \mathrm{Os}$ & $2 \sigma$ & rho $^{\mathrm{a}}$ \\
\hline \multicolumn{11}{|l|}{ Bulk samples } \\
\hline ORG-1505 & Crude & 225.9 & 0.5 & 0.3395 & 0.0005 & 5911.5 & 18.8 & 6.595 & 0.015 & 0.299 \\
\hline ORG-1504 ${ }^{\mathrm{b}}$ & $\mathrm{nC}-7^{\mathrm{c}} \mathrm{ASPH}$ & 906.3 & 2.0 & 1.3612 & 0.0023 & 5928.7 & 20.7 & 6.625 & 0.018 & 0.363 \\
\hline ORG-1511 & $\mathrm{nC}-7^{\mathrm{c}} \mathrm{MALT}$ & 12.164 & 0.015 & 0.02363 & 0.00007 & 4117.9 & 17.8 & 5.185 & 0.028 & 0.679 \\
\hline ORG-1503 & ADRES & 28.29 & 0.04 & 0.03934 & 0.00010 & 5804.4 & 23.5 & 5.305 & 0.025 & 0.682 \\
\hline \multicolumn{2}{|c|}{ Calculated crude oil concentrations ${ }^{\mathrm{d}}$ : } & 230.3 & & 0.35 & & & & & & \\
\hline \multicolumn{11}{|c|}{ H-series ASPH Sub-fractions } \\
\hline ORG-1506 & H-POW & 8.3 & 0.4 & 0.4750 & 0.0024 & 127.4 & 9.0 & 4.042 & 0.040 & 0.070 \\
\hline ORG-1581 & H1 & 421.3 & 3.0 & 0.7661 & 0.0024 & 4769.6 & 51.4 & 6.248 & 0.034 & 0.367 \\
\hline ORG-1582 & $\mathrm{H} 2$ & 419.5 & 5.0 & 0.667 & 0.005 & 5501.5 & 110.3 & 6.346 & 0.088 & 0.475 \\
\hline ORG-1510 & $\mathrm{H} 3$ & 1495.3 & 3.4 & 2.4764 & 0.0026 & 5368.4 & 17.3 & 6.605 & 0.011 & 0.217 \\
\hline ORG-1508 & $\mathrm{H} 4$ & 1179.1 & 2.9 & 1.7825 & 0.0024 & 5902.6 & 21.6 & 6.657 & 0.015 & 0.277 \\
\hline ORG- $1721^{\mathrm{e}}$ & $\mathrm{H} 4$ & 1192.1 & 2.5 & 1.806 & 0.005 & 5858.7 & 22.1 & 6.582 & 0.027 & 0.435 \\
\hline ORG-1509 & H5 & 678.3 & 1.6 & 0.8888 & 0.0011 & 6764.6 & 22.8 & 6.563 & 0.013 & 0.251 \\
\hline ORG-1583 & H6 & 423.1 & 0.9 & 0.5157 & 0.0008 & 7178.6 & 25.2 & 6.380 & 0.016 & 0.388 \\
\hline ORG-1958 & $\mathrm{H} 7$ & 46.5 & 0.7 & 0.0698 & 0.0004 & 5029.8 & 115.0 & 4.479 & 0.055 & 0.249 \\
\hline ORG-1586 & H-ADS & 218.2 & 0.5 & 0.2796 & 0.0005 & 6694.6 & 23.5 & 6.104 & 0.018 & 0.417 \\
\hline ORG-1917 & H-ADS & 221.2 & 1.6 & 0.3025 & 0.0016 & 6270.1 & 75.8 & 5.705 & 0.053 & 0.392 \\
\hline Calculated bulk & ASPH concentrations ${ }^{\mathrm{d}}$ : & 779.2 & & 1.17 & & & & & & \\
\hline \multicolumn{11}{|c|}{$A$-series ASPH Sub-fractions } \\
\hline ORG-1587 & A-POW-ADS & 88.38 & 0.34 & 0.336 & 0.005 & 2253.8 & 54.1 & 5.217 & 0.135 & 0.884 \\
\hline ORG-1590 & A-POW & 12.19 & 0.17 & 0.722 & 0.005 & 123.2 & 2.5 & 4.042 & 0.052 & 0.291 \\
\hline ORG-1588 & A1 & 1291.3 & 3.1 & 1.941 & 0.003 & 5923.9 & 21.6 & 6.623 & 0.017 & 0.287 \\
\hline ORG-1589 & $\mathrm{A} 2$ & 1276.7 & 3.3 & 1.6666 & 0.0018 & 6836.2 & 25.0 & 6.659 & 0.011 & 0.197 \\
\hline ORG-1585 & A3 & 946.4 & 4.4 & 1.4319 & 0.0011 & 5895.2 & 37.2 & 6.651 & 0.008 & 0.077 \\
\hline ORG-1725 & A4 & 1547.3 & 6.9 & 1.2657 & 0.0022 & 10794.0 & 68.2 & 6.508 & 0.018 & 0.182 \\
\hline ORG- $1831^{\mathrm{e}}$ & A4 & 813.0 & 1.7 & 1.395 & 0.003 & 5150.2 & 20.2 & 6.526 & 0.024 & 0.513 \\
\hline ORG-1726 & A5 & 766.1 & 2.2 & 1.1218 & 0.0017 & 6072.7 & 25.5 & 6.608 & 0.016 & 0.265 \\
\hline ORG-1727 & A6 & 515.3 & 1.0 & 0.8125 & 0.0024 & 5608.5 & 24.5 & 6.532 & 0.032 & 0.560 \\
\hline ORG-1728 & A7 & 472.0 & 0.7 & 0.5887 & 0.0010 & 7053.0 & 18.6 & 6.461 & 0.018 & 0.494 \\
\hline ORG- $1832^{\mathrm{e}}$ & A7 & 461.6 & 1.0 & 0.6389 & 0.0017 & 6321.4 & 27.0 & 6.383 & 0.028 & 0.500 \\
\hline ORG-1920 & A-ADS & 901.9 & 5.4 & 1.386 & 0.006 & 5714.2 & 55.0 & 6.425 & 0.047 & 0.363 \\
\hline Calculated bulk & ASPH concentrations ${ }^{\mathrm{d}}$ : & 918.4 & & 1.34 & & & & & & \\
\hline \multicolumn{11}{|c|}{ Maltene Sub-fractions } \\
\hline ORG-1913 & Saturates IIa & 0.0344 & 0.0017 & 0.00178 & 0.00005 & 94.7 & 8.0 & 0.136 & 0.014 & 0.314 \\
\hline ORG-1914 & Aromatics IIa & 8.606 & 0.028 & 0.01845 & 0.00006 & 2702.8 & 21.1 & 1.603 & 0.015 & 0.559 \\
\hline ORG-1915 & Resins IIa & 22.00 & 0.09 & 0.06184 & 0.00024 & 2511.2 & 19.3 & 3.690 & 0.030 & 0.487 \\
\hline \multicolumn{2}{|c|}{ Calculated bulk MALT IIa concentrations ${ }^{\mathrm{d}}$ : } & 11.9 & & 0.031 & & & & & & \\
\hline ORG-1918 & Saturates $1 b$ & 0.246 & 0.004 & 0.00783 & 0.00014 & 157.4 & 6.4 & 0.161 & 0.011 & 0.408 \\
\hline ORG-1921 & Aromatics Ia $+\mathrm{Ib}$ & 13.093 & 0.018 & 0.02311 & 0.00009 & 3941.8 & 24.1 & 3.523 & 0.028 & 0.720 \\
\hline ORG-1919 & Resins Ia + Ib & 12.30 & 0.07 & 0.04714 & 0.00023 & 1763.5 & 19.4 & 3.202 & 0.035 & 0.485 \\
\hline \multicolumn{2}{|c|}{ Calculated bulk MALT Ia + Ib concentrations: } & 11.3 & & 0.029 & & & & & & \\
\hline \multicolumn{11}{|c|}{$\begin{array}{l}2 \sigma \text { uncertainties are affected by uncertainties in spike weight and spike calibrati } \\
\text { uncertainties from the blank contribution, and the sample weight. Out of } 33 \text { ana } \\
\text { have relative errors of < } 3 \% \text {, and } 7 \text { analyses have relative errors of }<7 \% \text {. } \\
\text { a Rho is the calculated correlation coefficient; see Ludwig (2003). } \\
{ }^{\text {b }} \text { Contains only ASPH-adsorbed resins and insoluble powder removed through } \\
{ }^{c} \text { nC-7 refers to } n \text {-heptane. } \\
\text { d Calculated Re-Os concentrations are based on mass balance considerations. } \\
{ }^{\text {e }} \text { Repeat digestion }\end{array}$} \\
\hline
\end{tabular}


In the H-series ASPH sub-fractions, Re-Os concentrations both increase sharply from $\mathrm{H} 2$ to $\mathrm{H} 3$, and then decrease from $\mathrm{H} 3$ onwards (Fig. 4). In the A-series, Re and Os concentrations steadily drop from the first sub-fraction onwards. For the MALT separations, both saturate fractions contain very little Re and Os (Fig. 5). In Separation I, the aromatics have the highest Re concentration, while the resins have the highest Os concentration. In Separation II, Re and Os concentrations increase from saturates, to aromatics, to resins.

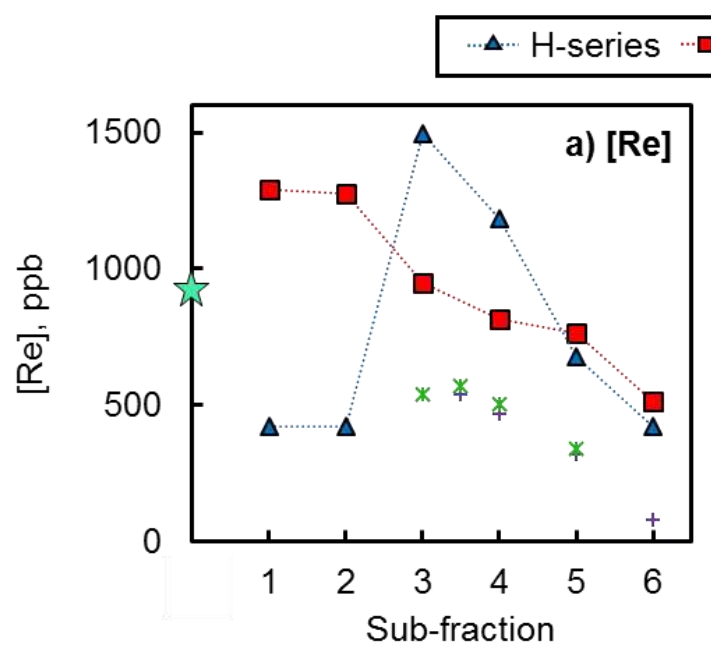

A-series $+\mathrm{K} 1 \quad * \mathrm{~K} 2$
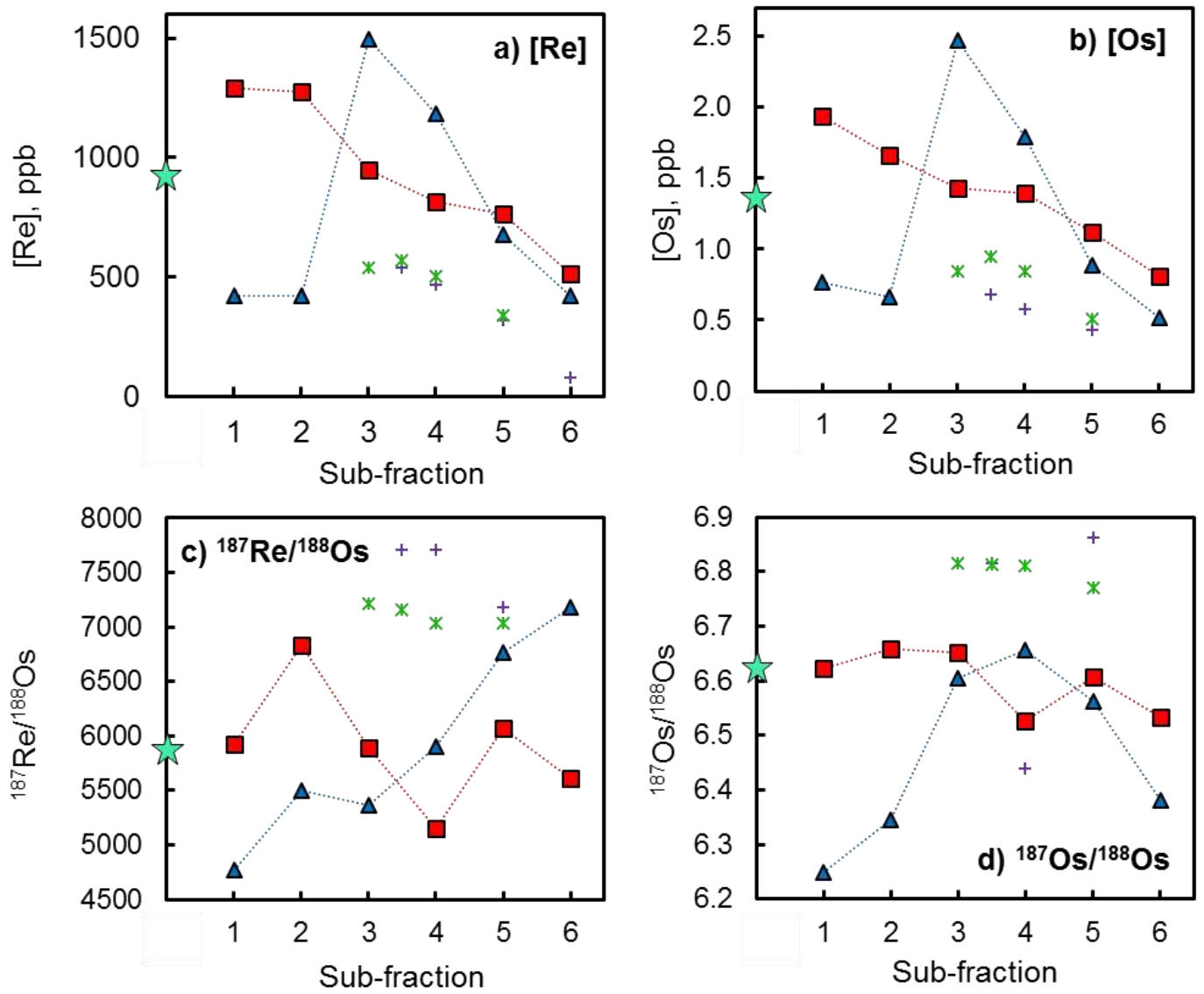

Figure 4: Re and Os concentrations (a, b) and isotopic ratios (c, d) of the $\mathrm{H}$-series and A-series ASPH subfractions. Stars on the vertical axes indicate concentrations/ratios of the bulk ASPH. K1 and K2 represent data from Mahdaoui et al. (2013) for heptane-DCM ASPH sub-fractions with precipitant:solvent ratios similar to those used in this study. The K1 and K2 series are plotted on a different vertical axis (1.5-10.7 ppb Re, 0.065-0.118 ppb Os, 87-

110 for $\mathrm{Re} / \mathrm{Os}$ [not ${ }^{187} \mathrm{Re} /{ }^{188} \mathrm{Os}$ ] ratios, and $1.19-3.31$ for ${ }^{187} \mathrm{Os} /{ }^{188} \mathrm{Os}$ ratios, respectively), as we are only interested in the comparing trends in this figure. 

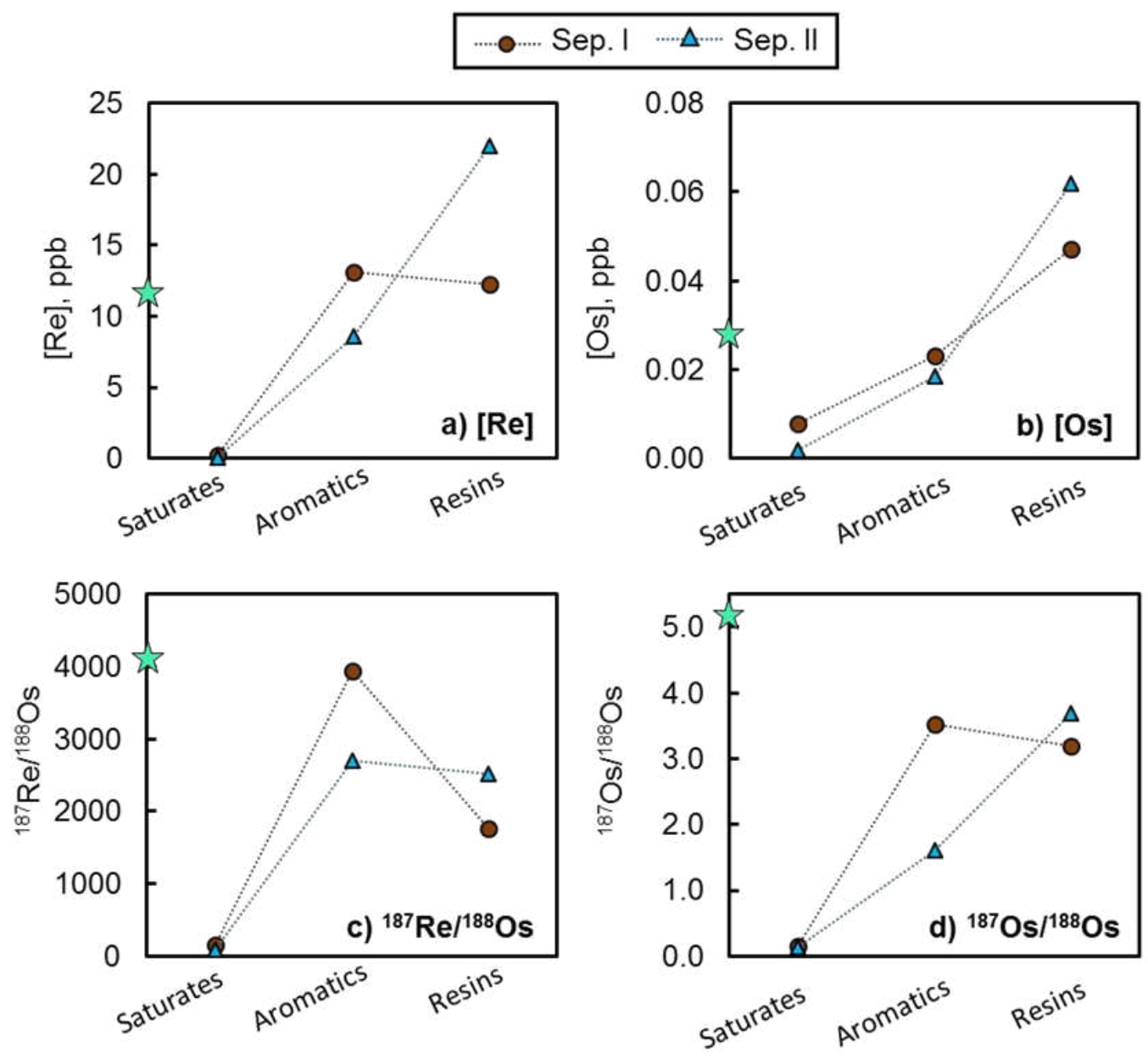

Figure 5: Re-Os concentrations (a, b) and isotopic ratios (c, d) of MALT sub-fractions for two separate runs. Stars on the y-axes indicate the Re-Os concentrations and isotopic ratios of the bulk MALT.

\subsection{Re-Os Budgets}

The Re and Os bulk crude oil budgets were calculated using adjusted weight percentages (excluding the insoluble powder that precipitated with the asphaltenes), and are shown in Figure 6 and Table 2. Budgets for the H-series ASPH sub-fractions were calculated using adjusted weight percentages (excluding the insoluble powder H-POW that precipitated with H1), and are shown in Table 3 and Figure 6. Budgets for the A-series ASPH sub-fractions were calculated with un-adjusted weight percentages as shown in Table 3, excluding A-POW and A-POW-ADS. 
Re-Os budgets for the MALT separations are shown in Table 4 and Figure 7. Calculated bulk crude oil, ASPH, and MALT concentrations are shown in Table 5.

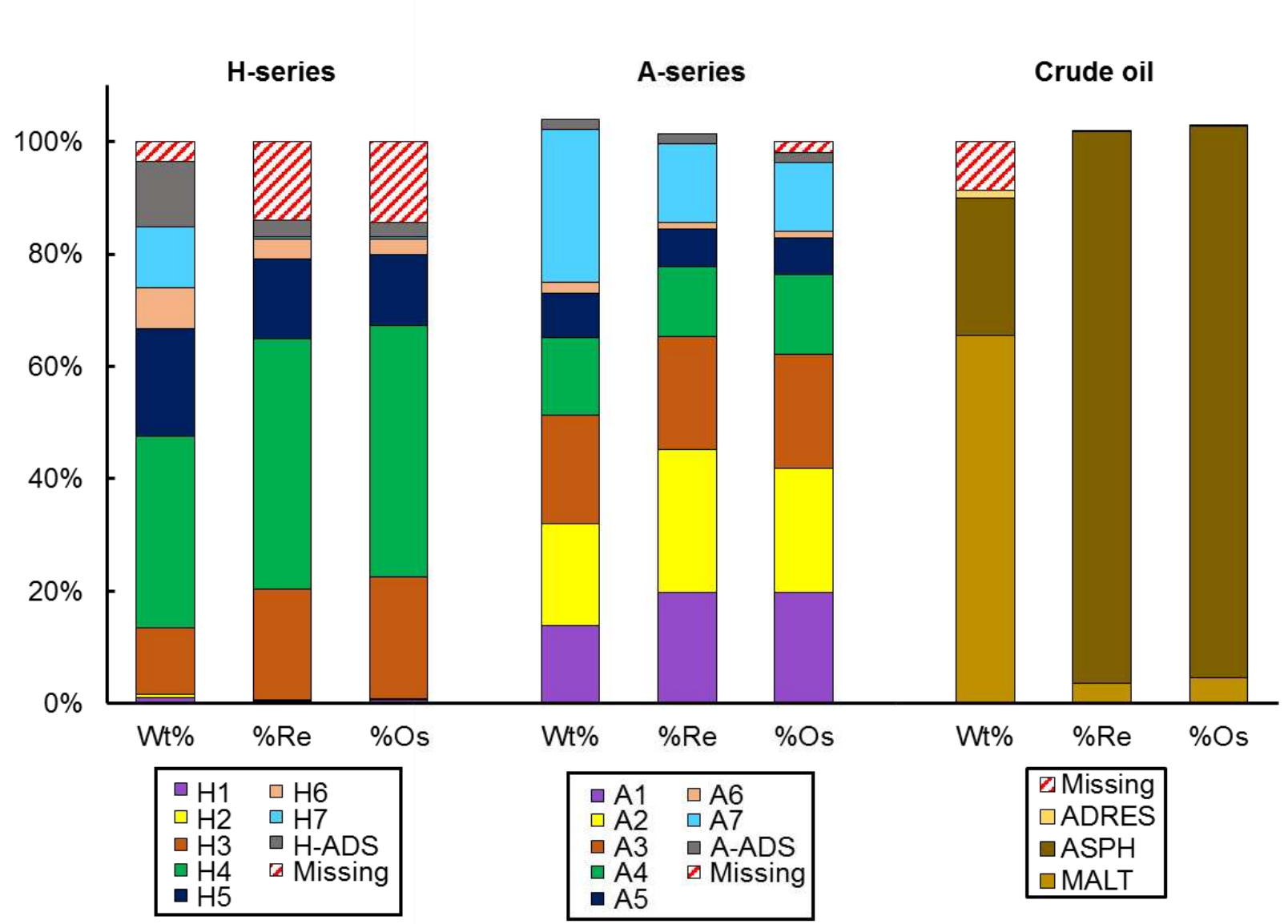

Figure 6: Weight percentages and Re-Os budgets of ASPH sub-fractions for two separate fractionations, and for the bulk crude oil. For sub-fractions with replicate analyses, we use average Re and Os contents (A7, H4, and $\mathrm{H}-$ ADS) or a single, more representative analysis (ORG-1831 for A4). Values for each bar are given in Tables 2 and 3. $\mathrm{H} 1$ and $\mathrm{H} 2$ are barely visible in the $\mathrm{H}$-series Re-Os budgets, as their percentages $(0.3 \%-0.6 \%)$ are very small.

\subsection{Re-Os Isotopic Ratios}

The ${ }^{187} \mathrm{Re} /{ }^{188} \mathrm{Os}$ and ${ }^{187} \mathrm{Os} /{ }^{188} \mathrm{Os}$ isotopic ratios of the bulk crude oil (5911.5 and 6.595, respectively) are intermediate between those of the bulk ASPH (5928.7 and 6.625, respectively) and the bulk MALT (4117.9 and 5.185, respectively). The ADRES ${ }^{187} \mathrm{Re} /{ }^{188}$ Os and ${ }^{187} \mathrm{Os} /{ }^{188} \mathrm{Os}$ ratios (5804.4 and 5.305, respectively) are in-between those of the bulk crude and bulk MALT. 


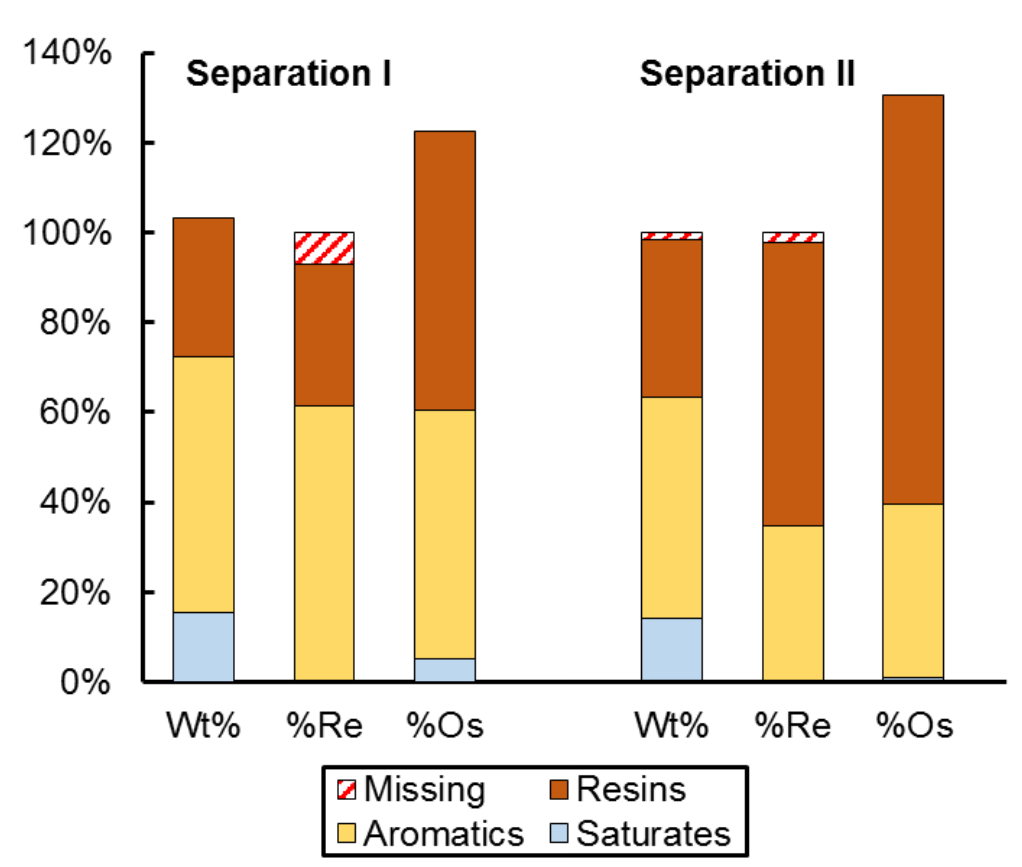

Figure 7: Weight percentages and Re-Os budgets of MALT sub-fractions for two separate runs. The vast majority of Re and Os is locked in the aromatics and resins for both separations. See Section 4.1.3 of the Discussion about excess Os in Separations I and II.

In the H-series ASPH sub-fractions, ${ }^{187} \mathrm{Re} /{ }^{188}$ Os generally increases from H1-H6, while ${ }^{187} \mathrm{Os} /{ }^{188} \mathrm{Os}$ increases up until $\mathrm{H} 4$ and then decreases (Figure 4). ${ }^{187} \mathrm{Re} /{ }^{188} \mathrm{Os}$ ratios for the A-series, on the other hand, are variable, and there are no clear trends as sub-fractionation progresses. The ${ }^{187} \mathrm{Os} /{ }^{188} \mathrm{Os}$ ratio reaches a maximum in $\mathrm{A} 2$, and then decreases with some deviation until A6. In both MALT separations, the saturates have the lowest ${ }^{187} \mathrm{Re} /{ }^{188}$ Os and ${ }^{187} \mathrm{Os} /{ }^{188} \mathrm{Os}$ (Fig. 5), whereas the aromatics have the highest ${ }^{187} \mathrm{Re} /{ }^{188}$ Os ratios. In Separation I, the ${ }^{187} \mathrm{Os} /{ }^{188} \mathrm{Os}$ ratio is highest in the aromatics, whereas in Separation II the ${ }^{187} \mathrm{Os} /{ }^{188} \mathrm{Os}$ ratio is highest in the resins. We consider Separation II to be more representative, as it was a cleaner separation, and the sub-fractions only passed through the column once. Interestingly, all measured MALT sub-fractions have lower ${ }^{187} \mathrm{Os} /{ }^{188}$ Os ratios compared to the bulk MALT. 


\subsection{ICP-MS results}

Detailed results of ICP-MS analyses are shown in the Appendix. Mo, V, Zn, Ni, Fe, Cu, $\mathrm{Mn}$, and $\mathrm{Cr}$ are all present at the tens to hundreds of ppm level, while most other elements are present at single to sub-ppm levels. Using knowledge of weight percentages of ASPH sub-fractions (Table 3) and our ICP-MS data for these sub-fractions and the bulk ASPH (see Appendix), we performed a mass-balance check for each measured element as a further quality assessment of trace metal content data. Here we report ICP-MS analyses and discuss trace metal data only for elements with acceptable mass balances (range arbitrarily set to between $74 \%$ and $109 \%$ of the bulk ASPH metal content). Data for eight trace metals (Mo, V, Ni, Pb, Re, Cd, Cu, and Se) that satisfy the acceptable mass-balance criteria are shown in Table 6. The results generally show decreasing concentrations from ASPH to ADRES to MALT, and decreasing concentrations within each consecutive ASPH sub-fraction in both the H-series and A-series.

Table 6: ICP-MS results (ppb) of trace metals that returned acceptable (74\%-109\%) mass balances.

\begin{tabular}{|c|c|c|c|c|c|c|c|c|c|}
\hline Sample & ICP ID & Mo & V & $\mathrm{Ni}$ & $\mathrm{Pb}$ & $\operatorname{Re}$ & $\mathrm{Cd}$ & $\mathrm{Cu}$ & $\mathrm{Se}$ \\
\hline $\mathrm{H} 3$ & ICP140 & 255550.3 & 532597.5 & 229105.8 & 2194.0 & 1547.2 & 959.2 & 12231.8 & 1798.4 \\
\hline $\mathrm{H} 4^{\mathrm{a}}$ & ICP141 & 173354.7 & 496781.6 & 250250.1 & 1528.8 & 1177.2 & 652.2 & 10001.8 & 2101.8 \\
\hline H5 & ICP149 & 77105.6 & 410658.4 & 212397.5 & 1176.5 & 650.0 & 301.0 & 6976.6 & 1692.5 \\
\hline H6 & ICP142 & 39977.1 & 391148.7 & 191270.7 & 1155.6 & 424.7 & 181.9 & 6120.8 & 787.0 \\
\hline $\mathrm{H} 7^{\mathrm{a}}$ & ICP155 & 2414.6 & 336543.4 & 116936.9 & 356.4 & $46.3^{c}$ & 18.6 & 2612.1 & 255.5 \\
\hline$H$-series mass balance: & & $79.2 \%$ & $88.5 \%$ & $82.2 \%$ & $81.2 \%$ & $88.6 \%$ & $74.9 \%$ & $83.3 \%$ & $79.3 \%$ \\
\hline $\mathrm{A} 1^{\mathrm{a}}$ & ICP138 & 197173.5 & 448360.0 & 257539.5 & 1937.2 & 1257.2 & 717.9 & 11684.1 & 2292.1 \\
\hline $\mathrm{A} 2^{\mathrm{a}}$ & ICP143 & 165026.1 & 438662.6 & 271023.0 & 1705.5 & 1092.4 & 599.0 & 10993.1 & 2073.9 \\
\hline $\mathrm{A} 3^{\mathrm{a}}$ & ICP144 & 125900.6 & 381879.4 & 223672.2 & 1563.8 & 880.0 & 461.0 & 8751.8 & 2047.2 \\
\hline A4 & ICP145 & 113664.7 & 388917.3 & 220490.7 & 1607.3 & 815.5 & 423.1 & 8332.7 & 1582.0 \\
\hline A5 & ICP146 & 66257.4 & 223709.3 & 131332.1 & 1800.0 & 478.4 & 247.6 & 6560.4 & 858.7 \\
\hline A6 & ICP147 & 70615.1 & 230905.9 & 150972.3 & 2239.6 & 509.0 & 296.3 & 7891.6 & 807.2 \\
\hline A7 & ICP139 & 52182.1 & 490160.6 & 171285.7 & 828.7 & 436.6 & 201.2 & 5613.6 & $<96.2^{\mathrm{b}}$ \\
\hline A-series mass balance: & & $87.1 \%$ & $99.8 \%$ & $99.8 \%$ & $108.8 \%$ & $97.6 \%$ & $79.7 \%$ & $104.0 \%$ & $84.0 \%$ \\
\hline Bulk MALT & ICP152 & 808.1 & 78517.4 & 40893.3 & 172.6 & 11.9 & 6.0 & 803.2 & 282.1 \\
\hline ADRES & ICP150 & 1562.8 & 234335.7 & 102309.9 & 546.4 & 28.9 & 14.3 & 1785.3 & 432.6 \\
\hline Bulk ASPH $^{\mathrm{a}}$ & ICP151 & 135539.5 & 425301.2 & 218641.3 & 1390.0 & 840.8 & 546.1 & 8314.9 & 1686.2 \\
\hline NIST SRM $1634 c^{a}$ & ICP157 & 73.8 & 24675.4 & 14683.5 & 407.5 & 1.4 & 2.1 & 234.9 & 36.5 \\
\hline
\end{tabular}




\section{CHAPTER 4 - DISCUSSION}

\subsection{Residency of Re and Os in Crude Oil Fractions}

\subsubsection{Re-Os in Bulk ASPH and MALT}

The vast majority of Re and Os in the studied Noto crude oil is locked in the ASPH component ( $\sim 98 \%$ ), with $<5 \%$ in the MALT component and $<1 \%$ in the ADRES (Table 2 ). This suggests the asphaltenes are the primary sink for Re and Os in crude oil, in agreement with the findings of Selby et al. (2007) and Georgiev et al. (2016). However, the percentage of Re and Os stored in the ASPH fraction of different oils varies in both of these studies, and we expect that oils with less ASPH may have a larger part of their Re-Os budgets stored in their MALT fraction. Regardless, the predominant affinity of Re and Os to the ASPH fraction suggests that Re and Os are preferentially fixed into the more complex molecules of the ASPH fraction. However, the specific structures hosting Re and Os, or even the main properties and characteristics of Re-Os hosting compounds (e.g., number and type of heteroatoms, aromaticity, functional groups, etc.) remain unresolved.

\subsubsection{Re-Os in ASPH sub-fractions}

The mechanism of sub-fraction precipitation in a heptane-DCM system is relatively straightforward: increasing the amount of $n$-alkane in the mixture causes the polarity of the mixture to decrease, which forces the most polar and aromatic ASPH to precipitate, leaving increasingly less polar fractions in solution (Nalwaya et al., 1999; Wattana et al., 2005; Mahdaoui et al., 2013). Here, sub-fractions $\mathrm{H} 3$ and $\mathrm{H} 4$ contain the majority of the Re and Os in the bulk ASPH ( 64-67\%), while $\mathrm{H} 1, \mathrm{H} 2$, and $\mathrm{H} 7$ each contain less than $1 \%$ of the total Re and Os (Fig. 6). These results suggest that the compounds that house Re and Os are very polar, or have an affinity for polar 
ASPH, which is in general agreement with Mahdaoui et al. (2013). However, we emphasize that our most polar sub-fractions (H1 and H2) have low Re and Os concentrations (Fig. 4), which suggests that molecular polarity may not be the only controlling factor for Re-Os binding or for precipitation of Re-Os-containing asphaltenes. Alternatively, our sub-fractions $\mathrm{H} 1$ and $\mathrm{H} 2$ may not be the most polar sub-fractions.

Calculated Re-Os contents of H-series ASPH based on mass-balance considerations are both $\sim 14 \%$ lower than the measured bulk ASPH (Table 5). These values may be explained by incomplete evaporation of solvent from some sub-fractions (although they add up to <100 wt.\%; Table 3), by incomplete sample recovery (the missing mass must have $3700 \mathrm{ppb}$ Re and $6 \mathrm{ppb}$ Os to make up for all the missing Re and Os), or by significant Re-Os loss from one of the subfractions during sample preparation (unclear mechanism and less likely). Additional mass balance calculations for specific Os isotopes show similar losses for radiogenic ${ }^{187}$ Os $(\sim 15 \%)$ and common ${ }^{192}$ Os $(\sim 14 \%)$, which suggests that Os isotopic ratios were likely not affected significantly by this Os loss. Despite the imperfect mass balance, we consider our Re-Os data for H-series ASPH sub-fractions representative for the general trends of changing Re-Os concentrations and isotopic ratios with progressive ASPH precipitation.

The changes in sub-fraction chemical character in the acetone-toluene precipitant-solvent system differ from the heptane-DCM series. According to Buenrostro-Gonzalez et al. (2002), the aromaticity and polarity of the mixture both help to keep larger aromatic molecules dispersed and dissolved at low precipitant volumes. When the mixture has $>50 \%$ acetone, however (e.g., past A1), this aromatic dispersive effect is too small to keep larger ASPH from naturally stacking, and the polarity is not enough to keep them dissolved. The most aromatic and most polar ASPH, therefore, should precipitate when the solution is $\sim 50 \%$ acetone (e.g. A1). From 
this point forward, the tendency of asphaltenes to associate and stack decreases (BuenrostroGonzalez et al., 2002).

The Re and Os budget is more evenly distributed between A1-A7 than between H1-H7 (Fig. 6), as the sub-fraction weight percentages and Re-Os concentrations are more uniform. This might suggest that polarity, rather than aromaticity, is the main control over Re-Os compounds. Mass balances are also much better for the A-series than for the H-series, likely due to more complete sample recovery. One main difference between the A-series and the H-series sub-fractions is that the first two sub-fractions (A1 and A2) have significant mass and the highest Re-Os contents, and therefore contain a notable portion of the total Re-Os budget. As Re and Os concentrations are highest in A1, and both systematically decrease with progressive precipitation, we suggest that highly aromatic and highly aggregating ASPH sequester or house most of the Re and Os, similar to the H-series (Fig. 4).

\subsubsection{Re-Os in MALT Sub-fractions}

In both separations, the saturates have the lowest amounts of Re and Os (Fig. 7). Similarly, in both separations the resins have the highest amount of Os. The main difference between the two runs is that in Separation I the aromatics contain most of the Re budget, while in Separation II the resins hold most of the Re. While calculated Re concentrations are slightly below the measured bulk MALT concentration (within 2-7\%), the calculated Os concentrations are $\sim 23 \%-31 \%$ higher than the bulk MALT concentration of $0.0236 \mathrm{ppb}$. Mass balance calculations reveal that ${ }^{192}$ Os is over-budget by $\sim 45 \%$ (Separation I) and 58\% (Separation II), while ${ }^{187}$ Os is $\sim 11 \%$ (Separation I) and $\sim 10 \%$ (Separation II) under-budget. This suggests that the method of separation, open column chromatography, may affect the isotopic composition of the sub-fractions to some degree. It is possible that there is significant common Os contribution 
to the MALT sub-fractions from the solvent, or possibly from the silica gel, during sub-fraction elution. However, it was not possible to correct for this discrepancy by removing the Os contributed by the solvent dried down with each MALT sub-fraction (see Appendix). It is unlikely that pre-concentration of the samples could have offset the mass balances, since the $\operatorname{Re}$ and ${ }^{187}$ Os budgets are not similarly affected. This suggests that radiogenic ${ }^{187}$ Os is mostly preserved during column chromatography, but common Os may be added in significant quantities from use of large amounts of solvent or silica gel.

Because Separation II was a cleaner separation (none of the eluates were visibly mixed), our discussion relies on data from this separation in the instances where the two separation runs disagree. Selby et al. (2007) suggest that Re and Os are partially bound by heteroatomic species (non-carbon atoms, usually found in cyclic molecules), which are generally polar and sequestered in the resins. The uneven distribution of Re-Os within the H-series ASPH subfractions and the more even distribution in the A-series suggests that Re-Os compounds are more affected by changes in polarity rather than aromaticity. Together, these hypotheses are reflected in the MALT sub-fractions; it appears that Re and Os are preferentially drawn to species such as furans, thiophenes, and pyridines (compounds typically found within the resin fraction) rather than to benzenes, naphthalenes, and substituted aromatics (typical compounds within the aromatics fraction). However, we emphasize that both the aromatic and resin fraction contain appreciable amounts of Re and Os, suggesting that both polarity and aromaticity play a role in the chemical binding of Re and Os. The only part of the crude oil that does not contain appreciable Re-Os is the saturates. This supports the arguments for heteroatom binding sites, as there are essentially no heteroatoms in the saturate fraction. This also means that, in the case of 
low-ASPH oils, the resin fraction may provide a sufficiently Re and Os-rich fraction for analysis, although such resin-containing isochrons remain to be studied.

\subsubsection{Nature of Re-Os Compounds in the Crude Oil}

In Section 4.1.2, we concluded that Re and Os are found in highly polar and aromatic ASPH sub-fractions. In this section, we discuss how Re (and by extension, Os) may be bound within those sub-fractions. In addition to data presented here, we use comparisons to published Re-Os and trace metal data for ASPH sub-fractions precipitated from an unrelated oil, the K-oil (a medium-density crude from Kazakhstan with $\sim 7$ wt.\% ASPH; Mahdaoui et al., 2013). Data from the $\mathrm{K} 1$ series show that Re concentrations are highest in the F2 sub-fraction (precipitated at 75\% heptane), while Ni and V contents are highest in the later sub-fractions (F3 and F4, precipitated at $80 \%$ and $90 \%$ heptane, respectively) (Fig. 8). Based on these concentration data and their other ASPH sub-fractionations, Mahdaoui et al. (2013) suggest that the compounds that house Re are different from Ni- and V-containing compounds.

Our data for the $\mathrm{H}$-series show that $\mathrm{Ni}$ is most concentrated in $\mathrm{H} 3$ and $\mathrm{H} 4$, and that $\mathrm{V}$ concentration decreases from $\mathrm{H} 3-\mathrm{H} 6$; Re concentration also decreases from $\mathrm{H} 3$ onwards (Fig. 8). The budgets of $\mathrm{Re}, \mathrm{Ni}$, and $\mathrm{V}$ in our sub-fractions also follow similar patterns, with $\mathrm{H} 4$ holding the majority of the Re, Ni, and V in the bulk ASPH. These data suggest that some Re may actually be held similarly to Ni and V porphyrin complexes as suggested by Miller (2004), or in similar non-porphyrin compounds (e.g. Reynolds, 1998, and references therein; Speight, 2004, and references therein; Zhao et al., 2014).

However, as previously discussed, a multitude of trace element sites are found in crude oil, and Re and Os may favor different compounds than those that house Ni-V. We explore this possibility further by examining the behavior of trace metals between ASPH sub-fractions 


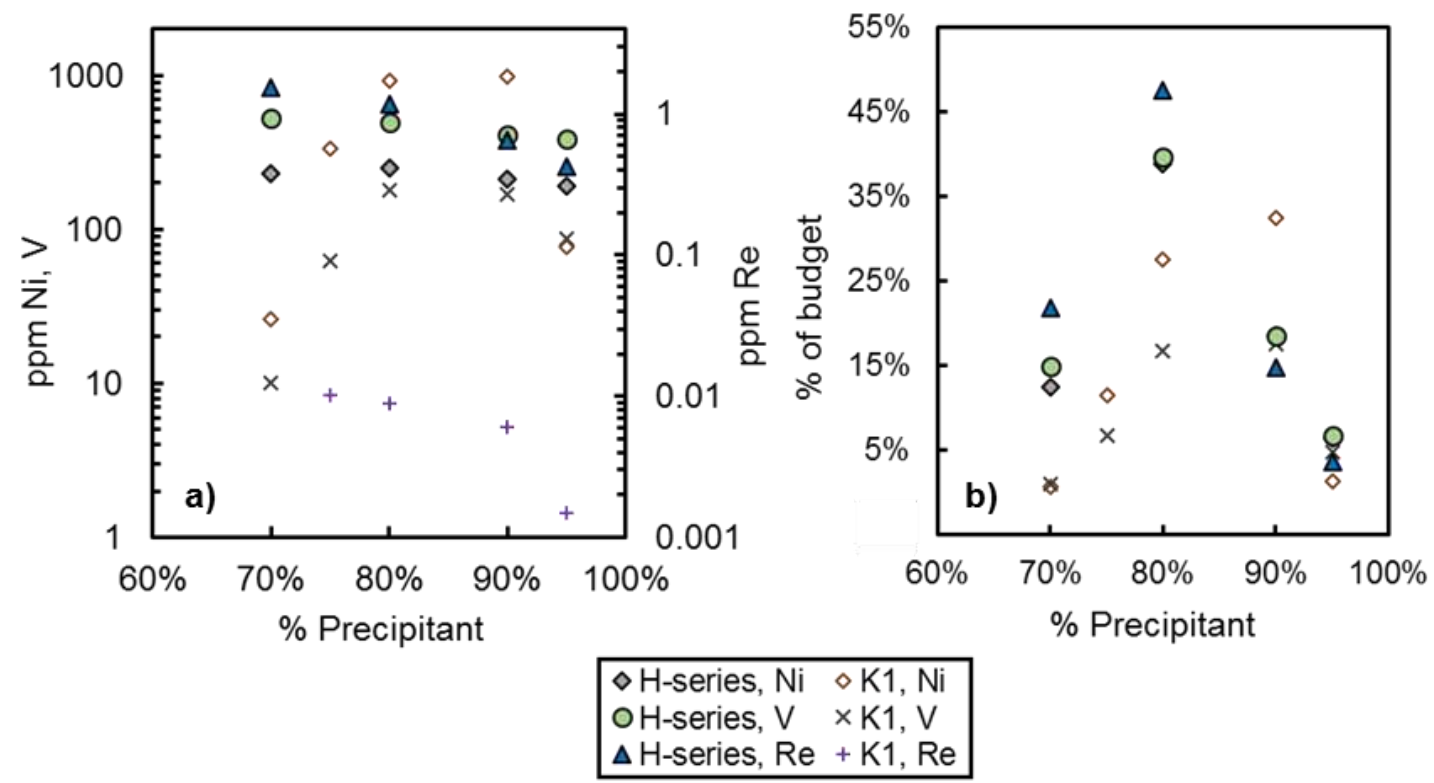

Figure 8: Ni, V, and Re concentrations (a) and budgets (b) in H-series ASPH sub-fractions. Sub-fraction number in the $\mathrm{X}$-axis is replaced with percent precipitant, which corresponds to the sub-fraction numbers used in this study (e.g., 70\% - H3, 80\% - H4, and so on; see Table 1) and in Mahdaoui et al. (2013) (e.g., 70\% - F1, 75\% - F2, $80 \%-\mathrm{F} 3,90 \%-\mathrm{F} 4,95 \%$ - F5). K1 represents data from the K-oil of Mahdaoui et al. (2013). Note that the plot on the left has logarithmic vertical scales.

with enrichment/depletion profiles (Fig. 9). Progressive ASPH sub-fraction precipitation results in fractions with progressively lower trace metal contents in both sub-fraction series. For both the H-series and A-series, behavior of Mo parallels that of Re and is very close to that of Os, following trends observed in some organic rich shales (e.g., Georgiev et al., 2011); Cd behavior is also very close to that of $\mathrm{Re}$ and $\mathrm{Os}$. $\mathrm{Cu}$ and Re profiles are also alike, while Se behavior is similar to that of Re in the A-series. In the A-series, $\mathrm{Ni}$ and $\mathrm{V}$ behavior is close to Re-Os behavior-however, Re-Os behavior in both series is more closely tracked by Mo and Cd than by Ni and V (Fig. 9). As Mo-Cd behavior is close to Re-Os between these two precipitantsolvent systems, we suggest that the complexes that bind Mo and $\mathrm{Cd}$ also bind $\mathrm{Re}$ or Os. Cd is likely precipitated in reducing sediments as CdS (e.g., Rosenthal et al., 1995; Sundby et al., 2004) and Mo is enriched by formation of thiomolybdates (e.g., Crusius et al., 1996; Erickson and Helz, 2000); however, little is known about the exact complexes these metals form in crude 
oil. The ionic radii of reduced forms of $\mathrm{Mo}\left(\mathrm{Mo}^{4+}: 0.65 \AA\right.$, and $\left.\mathrm{Mo}^{3+}: 0.69 \AA\right), \operatorname{Re}\left(\operatorname{Re}^{4+}: 0.63 \AA\right)$, Os $\left(\mathrm{Os}^{4+}: 0.63 \AA\right)$, and $\mathrm{Cd}^{2+}(0.78-1.31 \AA$, depending on coordination number) are similar, and the electronegativities of $\mathrm{Mo}(2.16), \operatorname{Re}(1.9)$, Os (2.2), and $\mathrm{Cd}$ (1.69) are also close; these parallels may contribute to similarities between Re/Os/Cd/Mo behavior in the ASPH.
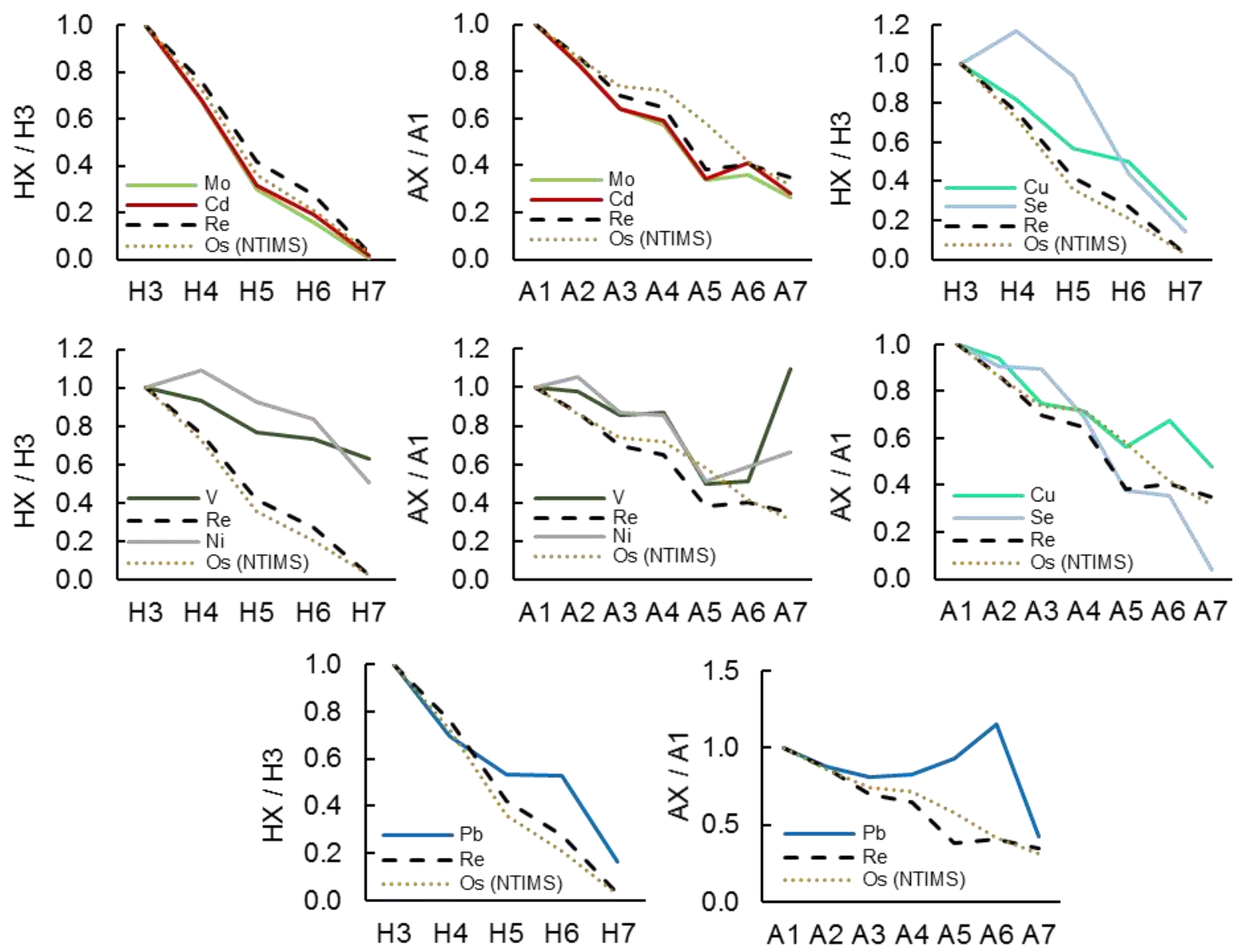

Figure 9: Enrichment/depletion plots of trace metals in the H-series and A-series ASPH sub-fractions. Only trace elements whose budgets amounted to a total of $\sim 74 \%-109 \%$ are shown. For other elements, see the Appendix. Trace element concentrations were normalized against the first sub-fraction in each series (either A1 or H3, as $\mathrm{H} 1$ and $\mathrm{H} 2$ were not analyzed), such that the first data point (A1 or $\mathrm{H} 3$ ) has a value of 1 and the successive data points (H4-H7 and A2-A7) have values other than 1 which reflect the degree of depletion $(<1)$ or enrichment $(>1)$ of each trace element in the sub-fraction.

\subsection{Re-Os Geochronology}

The isotopic ratios of H-series ASPH sub-fractions surround the bulk ASPH when plotted in ${ }^{187} \mathrm{Os} /{ }^{188} \mathrm{Os}$ vs. ${ }^{187} \mathrm{Re} /{ }^{188} \mathrm{Os}$ isochron space (Fig. 10), and there is significant scatter along the 

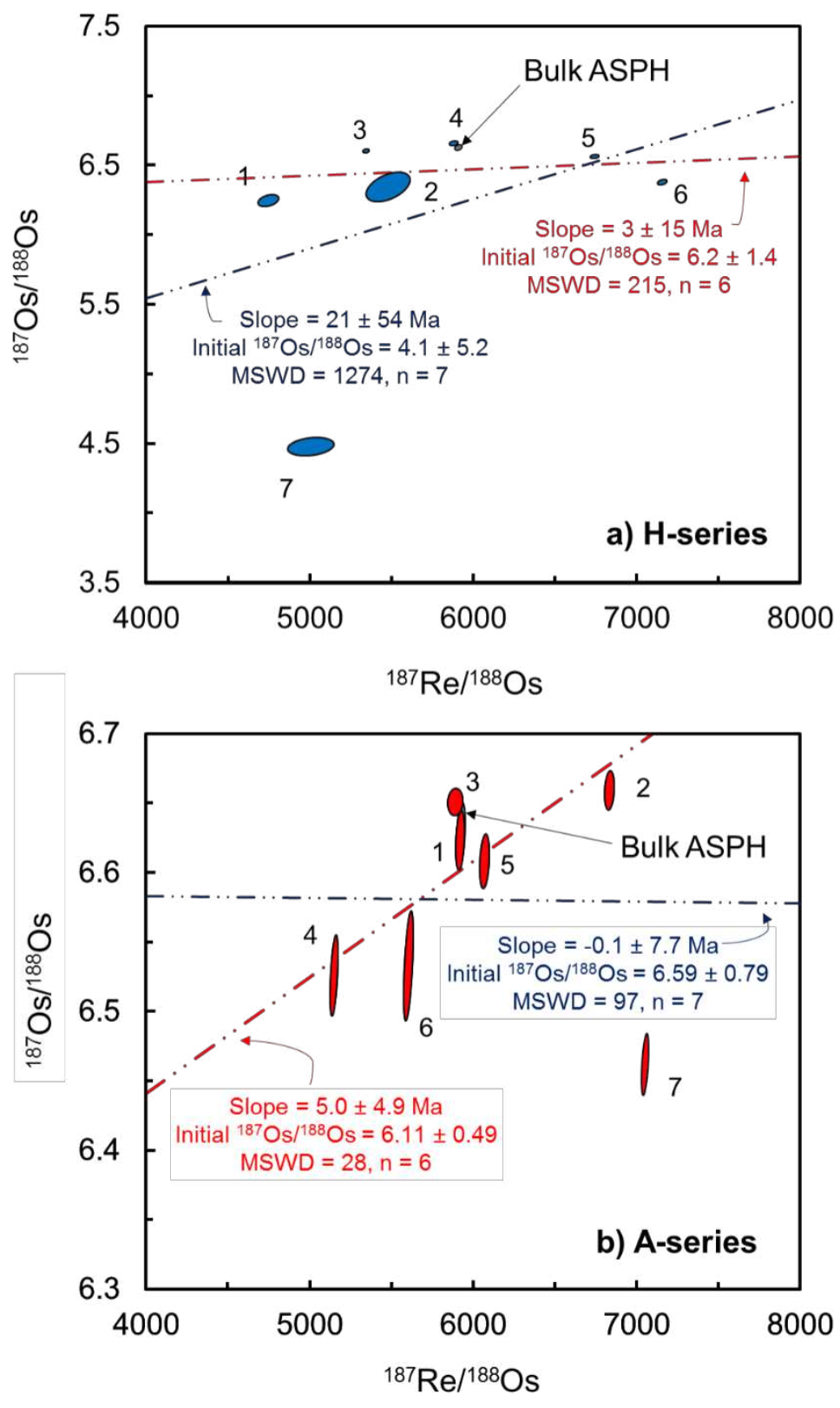

Figure 10: Re-Os isochron plots of the H-series (a) and A-series (b) ASPH sub-fractions. a) Re/Os isotopic ratios of the $\mathrm{H}$-series. One trendline (blue) shows the slope if all points are taken into account. The other (red) shows the slope if $\mathrm{H7}$ is dropped; b) Re/Os isotopic ratios of the A-series. The blue line represents the slope when all points are taken into account, while the red line represents the slope when A7 is dropped. All regressions are performed with Isoplot 4.15 (Ludwig, 2003), and data point error ellipses are $2 \sigma$. 
regression line. Six out of seven sub-fractions yield a Model 3 age of $3 \pm 15$ Ma with a high MSWD. This age is younger than the $28.3 \pm 4.3 \mathrm{Ma}$ Re-Os age previously obtained from the Noto oil (Georgiev et al., 2016). ${ }^{187} \mathrm{Re} /{ }^{188} \mathrm{Os}$ and ${ }^{187} \mathrm{Os} /{ }^{188} \mathrm{Os}$ in the A-series ASPH sub-fractions are also variable. Sub-fractions A1-A6 show a more linear relationship than H1-H6, but still with significant scatter that does not yield a Model 1 age (Fig. 10).

The scatter present in both the $\mathrm{H}$-series and the A-series indicates that the sub-fractions by themselves are not isochronous, perhaps suggesting that the compounds that house Re-Os did not form at the same time and from a uniform shale/oil, or the compounds did form at the same time but there was isotopic exchange later in their history. This isotopic exchange could have occurred during oil evolution, with changes in temperature or pressure in the reservoir, oil-fluid interactions, or during Re-Os sample preparation; recent tectonics in the Gela field related to the subsidence of the Gela foreland may have caused heating sufficient to cause such isotopic exchange (Novelli et al., 1988). Perhaps radiogenically produced ${ }^{187}$ Os is expelled from its parent Re site and forms a new compound; then, the non-isochronous nature of the ASPH subfractions may be due to the fractionation procedure. If Re and radiogenic ${ }^{187}$ Os are decoupled within organic matter, or if the compounds that house them are present in different amounts, then it may be expected that when the ASPH are separated based on polarity the sub-fractions will contain widely different Re-Os ratios. This would suggest that if the crude oil is broken up into small enough constituents, eventually those entities no longer resemble each other because of fundamental differences inherent in the molecules within those sub-fractions; then, splitting the bulk ASPH into its sub-fractions and using those separate sub-fractions as samples could undercut the isotopic integrity of the bulk ASPH fraction as a whole. This may be similar to ReOs systematics in molybdenite: as there is no welcoming site for Os in the molybdenite crystal 
structure, radiogenically produced ${ }^{187}$ Os moves to dislocations and kink bands and is concentrated there (Stein et al., 2001, 2003). This makes sampling strategies for molybdenite separations paramount, as erroneous ages may be obtained if sampling undercuts the isotopic integrity of the volume used for a mineral separate (Stein, 2006).

The differences in isotopic ratios between asphaltene sub-fractions might suggest that there are multiple or different complexes for Re and Os, as previously suggested (Miller, 2004; Selby et al., 2007). To investigate this further, ${ }^{192} \mathrm{Os},{ }^{187} \mathrm{Os}$, and Re concentrations are plotted in Figure 11. In the $\mathrm{H}$-series and A-series sub-fractions, ${ }^{192} \mathrm{Os}^{187} \mathrm{Os}$ are better correlated than are Re- ${ }^{187}$ Os or Re- ${ }^{192}$ Os. While good Os isotope correlations should be expected since nonradiogenic ${ }^{187}$ Os would strongly correlate with common Os, some amount of the total ${ }^{187} \mathrm{Os}$ is also radiogenic. This may further suggest that Re and Os are decoupled within crude oil. However, while the differences between the Re- ${ }^{187} \mathrm{Os}$ and Re- ${ }^{192} \mathrm{Os}$ correlations are small, Re is better correlated with ${ }^{187} \mathrm{Os}$ than with ${ }^{192} \mathrm{Os}$. This may suggest that at least some radiogenic ${ }^{187} \mathrm{Os}$ remains with its parent Re. These correlations reiterate that, in the case of crude oil, it may be difficult to evaluate ${ }^{187} \mathrm{Re}^{187} \mathrm{Os}$ decoupling possibilities. However, shaking or stirring a volume of crude liquid or dissolved asphaltene before sampling offers an easy precaution against erroneous isotopic ratios. Regardless of the cause of differences between ASPH sub-fraction isotopic ratios, those differences eliminate the possibility of being able to use ASPH sub-fractions to extend the range of ${ }^{187} \mathrm{Re} /{ }^{188} \mathrm{Os}$ ratios obtainable from a single sample of crude oil for isochron stability. The significant isotopic scatter from two different precipitant-solvent systems reinforces this conclusion. However, for dating single crude oils, we have already shown that when the crude oil is separated into its solubility fractions, ASPH and MALT, these fractions together with the crude oil can be isochronous (Georgiev et al., 2016). 

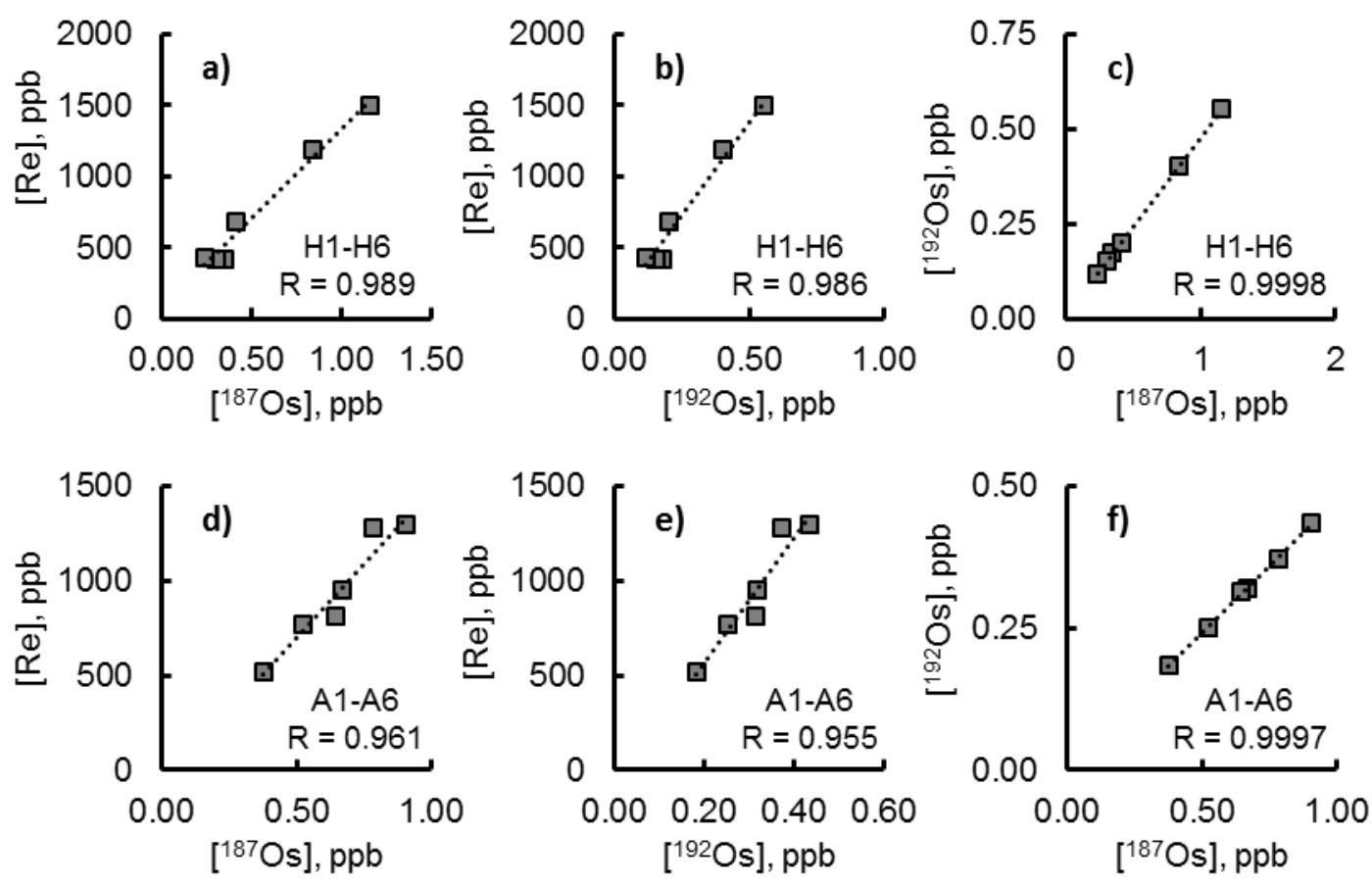

Figure 11: Correlations between Os isotopes and Re for ASPH sub-fractions. a), b), and c): H1-H6. d), e), and f): A1-A6. In both cases, the best correlations are between ${ }^{192} \mathrm{Os}$ and ${ }^{187} \mathrm{Os}$, which might suggest that ${ }^{187}$ Os is preferentially held in a different site than Re; in contrast, though the differences are small, Re correlates better with ${ }^{187}$ Os than with ${ }^{192}$ Os, which suggests Re and at least some ${ }^{187}$ Os share a site. Unfortunately, these results are inconclusive. All ASPH sub-fraction correlations are significant. Correlations of the bulk ASPH, MALT, and crude oil are not shown, as they all yield correlation coefficients of 1, and correlations between MALT sub-fractions were almost all insignificant.

The MALT sub-fractions, taken together, are not isochronous (Fig. 12). The aromatics (yellow line, $\left.92.9 \pm 1.8 \mathrm{Ma},\left({ }^{187} \mathrm{Os} /{ }^{188} \mathrm{Os}\right)_{\mathrm{i}}=-2.58 \pm 0.10\right)$ and resins (brown line, $39.2 \pm 3.2 \mathrm{Ma}$, $\left.\left({ }^{187} \mathrm{Os} /{ }^{188} \mathrm{Os}\right)_{\mathrm{i}}=2.05 \pm 1.2\right)$ regressed separately yield two-point lines with contrasting ages and initial Os intercepts that are semi-parallel to the calculated regression line. Two-point isochrons have doubtful reliability, but resin lines in particular merit more investigation, as it could be possible that multiple resins might form separate regression lines.

\subsection{Effects of Asphaltene Sub-fraction Precipitation}

Here, we revisit the possibility that ASPH precipitation at any point in the petroleum system might be a process for creating the range of Re-Os ratios found within crude oil. ASPH 


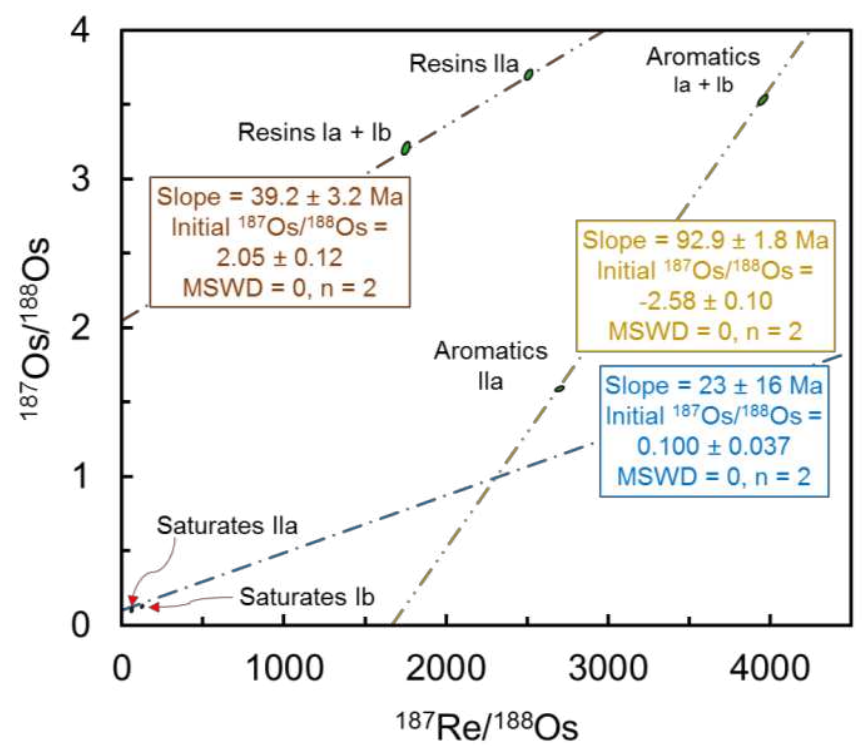

Figure 12: Re-Os isotopic ratios of separated MALT sub-fractions plotted in isochron space. All MALT subfractions taken together, like the ASPH sub-fractions, are not isochronous (slope of $53 \pm 52 \mathrm{Ma},{ }^{187} \mathrm{Os} /{ }^{188} \mathrm{Os}=0.4 \pm$ 2.0, MSWD = 8250). However, different sub-fractions may form their own lines. More MALT samples need to be separated to test this hypothesis.

precipitation is a natural process that occurs when there are pressure, temperature, or compositional changes in the reservoir (Hirschberg et al., 1984), and ASPH precipitation could remove significant Re and Os. Mahdaoui et al. (2013) argue that progressive ASPH precipitation generally does not produce changes in ASPH isotopic ratios, which would suggest that ASPH precipitation in turn does not change the isotopic composition of the remaining oil. Based on our precise isotopic data, we calculated the effect of ASPH sub-fraction precipitation on the Re-Os isotopic ratios of the remaining crude oil after ASPH removal (Fig. 13). For example: looking at the $\mathrm{H}$-series in Figure $13 \mathrm{a}$, the point at position 2 on the $\mathrm{x}$-axis indicates that combined precipitation of the volumetrically insignificant sub-fractions $\mathrm{H} 1$ and $\mathrm{H} 2$ produces virtually no change in the ${ }^{187} \mathrm{Re} /{ }^{188} \mathrm{Os}$ ratios of the remaining crude oil. However, if $\mathrm{H} 1, \mathrm{H} 2$, and $\mathrm{H} 3$ are precipitated together, the remaining crude oil will have a ${ }^{187} \mathrm{Re} /{ }^{188} \mathrm{Os}$ ratio of about 6070 at $\mathrm{x}=3$, a $~ 3 \%$ increase from the original crude ratio. Precipitation of H1-H4 increases the ${ }^{187} \mathrm{Re} /{ }^{188} \mathrm{Os}$ ratio to 6314 , a $\sim 7 \%$ increase over the original crude ratio. After the precipitation of $\mathrm{H} 4$, 

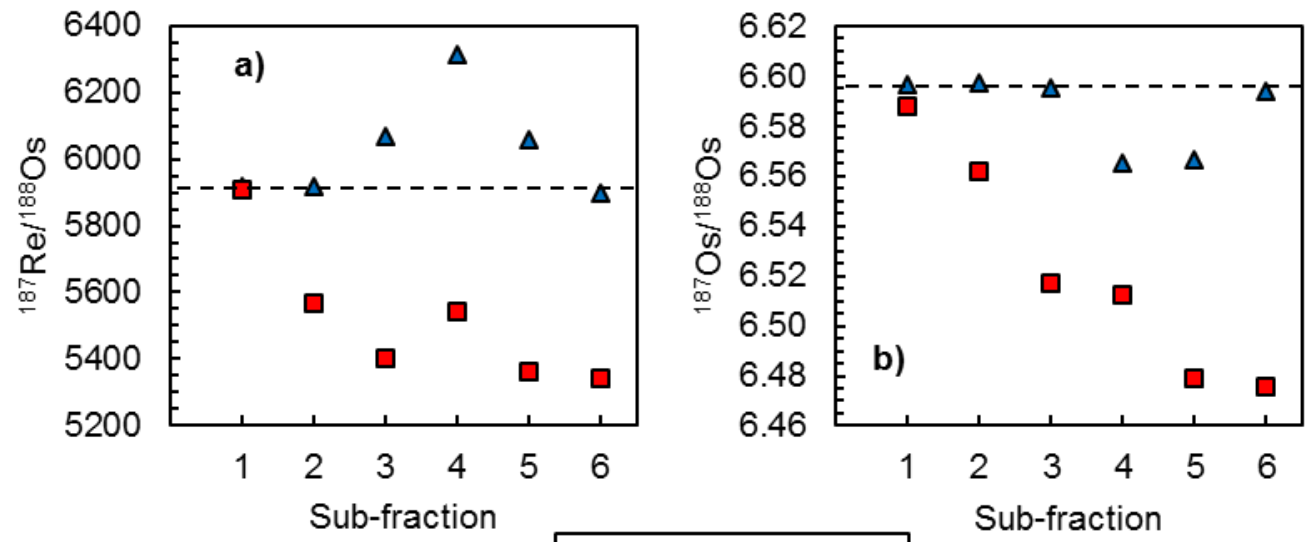

$\Delta \mathrm{H}$-series $\square$ A-series

Figure 13: Effect of the progressive precipitation of ASPH sub-fractions on the isotopic ratios of the remaining crude oil. Plotted symbols indicate the modeled a) ${ }^{187} \mathrm{Re} /{ }^{188} \mathrm{Os}$ and b) ${ }^{187} \mathrm{Os} /{ }^{188} \mathrm{Os}$ ratios of crude oil with progressive removal of ASPH sub-fractions. The dashed lines indicate the ratios of the starting crude oil without any ASPH precipitation. The changes in Re/Os isotopic ratios with successive precipitation suggest that natural precipitation of ASPH can have an effect on the resultant Re/Os ratios of the remaining oil.

however, the ${ }^{187} \mathrm{Re} /{ }^{188} \mathrm{Os}$ ratio decreases, and it returns to close to the original crude oil ratio after the precipitation of $\mathrm{H} 6$. The ${ }^{187} \mathrm{Os} /{ }^{188} \mathrm{Os}$ ratio changes at the most in the second decimal place. Precipitating $\mathrm{H} 1-\mathrm{H} 3$ only changes the Os ratio by $~ 0.01 \%$, but precipitating $\mathrm{H} 1-\mathrm{H} 4$ drops the ${ }^{187} \mathrm{Os} /{ }^{188} \mathrm{Os}$ ratio from 6.595 to 6.565 , a $\sim 0.5 \%$ decrease from the original ratio. Precipitation of $\mathrm{H} 1-\mathrm{H} 5$ has little effect, and further precipitation of the $\mathrm{H} 6$ fraction (so H1-H6 combined) brings the ${ }^{187} \mathrm{Os} /{ }^{188} \mathrm{Os}$ ratio back to within $\sim 0.02 \%$ of the original crude ratio.

In the case of the A-series, precipitation of A1 again has little effect on the crude oil's ${ }^{187} \mathrm{Re} /{ }^{188}$ Os ratio. However, precipitating from A1-A3 drops the crude oil ratio down to 5402, a $\sim 9 \%$ decrease from the original ratio of 5911. Precipitating A1-A4 decreases the original ratio by $\sim 6 \%$, and precipitation of $\mathrm{A} 1-\mathrm{A} 6$ drops the original ratio by $\sim 10 \%$. The ${ }^{187} \mathrm{Os} /{ }^{188} \mathrm{Os}$ ratio decreases by $\sim 1 \%$ when precipitating from $\mathrm{A} 1-\mathrm{A} 3$, and precipitation of A1-A6 only decreases the original ratio by $\sim 2 \%$.

In summary, Fig. 13 shows that the effect that progressive ASPH precipitation has on the crude oil isotopic ratios is dependent on the amount of precipitated ASPH, and on the solvent 
system used. For example, removal of $\mathrm{H} 1-\mathrm{H} 3$ changes the Re/Os ratio of remaining oil, whereas removal of $\mathrm{H} 1-\mathrm{H} 6$ has overall little effect on the crude oil's isotopic composition, as after H6 the Re-Os ratios return close to the bulk crude ratios. However, after precipitation of A1-A6, both the ${ }^{187} \mathrm{Re} /{ }^{188} \mathrm{Os}$ and the ${ }^{187} \mathrm{Os} /{ }^{188} \mathrm{Os}$ ratios are significantly different than the original crude ratios. Importantly, the changes we produced in ${ }^{187} \mathrm{Re} /{ }^{188} \mathrm{Os}$ and ${ }^{187} \mathrm{Os} /{ }^{188} \mathrm{Os}$ ratios are in fact small. The largest observed change in ${ }^{187} \mathrm{Re} /{ }^{188} \mathrm{Os}$ ratios are $+6.8 \%$ after precipitation of $\mathrm{H} 1-\mathrm{H} 4$, and $-9.6 \%$ after precipitation of A1-A6. The Os ratios at most change by $-0.5 \%$ after precipitation of $\mathrm{H} 1-\mathrm{H} 4$, and $-1.8 \%$ after precipitation of A1-A6.

In nature, it is very unlikely that ASPH sub-fractions such as these will precipitate in a chemically impeded, well-mixed environment, and our experimental design afforded the opportunity for precipitations to run to completion in a setting with virtually unlimited solvent availability. Thus, in nature, ASPH sub-fractions would not precipitate exactly as described, and precipitating sub-fractions would not be characterized solely by solubility in precipitant-solvent mixtures. A variety of system changes, including temperature and pressure fluctuations and interaction with waters, could induce precipitation of ASPH in a natural petroleum system. But while this model of cumulative precipitation might not perfectly mimic nature, we show that precipitation of certain sub-fractions of ASPH, such as those with high Re and Os concentrations, can alter the bulk crude oil's isotopic composition. This is something to be considered when interpreting oil isochrons, especially if there is excess geologic scatter around the regression line; it may be that oils that exhibit such scatter have experienced ASPH precipitation in their history. On the contrary, well-formed isochrons signal isotopic integrity in the components analyzed, and are unlikely to have experienced any perturbation in their ${ }^{187} \mathrm{Re} /{ }^{188} \mathrm{Os}$ and ${ }^{187} \mathrm{Os} /{ }^{188} \mathrm{Os}$ ratios in their geologic history. 


\section{CHAPTER 5 - CONCLUSIONS}

In this work, we show when asphaltenes are separated by precipitant-solvent pairs into solubility-defined sub-fractions, Re and Os are highly concentrated in the highly polar-aromatic sub-fractions. These sub-fractions have non-isochronous ${ }^{187} \mathrm{Re} /{ }^{188}$ Os and ${ }^{187} \mathrm{Os} /{ }^{188} \mathrm{Os}$ ratios, meaning that ASPH sub-fractions cannot be used as separate points on an isochron that also includes the bulk crude and MALT, even though the bulk ASPH, MALT, and crude oil might show isochronous relations (this study; Georgiev et al., 2016). This suggests that the different compounds in the ASPH sub-fractions formed at different times or experienced isotopic exchange, or that Re-Os may be decoupled and could exist within many different complex classes within organic matter. Correlations between Re, ${ }^{187} \mathrm{Os}$, and ${ }^{192}$ Os are inconclusive, and more advanced methods of structural determination should be considered to elucidate Re-Os decoupling possibilities. There is significant Re-Os in the aromatics and resins of the MALT; a single clean separation shows that the resin sub-fraction has the highest Re and Os concentrations. MALT sub-fractions as a group are not isochronous, but more work is needed to determine if certain sub-fractions, such as the resins, might be useful to Re-Os geochronology. In our sequentially precipitated ASPH sub-fractions, Re tracks Os, and Re strongly tracks Mo and $\mathrm{Cd}$ in asphaltene sub-fractions. This indicates that the complexes that sequester Re-Os may be similar to those that take in Mo and Cd. We also suggest that some Re may be held in metalloporphyrins. Finally, we show that the progressive precipitation of asphaltenes can change

the isotopic ratios of bulk crude oil ${ }^{187} \mathrm{Re} /{ }^{188} \mathrm{Os}$. This should be considered when interpreting isochrons that display significant geologic scatter; well-formed oil isochrons that exhibit minimal scatter, on the other hand, may point to an isotopically un-disturbed past. 


\section{REFERENCES}

Acevedo S., Guzmán K., Labrador H., Carrier H., Bouyssiere B. and Lobinski R. (2012) Trapping of metallic porphyrins by asphaltene aggregates: A size exclusion microchromatography with high-resolution inductively coupled plasma mass spectrometric detection study. Energy \& Fuels 26, 4968-4977.

Andersen S. I. and Speight J. G. (2001) Petroleum resins: Separation, character, and role in petroleum. Petroleum Science and Technology 19, 1-34.

Baker E. W. and Louda J. W. (1986) Porphyrin geochemistry of Atlantic Jurassic-Cretaceous black shales. Organic Geochemistry 10, 905-914.

Barwise, A. J. G. (1990) Role of nickel and vanadium in petroleum classification. Energy \& Fuels 4, 647-652.

Buchler J. W. (1975) Static Coordination Chemistry of Metalloporphyrins. In Porphyrins and Metalloporphyrins (ed. K. M. Smith). Elsevier Scientific Publishing Company, Amsterdam. pp. 157-231.

Buchler J. W. (1978) Synthesis and Properties of Metalloporphyrins. In The Porphyrins: Volume I (ed. D. Dolphin). Academic Press, New York. pp. 389-483.

Buenrostro-Gonzalez E., Andersen S. I., Garcia-Martinez J. A. and Lira-Galeana C. (2002) Solubility/molecular structure relationships of asphaltenes in polar and nonpolar media. Energy \& Fuels 16, 732-741.

Crusius J., Calvert S., Pedersen T. and Sage D. (1996) Rhenium and molybdenum enrichments in sediments as indictors of oxic, suboxic and sulfidic conditions of deposition. Earth and Planetary Science Letters 145, 65-78.

de Souza R. M., Saraceno A. L., Duyck C., da Silveira C. L. P. and Aucélio R. Q. (2007) Determination of Fe, $\mathrm{Ni}$ and $\mathrm{V}$ in asphaltene by ICP OES after extraction into aqueous solutions using sonication or vortex agitation. Microchemical Journal 87, 99-103.

Derakhshesh M., Bergmann A. and Gray M. R. (2013) Occlusion of polyaromatic compounds in asphaltene precipitates suggests porous nanoaggregates. Energy \& Fuels 27, 1748-1751.

Dreyfus S., Pécheyran C., Magnier C., Prinzhofer A., Lienemann C. P. and Donard O. F. X. (2005) Direct trace and ultra-trace metals determination in crude oil and fractions by inductively coupled plasma mass spectrometry. Journal of ASTM International 2, 1-8. 
Du A., Wu S., Sun D., Wang S., Qu W., Markey R., Stein H., Morgan J. and Malinovskiy D. (2004) Preparation and certification of Re-Os dating reference materials: Molybdenites HLP and JDC. Geostandards and Geoanalytical Research 28, 41-52.

Erickson B. E. and Helz G. R. (2000). Molybdenum(VI) speciation in sulfidic waters: Stability and lability of thiomolybdates. Geochimica et Cosmochimica Acta 64, 1149-1158.

Filby R. H. (1994) Origin and nature of trace element species in crude oils, bitumens and kerogens: implications for correlation and other geochemical studies. Geological Society, London, Special Publications 78, 203-219.

Filby R. H. and Van Berkel, G. J. (1987) Geochemistry of Metal Complexes in Petroleum, Source Rocks, and Coals: An Overview. In Metal Complexes in Fossil Fuels (eds. R. H. Filby and J. F. Branthaver). American Chemical Society Symposium Series No. 344, Washington, DC. pp. 2-39.

Franceskin P. J., Gonzalez-Jimenez F., La Rosa M. G., Abrams O. and Katan L. (1986) First observation of an iron porphyrin in heavy crude oil. Hyperfine Interactions 28, 825-828.

Furimsky E. (2016) On exclusivity of vanadium and nickel porphyrins in crude oil. Energy \& Fuels 30, 9978-9980.

Gaspar A., Zellermann E., Lababidi S., Reece J. and Schrader W. (2012) Characterization of saturates, aromatics, resins, and asphaltenes heavy crude oil fractions by atmospheric pressure laser ionization Fourier Transform ion cyclotron resonance mass spectrometry. Energy \& Fuels 26, 3481-3487.

Georgiev S. V., Stein H. J., Hannah J. L., Galimberti R., Nali M., Yang G. and Zimmerman A. (2016) Re-Os dating of maltenes and asphaltenes within single samples of crude oil. Geochimica et Cosmochimica Acta 179, 53-75.

Georgiev S., Stein H. J., Hannah J. L., Bingen B., Weiss H. M. and Piasecki S. (2011) Hot acidic Late Permian seas stifle life in record time. Earth and Planetary Science Letters 310, 389-400.

Gramlich J. W., Murphy T. J., Garner E. L. and Shields W. R. (1973) Absolute isotopic abundance ratio and atomic weight of a reference sample of rhenium. Journal of Research of the National Bureau of Standards-A. Physics and Chemistry 77A, 691-698.

Hirschberg A., deJong L. N. J., Schipper B. A. and Meijer J. G. (1984) Influence of temperature and pressure on asphaltene flocculation. Society of Petroleum Engineers Journal 24, 283-293.

Hurtig N. C., Stein H. J. and Hannah J. L. (2016) Re-Os systematics at the water-oil interface from an experimental perspective. Geological Society of America Abstracts with Programs 48, \#259-5(abstr.), Denver. 
Lewan M. D. (1984) Factors controlling the proportionality of vanadium to nickel in crude oils. Geochimica et Cosmochimica Acta 48, 2231-2238.

Ludwig K. R. (2003) User's manual for Isoplot 3.00. A geochronological toolkit for Microsoft Excel. Berkeley Geochronology Center Special Publication, 4 p.

Mahdaoui F., Michels R., Reisberg L., Pujol M. and Poirier Y. (2015) Behavior of Re and Os during contact between an aqueous solution and oil: Consequences for the application of the Re-Os geochronometer to petroleum. Geochimica et Cosmochimica Acta 158, 1-21.

Mahdaoui F., Reisberg L., Michels R., Hautevelle Y., Poirier Y. and Girard J.-P. (2013) Effect of the progressive precipitation of petroleum asphaltenes on the Re-Os radioisotope system. Chemical Geology 358, 90-100.

Manning D. A. C. and Gize A. P. (1993) The Role of Organic Matter in Ore Transport Processes. In Organic Geochemistry: Principles and Applications (eds. M. H. Engel \& S. A. Macko). Plenum Press, New York. pp. 547-563.

Markey R., Stein H. J., Hannah J. L., Zimmerman A., Selby D. and Creaser R. A. (2007) Standardizing Re-Os geochronology: A new molybdenite Reference Material (Henderson, USA) and the stoichiometry of Os salts. Chemical Geology 244, 74-87.

Miller C. A. (2004). Re-Os dating of algal laminites: reduction-enrichment of metals in the sedimentary environment and evidence for new geoporphyrins. MSc thesis, University of Saskatchewan, $143 \mathrm{p}$.

Miller J. T., Fisher R. B., Thiyagarajan P., Winans R. E. and Hunt J. E. (1998) Subfractionation and characterization of Mayan asphaltene. Energy \& Fuels 12, 1290-1298.

Mullins O. C., Sabbah H., Eyssautier J., Pomerantz A. E., Barré L., Andrews A. B., RuizMorales Y., Mostowfi F., McFarlane R., Goual L., Lepkowicz R., Cooper T., Orbulescu J., Leblanc R. M., Edwards J. and Zare R. N. (2012) Advances in asphaltene science and the Yen-Mullins Model. Energy \& Fuels 26, 3986-4003.

Mullins O. C., Seifert D. J., Zuo J. Y. and Zeybek M. (2013) Clusters of asphaltene nanoaggregates observed in oilfield reservoirs. Energy \& Fuels 27, 1752-1761.

Nalwaya V., Tantayakom V., Piumsomboon P. and Fogler S. (1999) Studies on asphaltenes through analysis of polar fractions. Industrial \& Engineering Chemistry Research 38, 964-972.

Novelli L., Welte D. H., Mattavelli L., Yalçin M. N., Cinelli D. and Schmitt K. J. (1988) Hydrocarbon generation in southern Sicily. A three dimensional computer aided basin modeling study. Organic Geochemistry 13, 153-164. 
Palmer S. E. and Baker E.W. (1978) Copper porphyrins in deep sea sediments: a possible indicator of oxidized terrestrial organic matter. Science 201, 49-51.

Pillay A. E., Bassioni G., Stephen S. and Kühn F. E. (2011) Depth profiling (ICP-MS) study of trace metal "grains" in solid asphaltenes. Journal of the American Society for Mass Spectrometry 22, 1403-1408.

Quirke J. M. E. (1987) Rationalization for the Predominance of Nickel and Vanadium Porphyrins in the Geosphere. In Metal Complexes in Fossil Fuels (eds. R. H. Filby and J. F. Branthaver). American Chemical Society Symposium Series, Washington, DC. pp. 7483.

Reynolds J. G. (1998) Metals and Heteroatoms in Heavy Crude Oils. In Petroleum Chemistry and Refining (ed. J.G. Speight). Taylor and Francis Group, Washington, DC. pp. 63-102.

Rosenthal Y., Lam P., Boyle E. A. and Thomson J. (1995) Authigenic cadmium enrichments in suboxic sediments: Precipitation and postdepositional mobility. Earth and Planetary Science Letters 132, 99-111.

Schiller S. B., Gonzalez C. A. and Watters, Jr., R. L. (2014) Standard Reference Material 1634c, Trace Elements in Fuel Oil. National Institute of Standards \& Technology Certificate of Analysis. Gaithersburg, MD, 3 p.

Selby D. and Creaser R. A. (2005) Direct radiometric dating of hydrocarbon deposits using rhenium-osmium isotopes. Science 308, 1293-1295.

Selby D., Creaser R. A. and Fowler M. G. (2007) Re-Os elemental and isotopic systematics in crude oils. Geochimica et Cosmochimica Acta 71, 378-386.

Selby D., Creaser R. A., Dewing K. and Fowler M. (2005) Evaluation of bitumen as a ${ }^{187} \mathrm{Re}-{ }^{187}$ Os geochronometer for hydrocarbon maturation and migration: A test case from the Polaris MVT deposit, Canada. Earth and Planetary Science Letters 235, 1-15.

Sen I. S. and Peucker-Ehrenbrink B. (2014) Determination of osmium concentrations and ${ }^{187} \mathrm{Os} /{ }^{188} \mathrm{Os}$ of crude oils and source rocks by coupling high-pressure, high-temperature digestion with sparging $\mathrm{OsO}_{4}$ into a multicollector inductively coupled plasma mass spectrometer. Analytical Chemistry 86, 2982-2988.

Smoliar M. I., Walker R. J. and Morgan J. W. (1996) Re-Os ages of Group IIA, IIIA, IVA, and IVB iron meteorites. Science 271, 1099-1102.

Speight J. G. (2004) Petroleum Asphaltenes - Part 1: Asphaltenes, Resins and the Structure of Petroleum. Oil and Gas Science and Technology - Rev. IFP 59, 467-477.

Speight J. G. (2006) The Chemistry and Technology of Petroleum, Fourth Edition. CRC Press, Boca Raton, 980 p. 
Stein H., Scherstén A., Hannah J. and Markey R. (2003) Subgrain-scale decoupling of Re and ${ }^{187}$ Os and assessment of laser ablation ICP-MS spot dating in molybdenite. Geochimica et Cosmochimica Acta 67, 3673-3686.

Stein H. J. (2006) Low-rhenium molybdenite by metamorphism in northern Sweden: Recognition, genesis, and global implications. Lithos 87, 300-327.

Stein H. J., Markey R. J., Morgan J. W., Hannah J. L. and Scherstén A. (2001) The remarkable Re-Os chronometer in molybdenite: how and why it works. Terra Nova 13, 479-486.

Sundby B., Martinez P. and Gobeil C. (2004) Comparative geochemistry of cadmium, rhenium, uranium, and molybdenum in continental margin sediments. Geochimica et Cosmochimica Acta 68, 2485-2493.

Vazquez D. and Mansoori G. A. (2000) Identification and measurement of petroleum precipitates. Journal of Petroleum Science and Engineering 26, 49-55.

Ventura G. T., Gall L., Siebert C., Prytulak J., Szatmari P., Hürlimann M. and Halliday A. N. (2015) The stable isotope composition of vanadium, nickel, and molybdenum in crude oils. Applied Geochemistry 59, 104-117.

Wattana P., Fogler H. S., Yen A., Del Carmen Garcìa, M. and Carbognani L. (2005) Characterization of polarity-based asphaltene sub-fractions. Energy \& Fuels 19, 101-110.

Wu B., Zhu J. and Li X. (2014) Distribution of calcium, nickel, iron, and manganese in superheavy oil from Liaohe Oilfield, China. Petroleum Science 11, 590-595.

Yang G., Zimmerman A., Stein H. and Hannah J. (2015) Pretreatment of nitric acid with hydrogen peroxide reduces total procedural Os blank to femtogram levels. Analytical Chemistry 87, 7017-7021.

Zhao X., Shi Q., Gray M. R. and Xu. C (2014) New vanadium compounds in Venezuela heavy crude oil detected by Positive-ion Electrospray Ionization Fourier Transform Ion Cyclotron Resonance Mass Spectrometry. Scientific Reports 4, no. 5373, 1-6.

Zimmerman A., Stein H. J., Morgan J. W., Markey R. J. and Watanabe Y. (2014) Re-Os geochronology of the El Salvador porphyry $\mathrm{Cu}-\mathrm{Mo}$ deposit, Chile: Tracking analytical improvements in accuracy and precision over the past decade. Geochimica et Cosmochimica Acta 131, 13-32. 


\section{APPENDIX A}

\section{A.1 List of terms and abbreviations used}

$A 1, A 2, A 3$, etc.: Asphaltene sub-fractions separated by mixtures of acetone and toluene.

ADRES: Resins that are adsorbed onto and precipitate with the asphaltenes, and that are released when the ASPH is washed with hot heptane.

$A D S$ : Refers to adsorbed asphaltenes.

$A-P O W$ : Insoluble mineral powder isolated by centrifugation prior to fractionation of the A-series.

A-POW-ADS: Asphaltenes that were adsorbed onto A-POW and removed by Soxhlet extraction with DCMM.

Aromatics: The portion of the maltenes released from activated silica when the silica is washed with toluene; representative molecules include benzene and naphthalene.

ASPH: Abbreviation for asphaltenes, the heptane-insoluble portion of the crude oil not including adsorbed resins or insoluble mineral powders.

$A S P H+P O W$ : The solids that remained in the Soxhlet extractor after removal of the ADRES.

These samples were used for the separation of the A- and H-series sub-fractions, which is why a powder fraction is associated with both.

$H 1, H 2, H 3$, etc.: Asphaltene sub-fractions separated by mixtures of heptane and dichloromethane.

Heteroatoms: Atoms that are not carbon (e.g., sulfur, nitrogen, or oxygen) that are often held in cyclic molecules.

HPA: High pressure asher, used to digest organic samples. 
H-POW: The insoluble mineral powder that was obtained during the $\mathrm{H}$-series fractionation. This precipitated with $\mathrm{H} 1$.

ID-NTIMS: Isotope dilution coupled with negative thermal ionization mass spectrometry

MALT: Abbreviation for maltenes, the heptane-soluble portion of the crude oil that can be broken into saturates, aromatics, and resins.

POW: Polar and non-polar solvent-insoluble mineral fragments that are separated from the crude oil during the precipitation of asphaltenes.

$P: S:$ Refers to the precipitant-solvent ratio used at different steps of sequential asphaltene subfractionation.

Resins: The portion of the maltenes released from activated silica when the silica is washed with a 9:1 toluene:methanol solution; representative molecules include furans and thiophenes.

$R S D \%$ : Relative standard deviation, defined as the standard deviation divided by the average, multiplied by 100 to give a percent.

Saturates: The portion of the MALTS released from activated silica when the silica is washed with heptane; representative molecules include alkanes and cycloalkanes.

\section{A.2 Bulk oil solubility fraction calculations}

Un-normalized percentages are used in all calculations. To calculate the weight percentages of ADRES in the heptane insoluble precipitates, the weight of ADRES recovered via Soxhlet extraction was divided by the weight of the heptane-insoluble fraction sample used in the Soxhlet. This yielded 5.079\% ADRES in the heptane-insoluble precipitates.

The following calculations are outlined in Figure 14. To calculate the weight percentage of POW in the heptane-insoluble precipitates, the weight percentage of ASPH+POW in the insoluble precipitates (94.099\%) was multiplied by the weight percentage of POW from the 


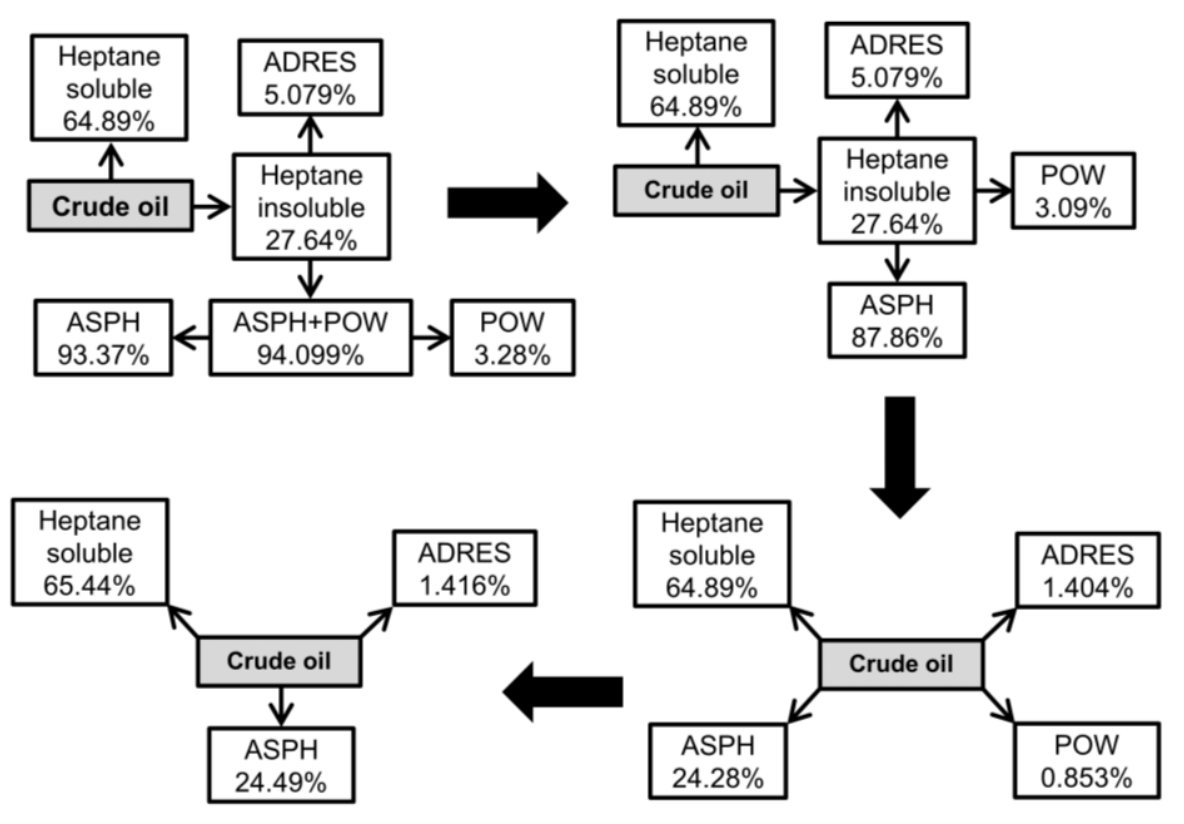

Figure 14: Procedure used for calculating adjusted weight percentages of crude oil solubility fractions. See Section A.1 for definitions of abbreviations.

H-series sub-fractionation (3.28\%); this yielded 3.09\% POW in the insoluble precipitates. The weight percentage of $\mathrm{H}-\mathrm{POW}$ was used here because calculating the weight percentage of $\mathrm{H}$ POW included fewer calculations than calculating the weight percentage of A-POW (which was separated from a bulk sample of the insoluble precipitate before the A-series fractionation).

To calculate the weight percentage of ASPH in the insoluble precipitates, the weight percentages of the $\mathrm{H}$-series sub-fractions were added (H1 to $\mathrm{H} 7$ plus H-ADS) and divided by the sample weight used in the H-series sub-fractionation, yielding 93.37\%, the weight percentage $\mathrm{ASPH}$ in $\mathrm{ASPH}+\mathrm{POW}$. This was multiplied by the weight percentage of ASPH+POW in the heptane-insoluble fraction (94.099\%), yielding $87.86 \%$ ASPH. To calculate the weight percentages of ASPH, POW, and ADRES in the crude oil, respectively, the above calculated weight percentages were multiplied by the weight percentage of insoluble precipitates (27.64\%) in the crude oil. This yielded 24.28\% ASPH, 1.404\% ADRES, and 0.853\% POW. 
All samples were filtered before being analyzed for Re-Os. Therefore, none of them contain remnants of POW which has low Re-Os concentrations compared to the crude oil, crude oil solubility fractions, and ASPH sub-fractions. In other words, the concentrations of the crude oil (ORG-1505), bulk ASPH (ORG-1504), bulk MALT (ORG-1511), and ADRES (ORG-1503) correspond to the crude oil, ASPH, MALT, and ADRES concentrations without dilution by the insoluble powder (POW). To calculate correct Re and Os mass balances for the crude oil, the weight percentage of POW was removed and the other weight percentages were adjusted to reflect that loss. This was accomplished by taking a theoretical sample of crude oil (10 g) and calculating the grams of each fraction (ASPH, MALT, ADRES, POW); the new weight percentages were calculated by subtracting the theoretical weight of POW from 10 (the theoretical sample size), and dividing the theoretical grams of each fraction by the resulting adjusted sample weight. This yields a theoretical, powder-less crude oil that is $24.49 \% \mathrm{ASPH}$, $1.416 \%$ ADRES, and $65.44 \%$ MALT for a total of $91.35 \%$. These numbers were not normalized for calculating Re-Os budgets and mass balances. Re-Os concentrations for the bulk crude oil were calculated using the below equation:

$$
[\mathrm{X}]_{\text {crude-filt. }}=f_{\mathrm{MALT}}[\mathrm{X}]_{\mathrm{MALT}}+f_{\mathrm{ASPH}}[\mathrm{X}]_{\mathrm{ASPH}}+f_{\mathrm{ADRES}}[\mathrm{X}]_{\mathrm{ADRES}}
$$

where $[X]_{\text {crude-filt. }}$ represents the calculated concentration of the analyte (Re or Os) in the filtered crude oil, $f_{\text {FRACTION }}$ represents the weight percentages of the MALT, ASPH, and ADRES in the filtered crude, and $[\mathrm{X}]_{\text {FRACTION }}$ represents the corresponding concentration of analyte (Re or Os) in the specified fraction. Re-Os budgets for the crude oil fractions and for all other fractionations were calculated with the equation below:

$$
\% \mathrm{X}_{\text {fraction }}=\frac{\left(w t . \% \frac{\text { fraction }_{\text {bulk }}}{}\right) \times[\mathrm{X}]_{\text {fraction }}}{[\mathrm{X}]_{\text {bulk }}}
$$


where $\% \mathrm{X}_{\text {fraction }}$ represents the calculated percentage of the analyte (Re or Os) in the specified fraction, wt.\% fraction/bulk represents the weight percentage of the fraction in the bulk sample, $[\mathrm{X}]_{\text {fraction }}$ represents the concentration of the analyte (Re or Os) in the specified fraction, and $[\mathrm{X}]_{\text {bulk }}$ represents the concentration of the analyte (Re or Os) in the bulk sample.

We use relative standard deviation (RSD\%) to compare between results in this study and those of Georgiev et al. (2016), as well as to model internal reproducibility between replicate analyses and in calculating ICP-MS propagated errors. RSD\% is calculated using the below equation:

$$
\mathrm{RSD} \%=\frac{\sigma}{m} \times 100
$$

where $\sigma$ is the standard deviation of the counts and $m$ is the average counts. The higher the RSD\%, the farther apart measured values are from each other; therefore, low RSD\%'s indicate good reproducibility.

\section{A.3 H-series asphaltene calculations}

The weight percentages of sub-fractions were adjusted to remove the contribution of the POW for the H-series sub-fractions. These calculations, listed below, are outlined in Figure 15. The H-series was separated from a sample of the bulk, Soxhlet-washed, heptane-insoluble precipitate that included the insoluble powder (ASPH+POW); following the precipitation of $\mathrm{H} 1$, the insoluble powder (H-POW) was separated from H1, washed with DCMM, and weighed before analysis, and the weight percentage of $\mathrm{H}-\mathrm{POW}$ in the bulk ASPH+POW sample was calculated (3.28\%). The weight of H-POW was subtracted from the weight of the original ASPH+POW sample to give a theoretical, powderless sample weight, and the weight percentage of each H-series sub-fraction was re-calculated based on the new, adjusted sample weight. These 


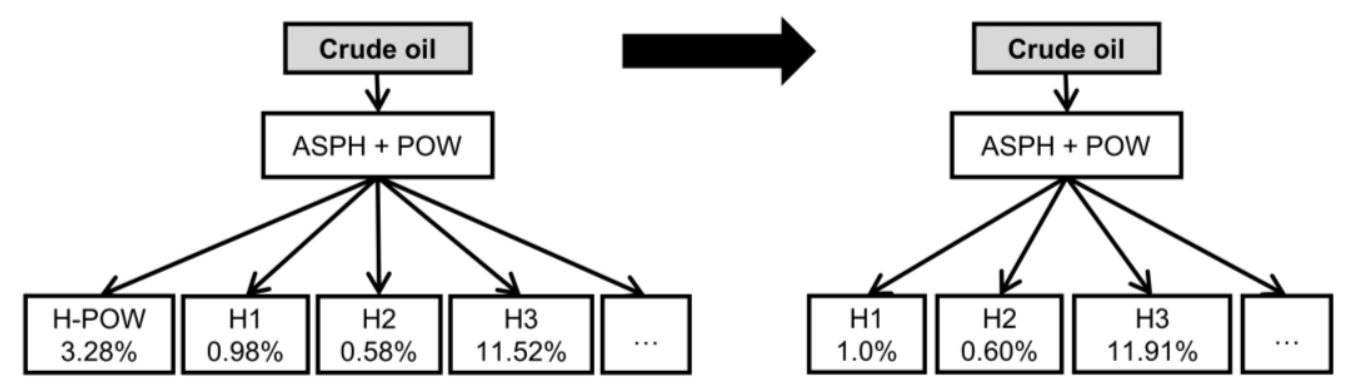

Figure 15: Procedure used for calculating the adjusted weight percentages of $\mathrm{H}$-series ASPH sub-fractions. See Section A.1 for definitions of abbreviations.

weight percentages were then used in their un-normalized form to calculate Re-Os bulk ASPH concentrations using the equation below:

$$
\begin{gathered}
{[\mathrm{X}]_{\mathrm{ASPH}}=f_{\mathrm{H} 1}[\mathrm{X}]_{\mathrm{H} 1}+f_{\mathrm{H} 2}[\mathrm{X}]_{\mathrm{H} 2}+f_{\mathrm{H} 3}[\mathrm{X}]_{\mathrm{H} 3}+f_{\mathrm{H} 4}[\mathrm{X}]_{\mathrm{H} 4}+f_{\mathrm{H} 5}[\mathrm{X}]_{\mathrm{H} 5}+f_{\mathrm{H} 6}[\mathrm{X}]_{\mathrm{H} 6}+} \\
f_{\mathrm{H} 7}[\mathrm{X}]_{\mathrm{H} 7}+f_{\mathrm{H}-\mathrm{ADS}}[\mathrm{X}]_{\mathrm{H}-\mathrm{ADS}}
\end{gathered}
$$

where $[\mathrm{X}]_{\mathrm{ASPH}}$ is the calculated concentration of the analyte (Re or Os) in the powderless ASPH, $[\mathrm{X}]_{\text {sub-fraction }}$ represents the concentration of the analyte (Re or Os) in the specified sub-fraction, and $f_{\text {sub-fraction }}$ represents the weight percentage of the corresponding sub-fraction out of the sample weight used in fractionation, un-normalized and adjusted to remove the contribution of H-POW.

\section{A.4 A-Series asphaltene calculations}

Sub-fraction weight percentage recalculations are outlined in Figure 16. For the A-series ASPH, the insoluble powder and its adsorbed asphaltenes ([A-POW + A-POW-ADS]) was first removed from a sample of ASPH+POW before sub-fractionation, so that the sub-fraction weight percentages did not have to be recalculated. The weight percentage of [A-POW + A-POW-ADS] in the bulk ASPH+POW sample was calculated (3.91\%), and the entire volume of [A-POW + A- POW-ADS] was washed with DCMM in a Soxhlet extractor. The weight 
percentage of the removed A-POW-ADS relative to the bulk [A-POW + A-POW-ADS] weight was calculated $(13.1 \%)$, and multiplying this by the weight percentage of [A-POW + A-POWADS] in the bulk ASPH + POW sample (3.91\%) yielded the weight percentage of A-POW-ADS relative to the bulk ASPH+POW sample $(0.510 \%)$. Since very little of A-POW was recoverable from the filter used in the Soxhlet extraction of A-POW-ADS, the theoretical weight of A-POW was calculated by multiplying $13.1 \%$ by the total weight of [A-POW + A-POW-ADS], and subtracting the result from the total weight of [A-POW + A-POW-ADS]. This excluded A-POWADS from the A-POW weight, leaving the theoretical weight of A-POW, which was divided by the bulk ASPH+POW sample weight to calculate the theoretical weight percentage of A-POW in the A-series ASPH+POW sample (3.4\%).

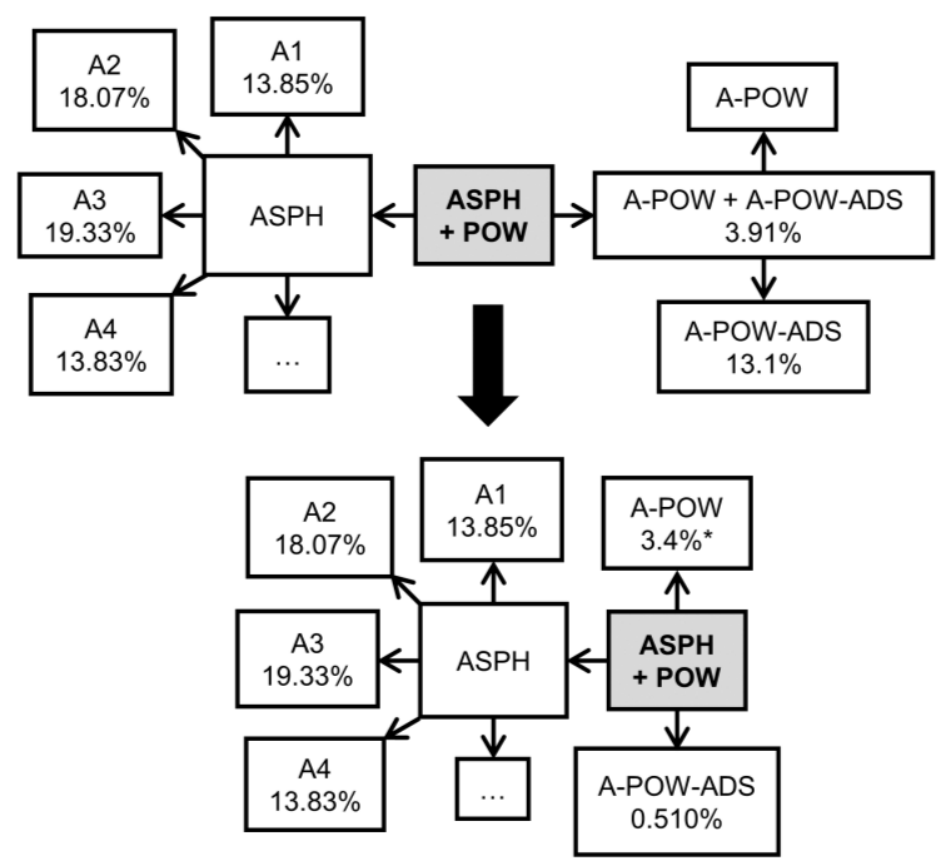

Figure 16: Explanation of weight percentage calculations of A-series ASPH sub-fractions. See Section A.1 for definitions of abbreviations. $*$ = weight percentage for A-POW is a theoretical value calculated by difference.

Including A-POW-ADS in Re-Os budgets shows that insignificant Re and Os is contributed to the total budget relative to the contributions of the other A-series sub-fractions, 
and excluding A-POW-ADS from the mass balance does not change the Re-Os budget proportions. Too many additional calculations are also required to account for A-POW-ADS, many of them purely theoretical, and so for simplicity, Re-Os budgets and A-series weight percentages are shown excluding A-POW-ADS.

The bulk ASPH concentrations for the A-series were calculated using the equation below:

$$
\begin{gathered}
{[\mathrm{X}]_{\mathrm{ASPH}}=f_{\mathrm{A} 1}[\mathrm{X}]_{\mathrm{A} 1}+f_{\mathrm{A} 2}[\mathrm{X}]_{\mathrm{A} 2}+f_{\mathrm{A} 3}[\mathrm{X}]_{\mathrm{A} 3}+f_{\mathrm{A} 4}[\mathrm{X}]_{42}+f_{\mathrm{A} 5}[\mathrm{X}]_{\mathrm{A} 5}+f_{\mathrm{A} 6}[\mathrm{X}]_{\mathrm{A} 6}+} \\
f_{\mathrm{A} 7}[\mathrm{X}]_{\mathrm{A} 7}+f_{A-A D S}[\mathrm{X}]_{\mathrm{A}-\mathrm{ADS}}
\end{gathered}
$$

where $[\mathrm{X}]_{\mathrm{ASPH}}$ is the calculated concentration of the analyte (Re or Os) in the powderless ASPH, $[\mathrm{X}]_{\text {sub-fraction }}$ represents the concentration of the analyte (Re or Os) in the specified sub-fraction, and $f_{\text {sub-fraction }}$ represents the weight percentage of the specified sub-fraction compared to the sample weight used in fractionation.

\section{A.5 Maltene sub-fractionation results}

Re-Os concentrations of $50 \mathrm{~mL}$ of DCM, acetone, methanol, and toluene were determined by ID-NTIMS analysis, and the results are shown in Table 7. A heptane solvent blank was not measured, but values of $(1 \pm 4) \times 10^{-6} \mathrm{ppb} \operatorname{Re}$ and $(4.0 \pm 0.2) \times 10^{-6} \mathrm{ppb}$ Os are reported by Georgiev et al. (2016). Considerably more than $50 \mathrm{~mL}$ of solvent was used in the

\begin{tabular}{|c|c|c|c|c|c|}
\hline Run \# & Sample & $\mathrm{Re}, \mathrm{ppb}$ & $2 \sigma$ & Os, ppb & $2 \sigma$ \\
\hline ORG-1507 & DCM $50 \mathrm{~mL}$ & $6.377 \mathrm{E}-5$ & $1.526 \mathrm{E}-6$ & $\angle \mathrm{TAB}^{\mathrm{a}}$ & $\angle \mathrm{TAB}^{\mathrm{a}}$ \\
\hline ORG-1722 & Acetone $50 \mathrm{~mL}$ & $1.520 \mathrm{E}-3$ & $2.616 \mathrm{E}-5$ & $2.296 \mathrm{E}-5$ & $1.952 \mathrm{E}-7$ \\
\hline ORG-1723 & Methanol $50 \mathrm{~mL}$ & $1.034 \mathrm{E}-4$ & $1.826 \mathrm{E}-6$ & $2.261 \mathrm{E}-5$ & $2.161 \mathrm{E}-7$ \\
\hline ORG-1724 & Toluene $50 \mathrm{~mL}$ & $1.738 \mathrm{E}-3$ & 3.307E-5 & $2.408 \mathrm{E}-5$ & $2.095 \mathrm{E}-7$ \\
\hline
\end{tabular}
separation of the MALT sub-fractions. However, if we scale up the volumes and Re-Os contents

to equal the $300-900 \mathrm{~mL}$ of solvent dried down with each sub-fraction, this results in more Os in the total solvent than there is in the actual measured sub-fractions. The issues with scaling up 
these volumes are presumably due to the low Os concentrations in the solvent blanks, and therefore, the reported Os concentrations in the MALT sub-fractions are uncorrected for solvent contributions. Subtracting out the pg of toluene and methanol Re from the measured aromatic and resin samples, as well as the pg of heptane from the measured saturate samples, yields $\operatorname{Re}$ concentrations of $0.242 \mathrm{ppb}$ and $0.029 \mathrm{ppb}$ for Saturates Ia + Ib and Saturates IIa, respectively; 10.3 ppb and 4.3 ppb for Aromatics Ia + Ib and Aromatics IIa, respectively; and 7.8 ppb and 16.5 ppb for Resins Ia $+\mathrm{Ib}$ and Resins IIa, respectively. Using these concentrations to recalculate the Re budgets results in a total of $\sim 65 \%$ and $\sim 68 \%$ total Re for Separation II and I, respectively. This significant loss suggests that the Re in the solvent blanks is also not scalable. Because of this, the reported Re concentrations are also un-corrected for solvent contributions. More importantly, the effects on Re-Os isochron diagrams are fairly insignificant when excess Re is removed; this is shown in Figure 17. Here, the Os isotopic ratios are uncorrected for solvent contributions, but the ${ }^{187} \mathrm{Re} /{ }^{188} \mathrm{Os}$ ratios in the saturate, aromatic, and resin sub-fractions have been corrected for Re contributed by heptane, toluene, and methanol. While it is true that the ${ }^{187} \mathrm{Re} /{ }^{188}$ Os ratios are lower than they would be without removing solvent blank Re, it is still not enough to push the separate MALT sub-fractions into a linear relationship. These solvent issues suggest that open column chromatography, although simple in set-up and implementation, is unfortunately not the best method for reparation of MALT sub-fractions for the purpose of Re-Os geochronology.

\section{A.6 ICP-MS data}

\section{A.6.1 Data acquisition and reduction procedure}

Six pre-made external standards were analyzed twice, before and after the samples, and each standard's blank- and drift-corrected counts were plotted against their concentrations to 


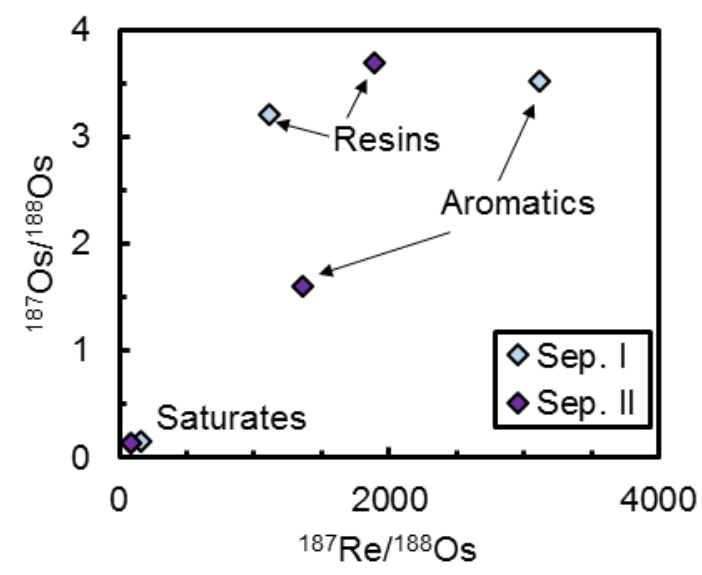

Figure 17: Plot of ${ }^{187} \mathrm{Os} /{ }^{188}$ Os vs. ${ }^{187} \mathrm{Re} /{ }^{188} \mathrm{Os}$ using Re-corrected ${ }^{187} \mathrm{Re} /{ }^{188} \mathrm{Os}$ ratios of MALT sub-fractions from Separations I and II. Even after subtracting out solvent Re contributed by heptane, toluene, and methanol, there is still no clear linear relationship between all the sub-fractions. Os ratios are uncorrected, as scaling issues yield negative total Os in the sub-fractions when solvent Os is removed.

create calibration curves. A total of nine spike solution blanks were also analyzed: one before and after the first six standards, five at intervals between samples, and one before and after the last six standards. After data acquisition, the counts for each element were manually reduced to account for drift and carryover. The limit of detection (LOD) and limit of quantitation (LOQ) were calculated for each element, where the LOD in cps equals the standard deviation of the average blank counts multiplied by three, and the LOQ is the LOD cps multiplied by three. If the counts of the analytical blank (TAB) exceeded the LOQ counts for any one analyte, an additional blank correction was applied by subtracting the blank counts from the sample counts; the TAB corrected elements are $\mathrm{Zn}, \mathrm{Zr}, \mathrm{U}, \mathrm{Ag}, \mathrm{Re}, \mathrm{Cr}, \mathrm{Fe}, \mathrm{Cu}$, and $\mathrm{Mn}$.

For sample H7, the only Re-Os-spiked sample, Re concentrations were calculated by isotope dilution using the ICP-MS-measured ${ }^{185} \mathrm{Re} /{ }^{187} \mathrm{Re}$ ratio. Though the TAB counts for ${ }^{187} \mathrm{Re}$ were above the LOQ, the TAB counts for ${ }^{185}$ Re were at the level of the LOQ, and so un-TAB corrected counts for both ${ }^{187} \mathrm{Re}$ and ${ }^{185} \mathrm{Re}$ were used to calculate the ratio. Ratios calculated using both uncorrected ratios, both corrected ratios, and only the corrected ${ }^{187}$ Re counts yielded 
concentrations that were all very close $(\mathrm{RSD} \%=0.4 \%, \mathrm{n}=6)$, and so only the ratio calculated using both un-corrected values is reported. The resulting concentration was cross-checked against the $\mathrm{H} 7{ }^{185} \mathrm{Re} /{ }^{187} \mathrm{Re}$ ratio already measured by NTIMS.

The average counts and standard deviation of each element per sample were used to calculate the relative standard deviation $(\mathrm{RSD} \%)$, which is the analytical uncertainty. This was propagated with a "calibration error," our measure of human error, which is the RSD\% between the concentrations yielded by all the possible calibration curves that could have been chosen in calculating the final concentration. Out of the six measured standards, there were six optional calibration curves. Of these, four were three-point lines, namely low (only the three lowest concentrated standards), intermediate-low (including the second, third, and fourth lowest concentrated standards), intermediate-high (including the second, third, and fourth highest concentrated standards), and high (including only the three highest concentrated standards). In addition to these three-point curves, all six standards (a 6-point line) or only the more concentrated standards (5-point line excluding the least concentrated standard) could have been used as well. If the sample counts were extremely low or below the counts of the low calibration curve, the calibration error was assumed to be zero, as only the low curve could have logically been used. If the counts fell between two of the curves, the calibration error was equal to the RSD\% between the two curves' concentrations. In this case, if either the 6- or 5-point line also gave a concentration close to or between the two chosen curves, these concentrations were also included in the RSD\% calculation. When the high calibration curve was the only option, both the 6- and 5- point lines were also included in the RSD\% calculation. For H7, part of the total digested solution was removed for Re-Os analysis, and the remainder was used for ICP-MS 
analysis; as this sample was measured out using a pipette, an additional pipette error is added on to the total uncertainty for all elements (except Re) for H7.

The error in Re concentration for sample H7 was handled differently because this sample was spiked with ${ }^{185} \mathrm{Re}$, and its concentration was calculated by isotope dilution. The ${ }^{185} \mathrm{Re}$ and

${ }^{187} \mathrm{Re}$ counts, corrected for drift and the dilution blank but not for the TAB, were used to calculate the sample's ${ }^{185} \mathrm{Re} /{ }^{187} \mathrm{Re}$ ratio, which was corrected to account for the variation in the standard's natural ratio compared to the accepted natural ratio. The absolute uncertainty in this ratio was calculated by combining the analytical uncertainty of the ${ }^{185} \operatorname{Re}$ and ${ }^{187} \operatorname{Re}$ counts from ICP-MS analysis (RSD\%) and multiplying the result by the calculated ratio. This ratio and its calculated uncertainty were input into our in-house isotope dilution-algebraic reduction spreadsheet. A previously measured Re-Os blank was used for the blank correction, and the resulting uncertainty also includes uncertainty in spike weights and blank subtraction. The concentrations and relative uncertainties for all samples are reported in Table 8 and Table 9, respectively.

\section{A.6.2 Instrument parameters}

Instrument parameters used for ICP-MS analysis are shown in Table 10.

\section{A.7 Re and Os isotope concentrations}

Re and Os isotope concentrations are shown in Table 11. These concentrations were used to model asphaltene precipitation and to make correlations from the bulk crude oil and ASPH and MALT sub-fractions. 
Table 8: Extended ICP-MS Results (ppb)

\begin{tabular}{|c|c|c|c|c|c|c|c|c|c|c|c|}
\hline Sample & ICP ID & $\underline{\text { Co }}$ & $\underline{\text { Mo }}$ & $\underline{\mathrm{V}}$ & $\underline{\mathrm{Zn}}$ & $\underline{\mathrm{Ni}}$ & $\underline{\mathrm{Sr}}$ & $\underline{\mathrm{Zr}}$ & $\underline{\mathrm{Ba}}$ & $\underline{\mathrm{U}}$ & $\underline{\mathrm{Sb}}$ \\
\hline $\mathrm{TAB}^{\mathrm{a}}$ & ICP107 & 0.01 & 0.08 & 0.005 & 0.65 & 0.41 & 0.04 & 1.36 & 0.06 & 0.002 & 0.04 \\
\hline $\mathrm{TAB}^{\mathrm{a}}$ & ICP106 & 0.005 & 0.005 & -0.008 & 2.92 & 0.12 & 0.04 & 1.00 & 0.40 & 0.001 & 0.02 \\
\hline $\mathrm{TAB}$ & ICP156 & $<0.01$ & $<0.01$ & $<0.08$ & 0.83 & $<0.07$ & $<0.03$ & 0.09 & $<0.07$ & 0.0003 & $<0.003$ \\
\hline $\mathrm{H} 3$ & ICP140 & 751.7 & 255550.3 & 532597.5 & 17120.3 & 229105.8 & 5106.8 & 495.7 & 10843.3 & 149.7 & 127.8 \\
\hline $\mathrm{H} 4$ & ICP141 & 762.2 & 173354.7 & 496781.6 & 8935.3 & 250250.1 & 1191.7 & 386.4 & 1027.4 & 53.9 & 173.3 \\
\hline H5 & ICP149 & 639.1 & 77105.6 & 410658.4 & 7791.1 & 212397.5 & 858.8 & 308.1 & 875.7 & 27.7 & 108.3 \\
\hline H6 & ICP142 & 565.0 & 39977.1 & 391148.7 & 14014.5 & 191270.7 & 1002.6 & 55.3 & 1427.0 & 22.0 & 64.1 \\
\hline $\mathrm{H} 7$ & ICP155 & 129.4 & 2414.6 & 336543.4 & 4326.5 & 116936.9 & 744.6 & 47.8 & 970.2 & 3.0 & 72.3 \\
\hline $\mathrm{A} 1$ & ICP138 & 808.9 & 197173.5 & 448360.0 & 18576.8 & 257539.5 & 3695.1 & 414.2 & 8606.5 & 94.1 & 169.9 \\
\hline A2 & ICP143 & 815.9 & 165026.1 & 438662.6 & 16905.3 & 271023.0 & 2064.8 & 447.1 & 2597.5 & 71.0 & 143.3 \\
\hline $\mathrm{A} 3$ & ICP144 & 696.9 & 125900.6 & 381879.4 & 14420.2 & 223672.2 & 1519.1 & 278.3 & 1474.4 & 60.4 & 143.0 \\
\hline A4 & ICP145 & 673.2 & 113664.7 & 388917.3 & 14493.4 & 220490.7 & 1216.2 & 196.9 & 910.1 & 51.8 & 122.0 \\
\hline A5 & ICP146 & 490.9 & 66257.4 & 223709.3 & 15165.2 & 131332.1 & 860.8 & 23.3 & 1373.7 & 35.3 & 49.6 \\
\hline A6 & ICP147 & 480.3 & 70615.1 & 230905.9 & 42816.4 & 150972.3 & 876.9 & $<36.3$ & 2591.9 & 39.2 & 38.0 \\
\hline A7 & ICP139 & 381.1 & 52182.1 & 490160.6 & 44366.4 & 171285.7 & 462.1 & 118.4 & 641.9 & 26.1 & 115.0 \\
\hline Bulk MALT ${ }^{b}$ & ICP152 & 84.4 & 808.1 & 78517.4 & 4005.4 & 40893.3 & 62.2 & 70.4 & 253.0 & 1.4 & 12.4 \\
\hline $\begin{array}{c}\text { NIST SRM } \\
1634 \mathrm{c}^{\mathrm{b}}\end{array}$ & ICP157 & 101.9 & 73.8 & 24675.4 & 4651.6 & 14683.5 & 322.8 & 4.1 & 1095.3 & 2.8 & 2.9 \\
\hline ADRES & ICP150 & 136.4 & 1562.8 & 234335.7 & 6424.0 & 102309.9 & 71.9 & 133.1 & 97.6 & 6.5 & 24.6 \\
\hline Bulk ASPH $^{\text {b }}$ & ICP151 & 1291.2 & 135539.5 & 425301.2 & 11599.5 & 218641.3 & 36452.7 & 1243.4 & 139811.9 & 134.4 & 3568.0 \\
\hline
\end{tabular}

Samples shaded in light gray indicate that two duplicates (dilutions) were analyzed. For these samples, italic font indicates an average of the two dilutions is reported. Medium-gray cells indicate cps below the LOQ. Dark-gray cells indicate cps below the LOD. Dashed boxes indicate TAB-corrected concentrations. All other values (e.g. not shaded, boxed, or italicized) result from single dilutions that are corrected for drift and blank contribution, but not for TAB contributions.

${ }^{\mathrm{a}} \mathrm{TAB}$ 's measured previously

${ }^{\mathrm{b}}$ Indicates un-filtered samples.

Table 8 Cont'd: Extended ICP-MS Results (ppb)

\begin{tabular}{|c|c|c|c|c|c|c|c|c|c|c|c|}
\hline Sample & ICP ID & $\mathrm{Pb}$ & $\mathrm{As}^{\mathrm{a}}$ & $\mathrm{Ag}$ & $\operatorname{Re}$ & $\mathrm{Cd}$ & $\mathrm{Cr}$ & $\mathrm{Fe}$ & $\mathrm{Cu}^{\mathrm{b}}$ & $\mathrm{Mn}$ & $\mathrm{Se}^{\mathrm{c}}$ \\
\hline $\mathrm{TAB}^{\mathrm{d}}$ & ICP107 & 0.18 & 0.008 & 0.01 & 0.002 & 0.004 & 0.26 & 2.90 & -0.113 & 0.12 & 0.23 \\
\hline $\mathrm{TAB}^{\mathrm{d}}$ & ICP106 & 0.02 & 0.006 & 0.007 & 0.001 & 0.002 & 0.10 & 3.23 & -0.125 & 0.07 & 0.18 \\
\hline $\mathrm{TAB}$ & ICP156 & $<0.02$ & $<0.009$ & 0.003 & 0.001 & $<0.003$ & 0.10 & 3.46 & 0.05 & 0.06 & $<0.10$ \\
\hline $\mathrm{H} 3$ & ICP140 & 2194.0 & 356.4 & 227.0 & 1547.2 & 959.2 & 2321.0 & 181427.4 & 12231.8 & 8700.5 & 1798.4 \\
\hline $\mathrm{H} 4$ & ICP141 & 1528.8 & 252.5 & 122.7 & 1177.2 & 652.2 & 1659.9 & 132164.2 & 10001.8 & 8752.1 & 2010.8 \\
\hline H5 & ICP149 & 1176.5 & 232.7 & 62.7 & 650.0 & 301.0 & 969.7 & 114403.7 & 6976.6 & 7145.8 & 1692.5 \\
\hline H6 & ICP142 & 1155.6 & 257.3 & 37.4 & 424.7 & 181.9 & 5770.6 & 114890.0 & 6120.8 & 6305.3 & 787.0 \\
\hline H7 & ICP155 & 356.4 & 131.0 & 5.5 & $46.3^{\mathrm{e}}$ & 18.6 & 355.5 & 40203.1 & 2612.1 & 1506.8 & 255.5 \\
\hline $\mathrm{A} 1$ & ICP138 & 1937.2 & 277.6 & 158.0 & 1257.2 & 717.9 & 2047.6 & 170268.4 & 11684.1 & 8104.2 & 2292.1 \\
\hline A2 & ICP143 & 1705.5 & 265.9 & 113.2 & 1092.4 & 599.0 & 1482.0 & 126457.6 & 10993.1 & 8151.4 & 2073.9 \\
\hline A3 & ICP144 & 1563.8 & 215.4 & 89.9 & 880.0 & 461.0 & 1420.7 & 115129.2 & 8751.8 & 6772.4 & 2047.2 \\
\hline A4 & ICP145 & 1607.3 & 227.0 & 84.2 & 815.5 & 423.1 & 1370.7 & 112086.9 & 8332.7 & 6464.5 & 1582.0 \\
\hline A5 & ICP146 & 1800.0 & 501.2 & 45.5 & 478.4 & 247.6 & 1337.0 & 130911.2 & 6560.4 & 3905.0 & 858.7 \\
\hline A6 & ICP147 & 2239.6 & 195.6 & 79.1 & 509.0 & 296.3 & 5420.0 & 331194.8 & 7891.6 & 5499.3 & 807.2 \\
\hline A7 & ICP139 & 828.7 & 220.8 & 154.9 & 436.6 & 201.2 & 2000.0 & 70186.4 & 5613.6 & 2961.8 & $<96.2$ \\
\hline Bulk MALT $^{f}$ & ICP152 & 172.6 & 99.7 & 1.0 & 11.9 & 6.0 & 150.4 & 12699.0 & 803.2 & 506.0 & 282.1 \\
\hline $\begin{array}{l}\text { NIST SRM } \\
1634 c^{f}\end{array}$ & ICP157 & 407.5 & 98.2 & 0.2 & 1.4 & 2.1 & 156.3 & 26747.4 & 234.9 & 218.6 & 36.5 \\
\hline ADRES & ICP150 & 546.4 & 136.1 & 2.7 & 28.9 & 14.3 & 513.9 & 16368.2 & 1785.3 & 375.4 & 432.6 \\
\hline Bulk ASPH $^{f}$ & ICP151 & 1390.0 & 2893.4 & 264.9 & 840.8 & 546.1 & 4257.8 & 2367360.7 & 8314.9 & 21350.0 & 1686.2 \\
\hline
\end{tabular}

See footnote of Table 8 for definitions of cell and text formatting.

${ }^{a}$ Values calculated using previously generated calibration curves.

${ }^{\mathrm{b}}$ Values calculated with the highest four standards only due to inconsistent standard behavior.

${ }^{\mathrm{c}}$ Se displayed inconsistent and non-linear standard behavior and negative blanks, and so these data should be regarded with suspicion.

d TAB's measured previously

${ }^{\mathrm{e}}$ Calculated using isotope dilution equation with the Re ratio obtained by ICP-MS

${ }^{\mathrm{f}}$ un-filtered 
Table 9: ICP-MS Propagated Uncertainties (RSD\%)

\begin{tabular}{ccccccccccccc}
\hline Sample & ICP ID & Co & Mo & $\mathrm{V}$ & $\mathrm{Zn}$ & $\mathrm{Ni}$ & $\mathrm{Sr}$ & $\mathrm{Zr}$ & $\mathrm{Ba}$ & $\mathrm{U}$ & $\mathrm{Sb}$ \\
\hline TAB & ICP-156 & 6.0 & 13.6 & 14.9 & 1.8 & 2.9 & 8.8 & 6.7 & 0.5 & 3.9 & 3.8 \\
H3 & ICP-140 & 1.9 & 1.8 & 2.7 & 15.2 & 2.7 & 5.2 & 18.8 & 1.0 & 2.8 & 5.0 \\
H4 & ICP-141 & 3.0 & 0.7 & 0.6 & 8.9 & 0.4 & 7.4 & 7.9 & 3.4 & 6.0 & 4.6 \\
H5 & ICP-149 & 2.5 & 0.6 & 0.4 & 5.7 & 0.5 & 3.4 & 8.7 & 1.0 & 2.3 & 4.2 \\
H6 & ICP-142 & 2.2 & 0.7 & 0.8 & 1.3 & 1.0 & 3.5 & 0.8 & 0.9 & 0.7 & 3.2 \\
H7 & ICP-155 & 4.4 & 1.3 & 0.8 & 0.7 & 1.9 & 8.3 & 4.3 & 2.7 & 3.0 & 1.5 \\
A1 & ICP-138 & 2.9 & 0.4 & 3.0 & 6.1 & 1.8 & 4.9 & 6.7 & 2.4 & 0.9 & 3.9 \\
A2 & ICP-143 & 3.4 & 0.4 & 1.7 & 4.2 & 2.0 & 4.9 & 8.6 & 1.8 & 3.0 & 3.2 \\
A3 & ICP-144 & 3.2 & 0.1 & 0.8 & 7.4 & 1.4 & 6.1 & 6.0 & 1.7 & 2.0 & 5.8 \\
A4 & ICP-145 & 2.4 & 0.6 & 0.4 & 3.6 & 0.8 & 1.0 & 22.0 & 2.5 & 2.0 & 3.6 \\
A5 & ICP-146 & 3.0 & 0.4 & 0.6 & 1.5 & 0.5 & 5.5 & 2.5 & 0.6 & 3.6 & 3.7 \\
A6 & ICP-147 & 2.0 & 0.3 & 1.8 & 2.1 & 1.2 & 4.2 & 0.6 & 0.6 & 4.0 & 0.6 \\
A7 & ICP-139 & 1.2 & 0.3 & 0.2 & 3.2 & 0.2 & 4.1 & 23.6 & 2.0 & 3.7 & 4.1 \\
Bulk MALT & ICP-152 & 1.3 & 0.9 & 0.8 & 1.2 & 1.0 & 4.5 & 2.4 & 0.5 & 3.8 & 0.7 \\
NIST SRM 1634c & ICP-157 & 1.6 & 1.1 & 1.2 & 4.1 & 1.7 & 3.3 & 6.6 & 0.7 & 3.8 & 2.4 \\
ADRES & ICP-150 & 1.8 & 0.2 & 0.8 & 3.9 & 0.7 & 13.8 & 10.0 & 5.1 & 10.4 & 7.7 \\
Bulk ASPH & ICP-151 & 4.3 & 1.8 & 4.1 & 0.5 & 3.2 & 4.7 & 4.6 & 0.6 & 2.3 & 2.2 \\
\hline
\end{tabular}

Shaded calls indicate two dilutions were measured per sample; italic font indicates the uncertainty is a combination of both samples' uncertainties. All other values are those of a single sample. Uncertainties for H7 for all elements except Re include a small pipetting error.

Table 9 Cont'd: ICP-MS Propagated Uncertainties (RSD \%)

\begin{tabular}{ccccccccccccc}
\hline Sample & ICP ID & $\mathrm{Pb}$ & $\mathrm{As}$ & $\mathrm{Ag}$ & $\mathrm{Re}$ & $\mathrm{Cd}$ & $\mathrm{Cr}$ & $\mathrm{Fe}$ & $\mathrm{Cu}$ & $\mathrm{Mn}$ & $\mathrm{Se}$ \\
\hline TAB & ICP-156 & 2.6 & 15.2 & 9.6 & 8.9 & 26.5 & 1.5 & 5.9 & 4.9 & 1.7 & 19.7 \\
H3 & ICP-140 & 2.4 & 6.5 & 1.9 & 2.5 & 2.0 & 6.2 & 2.5 & 4.6 & 3.6 & 26.9 \\
H4 & ICP-141 & 1.8 & 7.8 & 0.8 & 1.9 & 2.5 & 5.3 & 4.0 & 4.4 & 10.7 & 13.9 \\
H5 & ICP-149 & 0.9 & 1.8 & 1.1 & 1.5 & 0.4 & 1.9 & 2.7 & 2.4 & 7.7 & 12.8 \\
H6 & ICP-142 & 0.7 & 4.0 & 3.7 & 1.6 & 2.6 & 3.6 & 2.1 & 1.1 & 7.8 & 22.9 \\
H7 & ICP-155 & 2.0 & 4.9 & 2.2 & 14.0 & 7.1 & 3.8 & 6.2 & 3.8 & 6.9 & 13.6 \\
A1 & ICP-138 & 3.5 & 2.7 & 3.3 & 2.4 & 6.4 & 3.8 & 1.0 & 2.5 & 13.6 & 9.1 \\
A2 & ICP-143 & 2.5 & 3.7 & 3.5 & 2.4 & 3.4 & 7.4 & 3.1 & 1.1 & 0.9 & 15.9 \\
A3 & ICP-144 & 1.9 & 6.1 & 2.1 & 1.6 & 2.0 & 6.0 & 4.2 & 4.1 & 10.1 & 16.3 \\
A4 & ICP-145 & 1.2 & 3.6 & 0.2 & 2.1 & 0.5 & 4.4 & 2.6 & 2.7 & 3.7 & 13.7 \\
A5 & ICP-146 & 1.2 & 8.9 & 0.7 & 2.3 & 1.5 & 3.2 & 3.0 & 1.9 & 2.9 & 21.8 \\
A6 & ICP-147 & 1.0 & 3.6 & 1.5 & 0.9 & 1.4 & 4.2 & 2.3 & 1.8 & 1.8 & 27.7 \\
A7 & ICP-139 & 1.2 & 1.5 & 2.2 & 2.3 & 2.4 & 3.1 & 1.4 & 1.9 & 1.3 & 30.3 \\
Bulk MALT & ICP-152 & 2.2 & 2.4 & 7.0 & 2.3 & 3.8 & 7.5 & 4.6 & 4.3 & 3.8 & 13.9 \\
NIST SRM 1634c & ICP-157 & 2.2 & 4.8 & 5.6 & 3.4 & 2.6 & 2.5 & 4.8 & 3.5 & 5.5 & 48.8 \\
ADRES & ICP-150 & 2.1 & 3.5 & 3.3 & 1.5 & 3.5 & 5.1 & 3.3 & 2.9 & 4.0 & 98.6 \\
Bulk ASPH & ICP-151 & 3.6 & 3.5 & 3.7 & 3.1 & 4.7 & 8.5 & 2.3 & 1.3 & 8.1 & 14.2 \\
\hline
\end{tabular}

Shaded calls indicate two dilutions were measured per sample; italic font indicates the uncertainty is a combination of both samples' uncertainties. All other values are those of a single sample. Uncertainties for H7 for all elements except Re include a small pipetting error.

${ }^{a}$ Uncertainty propagated from ICP-MS analytical uncertainty, error resulting from blank subtraction, and spike weight errors. 


\begin{tabular}{|c|c|c|c|c|c|c|c|c|c|c|c|}
\hline Analyte & Mass & $\begin{array}{l}\text { Dynamic } \\
\text { range, ppb }\end{array}$ & $\begin{array}{l}\text { Measured } \\
\text { standard } \\
\text { range, counts }\end{array}$ & $\begin{array}{c}\text { Average } \\
\text { blank } \\
\text { cps }\end{array}$ & $\begin{array}{c}\text { LOD } \\
\text { cps }\end{array}$ & $\begin{array}{l}\text { LOD } \\
\text { ppb }\end{array}$ & $\begin{array}{c}\text { LOQ } \\
\mathrm{cps}\end{array}$ & $\begin{array}{c}\text { LOQ } \\
\text { ppb }\end{array}$ & $\begin{array}{c}\text { Dwell } \\
\text { times } \\
\text { ms }\end{array}$ & $\begin{array}{c}\text { Collision } \\
\text { gas }\end{array}$ & $\begin{array}{l}\text { Gas } \\
\text { flow } \\
\text { rate, } \\
\mathrm{mL} / \mathrm{s}\end{array}$ \\
\hline $\mathrm{Co}$ & 58.933 & $0.066-66$ & $208-686445$ & 120 & 52 & $5 \times 10^{-3}$ & 155 & 0.01 & 50 & - & - \\
\hline Mo & 97.906 & $0.02-65$ & $132-449331$ & 45 & 76 & 0.01 & 228 & 0.03 & 50 & - & - \\
\hline $\begin{array}{l}\mathrm{V} \\
\mathrm{Zn}\end{array}$ & $\begin{array}{l}50.944 \\
65.926\end{array}$ & $\begin{array}{c}0.65-650 \\
0.2-656\end{array}$ & $\begin{array}{c}16-60191 \\
272-791381\end{array}$ & $\begin{array}{c}8 \\
136\end{array}$ & $\begin{array}{c}8 \\
168\end{array}$ & $\begin{array}{l}0.08 \\
0.12\end{array}$ & $\begin{array}{c}23 \\
504\end{array}$ & $\begin{array}{l}0.23 \\
0.36\end{array}$ & $\begin{array}{l}30 \\
50\end{array}$ & - & $\begin{array}{l}- \\
-\end{array}$ \\
\hline $\mathrm{Ni}$ & 59.933 & $0.65-400$ & $49-207450$ & 68 & 25 & 0.08 & 74 & 0.22 & 75 & - & - \\
\hline $\mathrm{Sr}$ & 87.906 & $0.2-656$ & $42-131849$ & 2 & 2 & 0.01 & 5 & 0.02 & 50 & - & - \\
\hline $\mathrm{Zr}$ & 89.904 & $0.1-65$ & 104-844701 & 193 & 43 & 0.01 & 128 & 0.02 & 75 & - & - \\
\hline $\mathrm{Ba}$ & 137.905 & $0.02-65$ & $147-1024094$ & 436 & 398 & 0.02 & 1195 & 0.07 & 50 & - & - \\
\hline $\mathrm{U}$ & 238.050 & $0.0065-65$ & 434-1380248 & 3 & 2 & $7 \times 10^{-5}$ & 5 & $2 \times 10^{-4}$ & 50 & - & - \\
\hline $\mathrm{Sb}$ & 120.904 & $0.0065-65$ & $205-616693$ & 16 & 31 & $3 \times 10^{-3}$ & 92 & 0.01 & 50 & - & - \\
\hline $\mathrm{Pb}$ & 207.977 & $0.02-65$ & 209-683477 & 49 & 74 & 0.01 & 221 & 0.02 & 50 & - & - \\
\hline As & 74.922 & $0.02-65$ & $36-128769^{a}$ & 20 & 6 & $3 \times 10^{-3}$ & 17 & 0.01 & 75 & - & - \\
\hline $\mathrm{Ag}$ & 106.905 & $0.02-65$ & $282-858277$ & 18 & 2 & $1 \times 10^{-4}$ & 5 & $3 \times 10^{-4}$ & 75 & - & - \\
\hline${ }^{187} \operatorname{Re}^{\mathrm{b}}$ & 186.956 & $0.02-65$ & $190-604956$ & 2 & 1 & $1 \times 10^{-4}$ & 3 & $4 \times 10^{-4}$ & 100 & - & - \\
\hline${ }^{185} \mathrm{Re}$ & 184.953 & $0.02-65$ & $109-352758$ & 1 & 1 & $3 \times 10^{-4}$ & 4 & $8 \times 10^{-4}$ & 80 & - & - \\
\hline $\mathrm{Cd}$ & 110.904 & $0.0065-65$ & $67-200655$ & 4 & 3 & $9 \times 10^{-4}$ & 9 & $3 \times 10^{-3}$ & 75 & - & - \\
\hline $\mathrm{Mn}$ & 54.938 & $0.065-652$ & $1071-2277526$ & 43 & 62 & 0.01 & 185 & 0.03 & 50 & $\mathrm{NH}_{3}$ & 1 \\
\hline $\mathrm{Cr}$ & 51.941 & $0.065-65$ & 11-153768 & 101 & 22 & 0.01 & 65 & 0.03 & 50 & $\mathrm{NH}_{3}$ & 1 \\
\hline $\mathrm{Fe}$ & 56.935 & $6.5-650$ & $6-68751$ & 118 & 47 & 0.37 & 140 & 1.11 & 50 & $\mathrm{NH}_{3}$ & 1 \\
\hline $\mathrm{Cu}$ & 62.930 & $0.065-65$ & $361-40044^{c}$ & 54 & 26 & 0.04 & 79 & 0.11 & 75 & $\mathrm{NH}_{3}$ & 1 \\
\hline $\mathrm{Se}$ & 77.917 & $0.65-65$ & $0-7043$ & -6 & 12 & 0.10 & 37 & 0.29 & 75 & $\mathrm{NH}_{3}$ & 1 \\
\hline
\end{tabular}

Shaded cells indicate the analyte was measured in a DRC cell.

${ }^{a}$ Final concentrations were calculated using previous As standard measurements (listed here), as there were issues with the two most concentrated standards.

${ }^{\text {b }}{ }^{187} \mathrm{Re}$ was used to calculate concentrations for all samples except $\mathrm{H} 7$.

${ }^{\mathrm{c}}$ Includes only four most concentrated standards - the two most dilute standards were not used in data reduction due to erratic measurements. 
Table 11: Re-Os isotope concentrations

\begin{tabular}{|c|c|c|c|c|c|c|}
\hline $\begin{array}{l}\text { AIRIE } \\
\text { Run \# }\end{array}$ & Sample & $\begin{array}{l}{ }^{187} \mathrm{Re} \\
\text { (ng/g) }\end{array}$ & $\begin{array}{l}{ }^{187} \mathrm{Os} \\
\text { (ng/g) }\end{array}$ & $\begin{array}{l}{ }^{188} \mathrm{Os} \\
(\mathrm{ng} / \mathrm{g})\end{array}$ & $\begin{array}{l}{ }^{190} \mathrm{Os} \\
(\mathrm{ng} / \mathrm{g})\end{array}$ & ${ }^{192}$ Os (ng/g) \\
\hline \multicolumn{7}{|l|}{ Bulk } \\
\hline ORG-1505 & Crude & 142.0 & 0.1584 & 0.0241 & 0.0484 & 0.0760 \\
\hline ORG-1504 ${ }^{\mathrm{a}}$ & $\mathrm{nC}-7^{\mathrm{b}} \mathrm{ASPH}$ & 569.7 & 0.6366 & 0.0966 & 0.1938 & 0.3041 \\
\hline ORG-1511 & $\mathrm{nC}-7^{\mathrm{b}}$ MALT & 7.645 & 0.0096 & $1.87 \times 10^{-3}$ & $3.74 \times 10^{-3}$ & $5.88 \times 10^{-3}$ \\
\hline ORG-1503 & ADRES & 17.78 & 0.0162 & $3.08 \times 10^{-3}$ & $6.17 \times 10^{-3}$ & $9.70 \times 10^{-3}$ \\
\hline \multicolumn{7}{|c|}{$H$-series Sub-fractions } \\
\hline ORG-1506 & H-POW & 5.224 & 0.1658 & 0.0412 & 0.0828 & 0.1298 \\
\hline ORG-1581 & $\mathrm{H} 1$ & 264.8 & 0.3468 & 0.0558 & 0.1119 & 0.1757 \\
\hline ORG-1582 & $\mathrm{H} 2$ & 263.7 & 0.3041 & 0.0482 & 0.0965 & 0.1517 \\
\hline ORG-1510 & H3 & 939.8 & 1.1563 & 0.1760 & 0.3530 & 0.5541 \\
\hline ORG-1508 & $\mathrm{H} 4$ & 741.1 & 0.8358 & 0.1262 & 0.2531 & 0.3974 \\
\hline ORG- $1721^{\mathrm{c}}$ & $\mathrm{H} 4$ & 749.3 & 0.8417 & 0.1286 & 0.2577 & 0.4048 \\
\hline ORG-1509 & H5 & 426.4 & 0.4137 & 0.0634 & 0.1270 & 0.1995 \\
\hline ORG-1583 & H6 & 265.9 & 0.2364 & 0.0372 & 0.0746 & 0.1173 \\
\hline ORG-1958 & $\mathrm{H} 7$ & 29.24 & 0.0260 & $5.84 \times 10^{-3}$ & 0.0117 & 0.0184 \\
\hline ORG-1586 & H-ADS & 137.2 & 0.1251 & 0.0206 & 0.0413 & 0.0648 \\
\hline ORG-1917 & H-ADS & 139.0 & 0.1265 & 0.0223 & 0.0447 & 0.0702 \\
\hline \multicolumn{7}{|c|}{ A-series Sub-fractions } \\
\hline ORG-1587 & A-POW-ADS & 55.55 & 0.1286 & 0.0248 & 0.0498 & 0.0780 \\
\hline ORG-1590 & A-POW & 7.664 & 0.2514 & 0.0625 & 0.1255 & 0.1969 \\
\hline ORG-1588 & A1 & 811.6 & 0.9074 & 0.1377 & 0.2762 & 0.4337 \\
\hline ORG-1589 & $\mathrm{A} 2$ & 802.4 & 0.7816 & 0.1180 & 0.2366 & 0.3715 \\
\hline ORG-1585 & A3 & 594.9 & 0.6711 & 0.1014 & 0.2034 & 0.3194 \\
\hline ORG-1725 & A4 & 972.5 & 0.5863 & 0.0906 & 0.1816 & 0.2852 \\
\hline ORG- $1831^{\mathrm{c}}$ & A4 & 511.0 & 0.6474 & 0.0997 & 0.1999 & 0.3140 \\
\hline ORG-1726 & A5 & 481.6 & 0.5240 & 0.0797 & 0.1598 & 0.2510 \\
\hline ORG-1727 & A6 & 323.9 & 0.3773 & 0.0581 & 0.1163 & 0.1828 \\
\hline ORG-1728 & A7 & 296.7 & 0.2718 & 0.0423 & 0.0848 & 0.1331 \\
\hline ORG-1832 & A7 & 290.1 & 0.2930 & 0.0461 & 0.0924 & 0.1453 \\
\hline ORG-1920 & A-ADS & 566.9 & 0.6374 & 0.0997 & 0.1999 & 0.3140 \\
\hline \multicolumn{7}{|c|}{ Maltene Sub-fractions } \\
\hline ORG-1913 & Saturates IIa & 0.022 & $3 \times 10^{-5}$ & $2.3 \times 10^{-4}$ & $4.6 \times 10^{-4}$ & $7.2 \times 10^{-4}$ \\
\hline ORG-1914 & Aromatics IIa & 5.409 & $3.21 \times 10^{-3}$ & $2.01 \times 10^{-3}$ & $4.04 \times 10^{-3}$ & $6.33 \times 10^{-3}$ \\
\hline ORG-1915 & Resins IIa & 13.83 & 0.0203 & $5.54 \times 10^{-3}$ & 0.0111 & 0.0174 \\
\hline ORG-1918 & Saturates Ib & 0.155 & $1.6 \times 10^{-4}$ & $9.9 \times 10^{-4}$ & $1.98 \times 10^{-3}$ & $3.11 \times 10^{-3}$ \\
\hline ORG-1921 & Aromatics Ia + Ib & 8.229 & $7.35 \times 10^{-3}$ & $2.10 \times 10^{-3}$ & $4.21 \times 10^{-3}$ & $6.61 \times 10^{-3}$ \\
\hline ORG-1919 & Resins Ia + Ib & 7.733 & 0.0140 & $4.41 \times 10^{-3}$ & $8.84 \times 10^{-3}$ & 0.0139 \\
\hline
\end{tabular}

${ }^{\text {a }}$ Contains only ASPH - adsorbed resins and insoluble powder/mineral grains removed through Soxhlet extraction and centrifugation.

${ }^{\mathrm{b}} \mathrm{nC}-7$ refers to $n$-heptane.

${ }^{\mathrm{c}}$ Repeat digestion 